Utah State University

DigitalCommons@USU

$5-1947$

\title{
An Evaluation of Non-Directive Counseling in the Treatment of Delinquents
}

George D. Watt

Utah State University

Follow this and additional works at: https://digitalcommons.usu.edu/etd

Part of the Psychology Commons

\section{Recommended Citation}

Watt, George D., "An Evaluation of Non-Directive Counseling in the Treatment of Delinquents" (1947). All Graduate Theses and Dissertations. 5741.

https://digitalcommons.usu.edu/etd/5741

This Thesis is brought to you for free and open access by the Graduate Studies at DigitalCommons@USU. It has been accepted for inclusion in All Graduate Theses and Dissertations by an authorized administrator of DigitalCommons@USU. For more information, please contact digitalcommons@usu.edu.

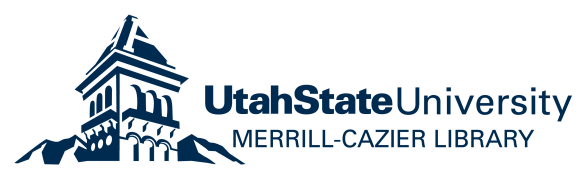


AN BUALUAqION OF NOR-DIRECI VI COUNS RLING IN

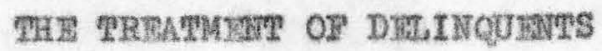

\author{
by \\ George D. Watt
}

THESIS

Submitted in Partial Mulfilinent of the Requirements for the Degree of

MASTER OF SCI WWCS

in

Psychology

1n.

TIM GRADUATS SCHOOL

of the

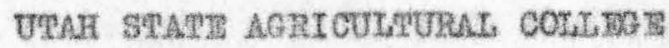

1947

Approved:

Deposited in College Library $\frac{5 / 29 / 47}{\text { Date }}$ 


\section{TABLE OP CONTENIS}

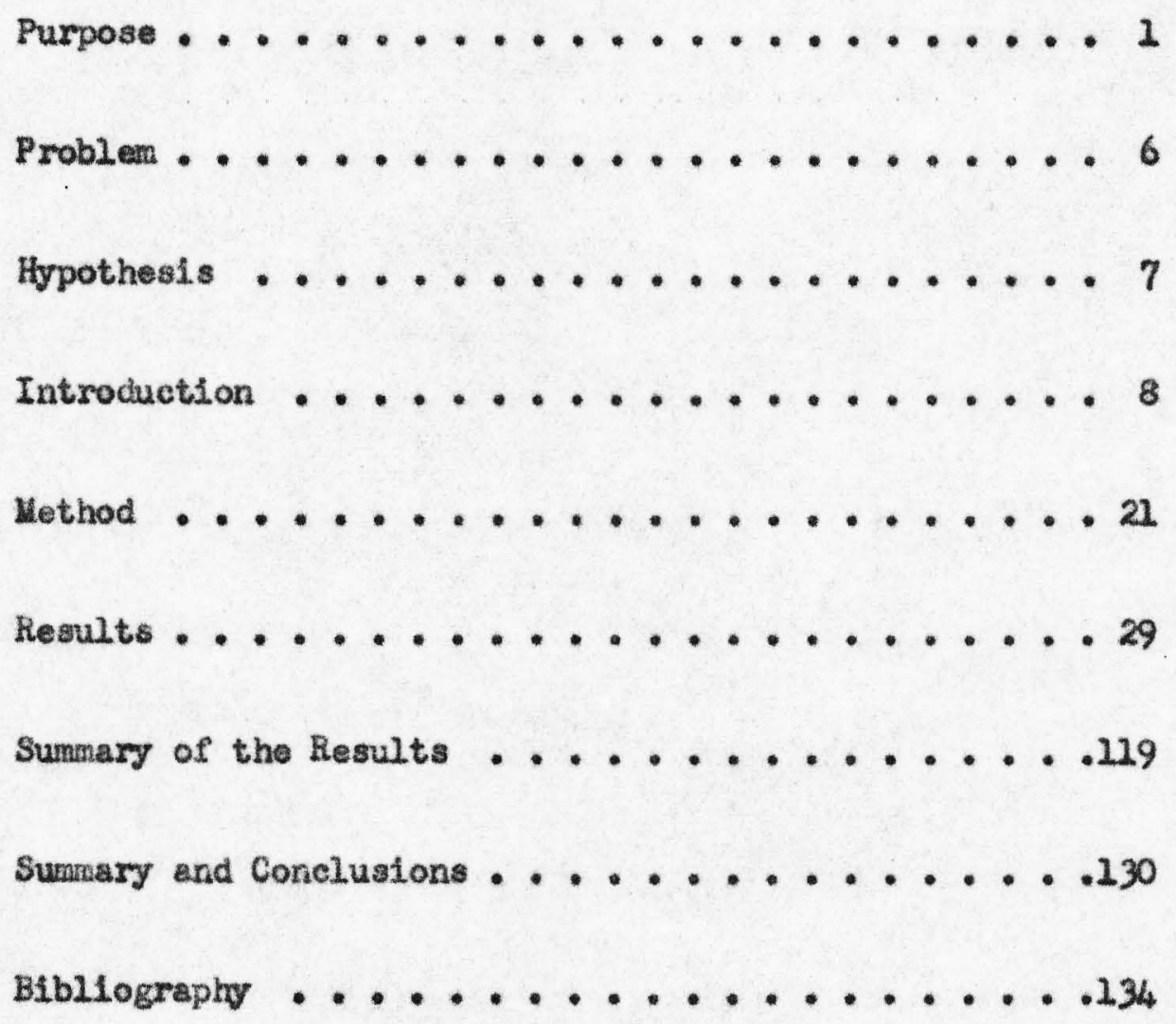




\title{
ACKWOWLEDGMENT
}

For their expert and understending assistance in making this stucy posaible, I wish to express a feeling of gratitucie to the following personst Dr. Arden Frandsen, Head of the Psychology Department and Chsirman of my Graduate Combittee; Superintendent Parley K1lburn, Utah State Industrial School; and all nembers of my Gracuate Comnittee.

For their assistance and loyalty during this year's work, I wish especially to express ay feeling of appreciation to the members of ny family, Beth, Jacque, and David.

\author{
George D, Viatt
}


PUEPOSE

Counseling is one method of desiling with the many adjustment problems which cause the individual to become a less useful, less efficient member of his social group. By counseling is meant a series of direct contacts with the individus which endeavors to offer him assistance in changing his attitudes and behavior with special reference to personal and social demands. $(28, p, 3)$

Much information is avallable to us on the outcomes of counseling in the fields of child guidance, student counseling, social work, mental hyglene, adult counseling, and industrial personnel work, and the importance of counseling has been denonstrated during the last war.

In the field of ehild guidance, some important studies have been made that indicate the value of such treatment in dealing with children. A study made by Healy and Bronner, from the Judge Baker Guidance Center, and an analysis of a year's work in the klochester Guidance Center of New York, give detailed outcones of two of the most fmportant studies. (18,p.4)

In high schools and colleges, we find counseling used as the most frequent method of meeting individusl problems. (18, p. 6)

In the field of mental hygiene services for adults, the deniands for such services exceeds the services offered. $(18$, p. 7$)$

Social workers are now being equipped to give their clients not only the traditional services, inclucing financial aid, but also counseling help.

Until recently, counseling was considered of little value in industrial personnel work. A recent study in personal relations made by Westem Electric Company gives promise of changing this view. Along 
with other results, this study shows that satisfying social and amotional adjustments arong its employess are more important to production then alterations in wages and hours. $(18, \mathrm{p} .8)$

In the field of juvenile delinquency, however, the success of nondireetive psychotherapy has not yet been conclusively demonstrated. What 1ittle bes been done with institutionalized delinquents in individual counseling has resulted in much indecision as to outcomes. The work of the larger clinics has been largely diagnostic and limited to the formulation of recomnendations for treatwent. The results of some studies would indicate a falure on the part of individual psychotherapy to be an outstanding method of delinquent treatment. Another study, as related in A. H. Burrow's, "The Problen of Delincuency", shows the average delinquent as possessing certain diferentiating characteristics that would seem to be accessible to a non-directive type of psychotherapy, which will be discused later in the stucy in more detail.

On the basis of some findings, the practlcability of using a nondirective trpe of psychotherapy with a rendom selection of delincuents may be challenged by sone. In an effort to strengthen our present case, and also to show brieny some of the results of stucies and thinking in the field, reference $\mathbf{1 1 1}$ be made to several such studies and to some implications which seem pertinent to this study.

In presenting a psychologleal view of the causes of criminal behav1or, Thorpe (42) reviewed several recent studies which attempted to determine the fundamental causative factors and set up specific characteristics of persons who are criminals. He states that: 
.....because psychiatrists and others found antisocial behavior to be comnon among persons with disordered personality, it was supposed that the criminal represented a unicque type of personelity, distinctly different from that of the general population... Subseçuent Investigations have, however, falled to lend support to this theory of the etiology of crine.

Thorpe goes on to sumierize a study made by Karpman, who attributes

recognized neuroses to a relatively inconspicuous portion of the reactions among crimins, especially of the habitual type. Another study, made by the Psychiatric Clinic of the Court of Ceneral Sessions in New York City, has disclosed a similar situation. In reviewing this study, Thorpe states:

......1t was found that only 2.4 percent were ment\&lly defective and 1.5 percent psychotic. The psychoneurotic group constituted but 6.9 percent of the total. Of the 82 percent who were regarded as being relatively normel, 21 percent were characterized as being "adjusted". The remalnder, silthough not seriously abnornal, were classified as being anti-social, aggressive, enotionally unstable, unethical, socialiy immeture, egocentric, shiftless, submissive, nouadic, and chrontcally alcoholic. The investigators coneluded that mental deficiency, psychoneurosis, and paychosis play relatively minor role in the causation of crime. It is their bellef that the 82 percent who conpromise the somcalled nomal group, but who are experiencing serlous personality problens, constitute the bulk of the criminal population.

"Simllax flndings have been reported by Healy and Bronner," accord-

Ing to Thorpe in the same review, "who concluded that 91 percent of a group of juvenile delinquents examined by them gave evidence of being unhappy, discontented, or otherdise enotionally disturbed."

Thorpe (42) sums up his article by statings

It can be concluded from evidence presented in the above and other studies that the majority of delinquents and criminals are individuals experiencing serious difficulties, only a small minority being afflicted with inner conflicts of a kind likely to lead to outright psychotic or psychoneurotic disorders. It would appear thus that, instead of necessarily being an innately unstable group, they are relatively typical indivicuals who are in most respects similar to the general population, but who are experiencing more or less severe stress-producine personality problems. This statement is in harnony with the findings 
of an extensive reviev (5) of the personality status of criminals In which it was noted that, although they are not characteristically mentally disordered, offenders are somewhat inferior in certain raspects, such as the tendency to worry, retarded social devalopment, and exotional instability. In short, mary offenders are not "gystematic" criminals who flaunt the mores of a conflictIng cultural group without feeling reprehensive; they are, rather, more or less meladjusted, though not outright abnomal, individuals whose occasional criminal acts are merely symptons of the underlying paychologieal conflicts with which they are struggling.

In view of the above flndings and descriptions of some factors

underlying criminal and anti-social behavior, it seems logical enough to make application of a non-directive type of psychotherapy in treating

such behavior. Rogers $(18, \mathrm{pp} .78,80)$ states, in giving a description of types of maladjustments rost accessible to a non-directive approach, the following:

It will be seen thet. . . some groups tend to be designated as suitable or unsuitable for counseling treatrent. . . the inciplent psychotic, who is beginning to lose contact ith reality, is often unable to take counseling help, ... Mentally defective individuals are also poor candidates for counseling, . Nor is the type of counseling described suitable for the welladjusted individual who feels no uncomforteble strain in his life adjustnent. . . On the contrary, counseling is a process which is of help primarily to those who are suffering from definite tensions and raladjustments.

In another place Rogers (18, pp. 53, 54) continues:

Counseling can be of help only when there is a certain anount of psychological distress arising out of a condition of di aequilibriun. These stresses may be almost entirely psychic in origin, growing out of conflicts of desire. . . More often these stresses are caused, at least in part, by the elenents of the environment coming in confliet with the needs of the individual. - . The delinquent from a gang nelghborhood may have little or no inner conflict over his activities, but stress and tension are created when the community imposes its standards, which are in conflict with his own.

Again Kogers (18, p. 252) states:

Counseling is especially adapted, . . to the individusl who is conflicted, maladjusted, struggling with hinself or with 
his environaent. For the individual who is vocationeliy confused or eductionally maladjusted, or whose personal conflicts are resulting in vocational and educational fallure, a client-centered typo of counseling has a greet ceal to offer.

Pierson (17) states that this type of treatment, referring to nondirective counseling, is "for the disturbed student."

Symonds (40) in cescribling the type of person having problems fallIng within the scope of the paychologlst to deal with says:

The person has mild personality or behavior probleas, but his corplexes and conflicts do not lead to full-blossored neur oses. He mey show such problems as stuttering, lack of sphincter control, pronounced feelings of inferiority, bad habits such as maturbation, lying, petty stealing. In school he is a problem child and referred for special study. Is distinctly unheppy at times or gives his sssociates concern. The difficulty is readily cleared by enviromental readjustments or simple psychotherapy.

Combs (9) states that, "while non-directive counseling is by no means a panaces for 0.1 the $111 \mathrm{~s}$ of counseling, it does have signifleant contributions to make in dealing with problens of personal, social, and emotional adjustment,"

Two factors have been briefly reviewed. (1) Some opinion arising out of research polnts out fundasental characteristics of the average social offender. (2) Other opinion describes some of the characteristics and maladjustments which scem most accessible to a non-directive counseling approach. It would seam, in view of such expressed opinion and Iindings, that to asaume a non-directive type of psychotherapy to hold some promise in delinguent treatment would be a ressonable supposition.

There are conflioting yiews and lack of evidence as to the value of non-directive paychotherapy in treating delinquent behavior. It is Indicated in some studies that many delincuents are under the influence 
of enotional conflicts and stresses that apparently are accessible to psychotherapy and, therefore, would seemingly make good subjects for a study of this nature. It is our purpose in this study to apply nondirective psychotherapy to institutionalized delinquents, and make an evaluation of the outcomes.

\section{PROBLEA}

We may specifically ask, in the form of a problem, can individual and social adjustrnent of Institutionalized delinquent,s be improved to any degres by non-directive counseling; and, if so, will such inprovement be renected in the personality tests and behavior rating scales used in this study?

In order to narrow the teras personel and social adjustment to our purposes in this study, three corollaries to the general hypothesis will be constdered and dealt with. (1) We shall assume that the improvenent In personal and social adjustment with which we are concerned will be reflected in scores on the Celifornia Teat of Personallty and on the Minnesota Multiphasic personality Inventory, which are indicative of better personel end socilal adjustzent. (2) We shall assurve that certain improvenents in personel effielency, social behavior, and ettitudes will be apparent to, and be recorded as anecdotes and as ratings on the Haggerty-01son-licicman Behavior Rating Sehedules. These recordings and evaluations will be made by school administrators and instructors who deal personally and diroctiy with the Lidividuals Included in the study. (3) Certain therepeutic objectives are attained in non-directive counsel1ng. Growth and development of an individual during a series of interviews 
are sssuned to take place to the extent to which these objectives are attained. Notes taken during each interview, when posalble, or inmedLately following, are assumed to be indicative of the degree to which these objectives are achleved with each subject. We are concerned, then, with only those phases of personal and social adjustment that may be rodified by non-directive counseling procecure and which can be measurad to sone degree by utiliaing (1) standardized personality inventories, (2) personal opinion, as recorded on social behavior rating scales, and (3) the observed attainment of the therapeutic objectives.

\section{WPOTHUSIS}

It may be stated specifically, then, that non-directive counseling will improve the personal and social adjustments of institutionslized delincuents. Supporting this general hypothesis sre the following

corollarieas (1) that improved personal and soctal adjustment will be reflected in the scores of personality tests; (2) that improved personal and social adjustment, and soclal behavior will be reflected in social. behavior rating scales; and, (3) that the therapeutic objectives of non-dil rective counsoling will be attalned during the interviews.

To the extent that each corallary is attained, the main hypothesis will be supported. Our method desls with testing the three corollaries to the general ivpothesis. 
INTHODUCTION

In analyzing the techniques, and describing the aims and process of non-directive counseling, we are presenting only one point of view In the field of psychotherapy. We do not wish to evaluate it, but only describe and make applicetion of its method. Rogers $(18$, p. 17) feels that it is wiser to work toward clarification in the field of counseling by presenting one viewpoint adecustely, rather than to increase the confusion through a hodge-podge of conflicting views.

His method has evolved from over a dozen years of experience and experiment in the field of child-gutdance. It has also been influenced by experience in the flelds of student counseling and marital guidance, and has drawn freely from the thinking and expexience of others in these flelds. It is a viewoolnt which has been enhanced and clarified by the results of a research program in which wary counseling interviews, both single interviews and series of interviews, were electrically recorded on phonograph recorda for research analysis. From these various sources, definite principles and hypotheses have developed which offer a basis for further advance.

The basic hypothesis of non-directive counseling, as put by Rogers (18, p. 18), is as follows:

Effective counseling consists of a definitely structured, permissive relationship which allows the elient to gain an understanding of himself to a degree which enables him to take poaitive steps in the light of his new orientation.

In an article appearing seven gears later (21), he restates the basic hypothesis of non-drective counseling as follows: 
Counseling consists of a defintely structured relationship, highly permissive in nature, in which the client finds an opportunity to explore, freely and without defensiveness, his $\mathrm{d}^{\prime}$ ficulties and emotfonalized attltudes which surround thes. As a result of this exploration and catharsis, the client gains an understending of himself which brings his behavior within the sphere of his conscious control, and enables him to take positive steps in new directions in light of his new orientation. The counselor's role in this process is not to offer a solution to the ellent's problems, but to assist the client to see himself more clearly in all his negative, positive, and contradictory aspects in order thet insight may develop.

All techniques used should aim toward developing this free and permissive relationship, this self-underatanding in the counseling relationship, and this tendency toward positive, self-initiated action,

This method stands out in contrast to some of the older types which eaploy such devices ss (1) acivice and pereusston, (2) ordering and for bidding, (3) exhortation, (4) suggestion, (5) reassurance and encouragement, and (6) diagnosine and preseribing. All of these approaches to the poorly adjusted Individual have two basic assumptions in comon. They assurae that the councelor 18 the one rost competent to decide what are desirable goal for the ludividual and by what value the situation Is to be judged. A second basic assurption is that, by searching, the counselor can discover techaiques wich will get the client to the counselor-chosen gosl in the nost efficient manner. (18, p. 27)

Against these methods of psychotherapy is this newer approach, as described by hogers (16, pp. 27-31). It represents a fundamentally different viewpoint. It assumes that psychotherapy is not a satter of dolns something to the indjvidual, and of inducirg hiro to do sonething about himself, but a mattex of freelng hin for nomal growth and development; of renoving obstacles so that he can again nove forvard. It 
assumes also that most maladjustments are not fallures in knowing, but that knowledge becones inefiective because it is blocked by enotional. satiafactions which the Individual achiaves through his present maladjustments. It attempts to operate directly in the field of emotions and feelings, rether than attenpting to achieve enotional reorgandzation through an intellectual approach. Greater emphasis is placed upon the Imaediate situation than upon the individual's past. It assumes that the a gnilioant enotional patterns of the individuel, the onez that are causing disturbances and that need serious consideration, show up just as well in his present adjustment, and even in the counseling hour, as they do in his past history. For therapy, or growth, to take place, past history, as important as it may be for other purposes, is not necessarily important. There is one other important characteristic that contrasts the non-directive approsch from the others mentioned. In the directive approach, the individual is assumed to grow and chenge and make better adjustments after the interview experience. In the newer approach, the therapeutic contact is ltsalf a growth experience. In the newer approach, the therapeutic contrat is itself a growth experience. This might be compared to the educationel discussion as to whether ecucation is preparation for life, or whether it is life. This type of therapy is not only preparation for change, it is change. In another writing, Rogers emphesizes three bastc differences between directive and non-directive counseling when he states:

(1) The first of three distinctive elements of clientcentered therapy. - . is the predictability of the therepeutic process in this approach. We find, both clinically and statistically, that a predictable pattern of therapeutic development takes place.

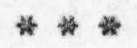


It may be sald that we now know how to Initiste complex and predictable chain of events which operate effectively in problea situations of the most diverse types.

$$
\text { ॠँ }
$$

Clinically we know that sometines this process is relatively shallow, involving primarily a fresh reorientation to an immediate problen, and in other instances so deep as to involve a complete reorientation of personelity. It is recognizably the same process whether it involves a girl who is unheppy in a dormitory snd is able in three interviews to see something of her childishness and dependence, and to take stops in a mature direction, or whether 1t Involves a young man who is on the edge of a schizophrenic break, and who in thirty interviews works out deep insights in relation to desire for his father's death, and his possessive and incestuous inpulses toward his mother, and who not only takes new steps but rebuilds his whole personelity in the process. Whether shallow or deep, it is besicaliy the same.

$$
\text { * * * * * }
$$

It is the fmplication of this predictablifty which is startiling. . . Hence, we regard this orderly and predictable nature oi non-directive therapy es one of ita nost distinctive and ajaificant points of difference from other approaches. .

(2) Naturally the question is ratsed, what is the reason for this predictability in a type of therapeutic procedure in which the therapist serves only a catalytic function? Basically the reason for the predictabilsty of the therapeutic process Lies in the discovery - and I use that word intentionally - that within the client resicie constructive forces whose strength and unifornity have been either entirely unrecognized or grossly underestinated. It is the clear cut and disciplined reliance by the therapist upon thses forces within the client, which seens to account for the orderilness of the thorapeutic process, and Its consistency from one client to the next.

$$
\text { ** * * }
$$

The client-centered theraplst. . has learned that the constructive forces in the individual can be trusted, and that the wore deeply thoy are relied upon, the aro doeply they sire released. He has cone to bulld hls procedures upon those hypotheses, which are rapidly beconing established as frcts; that the client knows the areas of concern which he 1 s reacy to explore; that the chiont is the best judge as to the nost deairable frequency of interviews; that the client can lead the way are officiently thas the therapist into deeper concerns; that the client will protect himself from panic by ceasing to explore an area which is bocoming too painful; that the elient can and 
w11 uncover all the repressed elenents which it is necessary to uncover in order to build a confortable adjustaont; that the client can achieve for himself far truer and more sensitive and accurate insights than can possibly be given to him; that the client is capable of translating these insights into constructive behnvior which welghs his own needs and desires realistically against the demands of society; that the client knows when therapy is completed and he is ready to cope with ife independently.

$$
* \text { * * }
$$

The willingness fully to accept this strongth of the cllent, with all the remorientation of the therepeutic procedure which Implies, is one of the ways in which client-centered therapy differs most sharply from the other therapeutic approaches.

$$
\text { *3 } 4 \text { क }
$$

(3) Unlike other therspies in which the skinls of the therapist are to be exercised upon the client, in this approach the skills of the therapist are focused upon creating a psychologlcal atmosphere in which the client can work. If the counselor can create a relationship perneated by warnth, uncierstandIng, safety from any type of attack, no natter how trivial, and basic aceeptance of the person as he 1. , then the client will drop his natural defonsiveness and use the situation.

$$
\text { of to to }
$$

We have come to recognize that if we can provide understandIng of the way the client seems to himself at this moment, he can do the rest. The therapist muet lay aside his preoccupation with diagnosis and his dignostic shrewdness, must discard his teadency to nake prolesalonal evaluations, mast cease his endeavors to formulate an accurate prognosis, rust give up the teraptation subtiy to guide the individual, and must concentrate on one purpose only; that of providing deep understanding and acceptance of the attitudes consciously held at this moment by the client as he explores step by step into the dangerous areas which he has been denying to consciousness.

$$
\text { is }
$$

I trust it is evident from this description that this type of relationship can exist only if the counselor is deeply and genuinely able to adopt these attitudes. Client-centered counseling, if it is to be effective, cannot be a trick or a tool. It is not a subtle way of guiding the client walle pretending to let hin guide himself. To be effective, it must be genuine. It is this sensitive and sincere "client-centeredness" in the therepeutic relationshp that I regard as the third characteristic of non-directive therepy which sets it apart from other approaches. 
A surnary of the characteristice of non-directive counseling (18, pp. $28-3 i)$ are listed as follows:

(1) The non-directive nethod of counseling aims at greater independence and integration of the individual.

(2) The individual, not the problem, is the focus.

(3) The ain is not to solve problens, but to aid the individual to grow.

(4) It does not aim to induce the indiviciuel to do sonething about hisself, but is a matter of freeing hinself for normel growth and developaent.

(5) It is a matter of removing obstacles so that he can solve his own problems and again move forward.

(6) It places exphasis upon anotional aspecto and feelings, rather than upon the intellectual factors.

(7) It assunes that most naladjustnents are not failures in knowing, but that knowledige is ineffective because it is blocked by emotional satisfactione whioh the Individual achieves through his present maladjustments.

(8) It piaces greater stress upon the imediate sitiation than upon the past.

(9) It assunes that significant enotionsl patterms show up as well in the present adjustment as in the past.

(10) That for therapy to take place, a case history is not important.

(11) It stresses the therapeutic relationship itself as a growth experience.

(12) It eccepts the assurption that the Andividual changes and grows during the interviews as well as after the interviews are terninated.

(13) It assumes that the individual learns to understand himself better, learns to make 1raportant independent choices, and he learns to relate himalf successfully to another adult person. (14) It assuaes that counseling is not oniy a preperation for change, but that it is change.

Up to this point we have atterapted to present the basic assurptions, 
or point of view of non-directive counseling. In order to get a more comprehensive understanding of the non-directive viewpolnt, we w11. turn to the process of therapy. Rogers (18, p. 30) refers to the procedure, (all that usually happens from the begiming of the Interviews to the end) as the "therapeutic process". It should be fully recognized that these steps, as presented, do not follow esch other as a series of separate and distinct processes, but that there is an overlapping and a gradual merging of one into another. In suruarizing Rogers' discussion $(18, p p .30-45)$ of these characteristic steps in the therapeutic process, the following twelve steps are subuitted:

(1) Usually the Individual, unable to solve for hirself sone pertInent problen, comes to the counselor seeking help. He may or may not be exercising his own initiative in this initial step. He may have cone at some one elso's suggestion, or he may have come independently, as a direct result of his own recognition of a disturbing problem and a desire for assistance in its solution. If the client has been inAuenced to subject himself to the Interviews umwlilngly, then the problem of putting on hin the responsibility of resching his own solution may be difficult. If he comes to the counselor as a result of his own choice, having been motivated by a desire for a solution to his own problas, then he will usually accept the responsibility for working out his own solution.

(2) In the initial contact, the counselor usually defines the helpIng situation. The client is made avare of the fact that upon him and not the counselor rests the responsibility for the solution of the prob1em. The counselor admits not having the answers, but explains that 
the interviews may provide a place where the client, with the counselor's help, can work out satisfactory answers for himself. The client must understand at the outset that it is not the counselor's responaibility to give the answers, but that he must work out his own. By words and actions, the client is made to feel that the counseling hour is his, to take responsibility, and to work out his problems in an attitude that is free from restraint.

(3) The counselor encourages a free expression of feelings on the part of the client in regard to his difficulties. The counselor accepts the expressed feelings of the client and atterpts to encourage these feelings by a friendly, pernissive attitude. If the counselor succeds In developing a complete sense of freedom and understanding, the olient will ususlly not hesitate to give expression to his feelings of hostility and concern. The counselor's primary concern at this point is to encourage free expression. The context of these expressions, if not influenced by the counselor, are usually negative, violent, and full of feelings of hostility.

(4) In the fourth phase of the therapeutic process, the counselor accepts, recognizes, and clarifies these negative feelings. His job here is to respond to the feelings expressed, rather than to the intellectual content of the client's statement. Feelings of ambivalence, hostility, and inadequacy are usually expressed at this point. Whatever kinds of feelings are expressed, the counselor must reflect them in a way that the client can come to recognize that he has such feelings and can accept then as part of himself, rather than project them on others, or hide them behind defensive behavior. The counselor simply verbalizes these feelings as accurately as possible, thus allowing 
the client to progress from one negative expression to another with as Little influence or interference as possible. If the feeling is inaccurately or inadequately interpreted, progresa is usually interrupted while the client atteapts to make a clearer verbalization of his feelIngs, which he inevitably does. So, at this point, the counselor's specific duty is to enhance the client's progress by a careful analysis and verbal interpretation of his feelings, not words, as he progresses from one expresaion to another, in this effort to explore his own feclings.

(5) Following a full expression of all negative feeling, come expreasions indicating feelings of a more positive nature. These positive expressions come faintly and with little enthusiasm at first, and usually overlap and are mingled with the negative expressions, which now becone less violent in degree. Signs of these positive feelings sometime appes while the negative expressions still seem to be In full force. But eventually the statements and feelings of a negative nature disappear and are replaced by these statements givIng expression to positive inapulses. The appearsnce of these positive statements is the most certain and predictable of the whole therapeutic process. The more violent and deep the negative expresstons are, if they are reoognized and accepted by the counselor, the nore certain are fortheoming statements indicating positive feelings, These usually take the forta of expressions of accepting the situstion, usually unpleasant, as a result of the cllent's own behavior, of social impulses, and of a desire to be mature.

(6) The postive feelings which are expressed are accepted and 
recognized by the counselor the same as the negative ones. No praise or advice in any manner is indicated in responding to these feelings. They are accepted without bias or evaluation. It is this acceptance of both the negative and positive expressions of feeling that give the elient the opportunity, perhaps for the first time, to see himself as he actualiy is. He is given every opportunity to express his negam tive feelings and he is given no encouragenent to over value his positive feelings. It is in this kind of situation that he is able to gain insight and self-understanding.

(7) The gaining of insight and self-understanding is the next step in the therapeutic process. This experience of relating feelings that have previously been inhlbited does more than bring about a sense of release. In addition to this, it gives the client a changed perception of himself. Gradually, because of this changed perception, the client comes to re-orient hirself and to show by his behavior that he is conscientiously taking this new role. Upon the strength of this assumption, we have assumed, in this study, that the change that takes place in the individual during the therapeutic process can be objectively measured by the use of tests.

(8) The cllent, in response to this new insight, expresses himself in the difection of making decisions in 11 ght of his new orientation. Here the ollent usually finds himself in a soawhat confused position. He mast consider and clarify possible choices, possible courses of action. He experiences some confusion and has a feeling of hopelessness in vieving his new situation. The counselor's function here is to help clarify the different possible choices suggested 
by the client, and to recognize and make him fully aware of his fears and hesitations to make independent cholces, It is not his function to influence a decision, or to urge a particular course of action, or to offer advice or persuasion in any way.

(9) Following this usual period of indecision, comes positive action. At first these are observed to be reactions of an insignificant nature, but they are highly signifleant to the client. It is sonetimes his first experience of taking the responsibility of making his own decisions, and then Independently acting upon them. Once insight $1 \mathrm{~s}$ gained, the actions that are taken, and the decisions that are made, are usually suited to the new insight.

(10) After the client has achieved considerable insight and has had some experience at positive behavior and making decisions, the renaining three steps of the therapeutic process are merely indicstions of further growth. Further insight is developed and a more conplete and accurate self-understanding is acculred by the individus, as he galns experience and gets more confldence in hinself.

(11) Likewise, more definite and integrated positive action in the light of his new orientation is assuned by the client. There is 2 lessening degree of fear and anxiety over making independent choices and wore confldence is gained in his self-direction.

At this point, too, a new relationship is uøually experienced between the client and the counselor. This relationship becomes extremely personal. The client becomes interested and incuisitive about the personal aspects of the councelor, and expresses a friendly and genuine interest in hin. Actions and experiences and reflections, 
relative to the interviews, are now brought into the open and discussed freely and with little fear or uncertainty. Dependence upon the counselor grows less and a definite strength and independence is observed in the client.

(12) We find in the final step of the therapeutio process a feelIng of decreasing need for help and the client's recognition of the faet that the relationship must end. The counselor helps to olarify this feeling, as usual, by accepting the fact that the client is now better able to handle his own affairs and decide his own course of action. There is no attempt on the counselor's part to elther get the client to leave, or to prolong the interviews. The contact remains non-directive to the end.

In such a course of events as we have described as the therapeutic process, any attempt to break the process down into isoleted steps, as we have done here, should be recognized as being subjective and approximate. On the othor hand, it shovid also be kept in mind that this process is orderly, consistent, and predictable, in its major outlines.

The following is a brief sumary of the characteristic steps in the therapeutic processt

(1) The individual comes for help.

(2) The counselor defines the helping situation.

(3) The counselor encourages free expression.

(4) The counselor accepts, recognizes, and clarifles feelings expressed by the elient, usually negative at first. 
(5) Expreselons of negative feelings are usually followed by expressions Indicative of positive feelings.

(6) Counselor accepts, recognizes, and clarifies positive feellngs.

(7) The client expresses foelings indicating a better understanding of his problems and gains some insight.

(8) The client, in view of this new insight into his problems, expresses himself in the direction of making decisions in 11 ght of his new orientation.

(9) The client expresses himself as having taken some action in the direction of his new decisions.

(10) The olfent geins further insight,

(11) The cllent indicates further positive action.

(12) The client indicates by his statements a decressing need for holp toward a better adjuatnent, and the interviews are terminated.

The therapeutic objectives, as referred to throughout the study, will include the following four major objectives:

(1) Free expression.

(2) Insight.

(3) Decision.

(4) Action.

Evidence of these objectives having been attained during the counseling interviews, will be indicated by responses and statements made by the subjects during the interviews. Evidences of the counselor's techntque in the use of the non-directive method way also be ovaluated from responses made in the interviewa. A sarpling of the 
counselor's responses are recorded verbatum in the study.

A more corplete presentation of non-directive psychotherapy, than described here, 1s given by Rogers (18), and further discussed by Snyder $(35,36,37)$, Blxler $(3,4,5)$, Royer $(32)$, and others. Besides logers, Snyder (36), Bixler $(4,5)$, Axline (1), Sargent $(33,34)$, Wuanch $(16)$, Combs $(8,9)$, and others, have clatmed excellent results fron the use of the non-drective techndque in varIous types of personality disorders.

\section{METHOD}

The problem of selecting a group of subjects for the experimental purpose of the study, presented some dfflculties. Some individuals who have problens of maladjustment mey be lass apt to profit frora counseling than others. According to Rogers $(18, p .61)$, a client who is unable to cope with hia situation hes little chance to improve. He atates:

A moment's reflection will reveal the fact that some individuals are so weighted down by unfortunate circumstances or 30 weakened by personal inadecuacies that no reorganzation of attitudea will enable them to meet life on a nomal basis. Here is a delinquent boy, living in a so-called "delinquent area", where soctal forces encourage delinquent acts, residing in a home where he is rejected in favor of a younger brother, attending a school which makes no allowance for his retarded mentelity, but continually makes him conscious of his failures. No amount of counseling or psychotherapy is 11kely to be successful in such a case.... Even if he could achieve a high degree of insight into his situation, there sre fow elements of his 1ife over which he could exercise control. This is a case in which environmental treatment must be the primsry approsch. Counseling can play only a secondary role.

In addition, the client who recognizes a need for help and has a desire to be helped Is likely to be more susceptible to successful 
counsoling than the client who may need assistance just as badiy, but fails to recognize the need or display any inclination to be helped. When need for help is felt strongly by an individusl, he is more likely to work out his problems more quickly and more successfully than if the desire for help is lacking (18, p. 66).

Wh the fully independent adult, the opportunity for contacts is not 1ikely to exist unless there 1 a a real dealre for assistance. Two studies made at the Smith College School of Social Work confirm this statement $(18, p .72)$. Investigation of cases in two child-guidance clinics showed that when parents brought thetr children unwillingly to the clinic, simply because school or court authorities advised them to do so, little treatrent progress was likely to be made (18, p. 72). Llkewise, a cllent needs to be in a state of tension or stress. It is necessary thet some sort of conflict or psychological stress exist within the patient before it can be considered that he ila in need of psychological counseling $(18, \mathrm{p}, 63)$.

Undoubtedly counseling gets off to its nost confortable start when . . the individual is under stross, eager for help and able to talk about his problems. $(18, \mathrm{p} .67)$.

Another aspect of the problem of who can be most successfully counseled with a non-directive method, is whether the client is independent of farily control.

As long as a child la enotionally dependent on his parents, subject to parental control, and living in his own home, counseling of the child alone is very often unsuccessful, and may even increase his difficulties. $(18, p .72)$

It is supposed, also, that counseling is likely to be more successful with individuals of certain age levels and certain intelligence levels than whth others. Rogers $(18$, p. 74 ), in referring to Healy and 
Dronnex's study states that, ". . their findings would lesd us to constaer the Individual of low Intelligence whth wome eare before deciding upon counseling as the best trestrunt epproseh"

The question of age is even pore uncertain. The conclusions are to the effect that, slthough 1fttle is known about the influence of age on successful counseling, "careful consideration should be given to this question when the elient ia beyond the age of fifty." $(18, p .74)$ the lower age limit presents a similar problex. "Counseling, in which the apprcach is entirely verbal, would not often be utilized below the age of ten." (18, p. 74)

The highy unstabio individual, slso, seeus to respond leas woll to couriseling. This lo true sspecially when such instability results from a secaingly organic or hereditary condition. hogere (18, p. 75) adrits the looseness of the term stability. He also reviews the controm versial evidence of some studies on the outcones of counseling adth supposedly unstable Individuals, but he concludes that with some Individuels with charaeteriatics indicative of instablilty, non-di reetive psychotherapy is Iikely to be unsuccessful in producing desireble growth. These tentative criteria for successful counseline have been reviewed because they bear drectly upon the problemo encountered in siakIng a selection of subjects for courseling in this study. Before considaring these probless as they have affected the stucy, we will set thes out in the fork of a sursery. It would seen that froes what has been seid, thet non-directive counseling, involving a series of contacts Wth the Individual is advisable, providing the following conditions exist (18, pp. 76-77):

(1) That the individual has a desire to be helped. 
(2) That he is, to sone degree, suffering frosa a condition of stress, or tension.

(3) That he possesses some capacity to cope with his situation. That is, that his circurstances are not so unchangeable or adverse that he has no control over theran.

(4) Thet he is reasonably independent of close family control.

(5) That he is froe from extrene behavior, indicating a condition of instability of an organic or hereditary nature.

(6) That he possesses adeçuate intelligence to discuss and understand his problens.

(7) That he is of autable age. This means old enough to have some independence, and young enough to be able to make sone adjustment. In terms of actual age, it ma indicate roughly from ten to fifty. Selection of Subjects. In the task of selecting subjects for the study from a group of institutionalized delinquents, these criterla of success necessarily came under consideration. Two alternatives were appsrent. One was undoubtedly the wiser choice if our chief purpose was considered to be successinl outcomes in tems of reaching the therapeutic objectives. This would have involved a selection of subjects, If possible, who would meet these criteris of success. The other choice would be to select subjects which would represent a random sasple of the entire group. This latter selection would have the advantage of testing the outcomes of non-directive counseling over a wider range of Individual personslity variation. It raey also be more indicstive, than the former method of selection, of the proportion of institutioneliged delinqquents who may be helped by a non-directive psychotherapeutic 
treatment.

The method of selection that was actually used did not represent a clear-cut choice of elther a group selected on the basis of these criteria, or a group randomly selected from the total enrollment. Some limitations were encountered in selecting the subjects. There were approximately eighty students at the school at the time the study was initiated. It was estinated that three or four months would be required to complete the experimental work. This mide it necessary to select subjects whose tems at the institution would not terminate within the required time needed to complete the work. In view of this limitation, it was necessary to make a selection from a group which comprised about one half of the total enroliment. From this latter group, then, twenty two subjects were selected.

Eouating Pairs of sublects. In addition to merely making a selection, the study required that the individuals included in the experimental group, totaling eleven, be equated into pairs with those included In the control group. This pairing was done for the purpose of making a selection of two subjects who would be matched as ecually as possible on the basis of their ability to respond successfully to treatment. logers $(18$, pp. 53-77) has stated some tentative criterid upon which 1s besed the advisability of counseling as a possible means of succesgful treatment in a particular case. These criteria have been listed previously in this study. From the 1ist, it wes felt that two are objective enough that they could be used safely in an attempt to eçuste the subjects. These are age and intelligence. Of the other criteria IIsted, (1) a desire for help, (2) a degree of tension existing within 
the individual, (3) some eapacity to cope with IIfe situations, (4) ability to express himself, (5) that the individual is reasonably Independent of fardily control, and (6) that he is free frone excessive instabllities, the first five were assumed to be present in all the subjects. In making the selection, the superintendent of the school and his assistant, on the basis of thelr knowledge of the subjects, attempted to elininate from the study ary student who, in their opinion, wight be excessively unstable.

The subjects were equated, then, upon the basis of the two criteria, age and intelligence. In this procedure, we were further limited in the total number from which a selection could be made. Sone of the group from which it was possible to choose subjects, could not be matched equally with any other member of the group. This further necessary process of elimination reduced the group finally to a number only a few above the total number required for the study. Thus, it Is felt that our experimental and control group, as they were finally selected, constituted a fairly representative cross-section of the entire school membership at that time.

After the flnal selection of twenty two subjects had been acconplished, who could be matched in pairs of equal, or nearly ecqual age and Intelligence, the next step was to determine which subject of each equated pair would be counseled. In making this selection, a randow choice of one from each pair was made. The eleven individuals thas selected made up the experimental group and the remaining eleven made up the control group. 
Pre-testing. Preceding the interviews, the Californis Test of Personality and the Minnesota Multiphasic Personality Inventory were given to each individuel in each group. These tests were given to the subjects of each pair as nearly the same time ss possible. Results of these tests will be conpared with the results obtained from a retest following the interviews.

Also preceding the interviews, the Haggerty-OLan-Wickman BehavLor Rating Schedule was executed with each individual by two persons at the school who, it was folt, were probably most familiar with the subjects being rated. The results of these behavior rating indexes are to be coapared with the results of the same schedules executed again, with the same subjects, at the end of the counseling interviews.

Counseling. Following the first administration of the objective tests and the behavior rating schedules, a series of counseling interviews were conducted with each subject included in the experimental group. These contacts proceeded on a non-directive and permissive basis, described in the Introduction of the study. Each subject was interviewed once every week for a period of forty five minutes, except in a few cases where the subject expressed a wish to miss an interview. The number of intervi ews reçuired to complete each series varied from four, for the shortest series, up to seventeen for the longest series. The average length of each series was about nine intervlews. With the exception of two subjects, the termination of each series was completed upon the suggestion of the subject. Rlogers $(18, \mathrm{p}, 220)$ tells us of the predictableness of this phase of the therapeutic 
process. The frequency of the interview contacts, usually left pretty much up to the client, in this case was conducted on a weekly basis. This was necessary because of the limited amount of time available. In order to determine to what extent the therapoutic objectives were reached with each subject, a set of notes were taken during, or Immediately following each interview. Sone verbatum statenents have been recorded that w111 be made avallable and ueed as an incication of having reached, or of not having reached, these objectives. In adaition, the counselor hes, as accurstely as possible, recorded the outstanding feelings expressed by each subject during each interview. An atterapt was made to achieve the therapeutic objectives with each subject. The mumber of Intervilews that have been necessary to fully achleve these objectives, has varied with each Individual, and in some cases they were not achieved at all.

End-testins. Upon the termination of each series of contacts, the same objective tests that were adrainistered preceding the interviews were given again in a smilar manner. At this time the same tests were again adrulnistered to the equated subject of the control group. This procedure is aimed to eliminate the influences of uncontrolled factors. A detailed description of the outcones and results of the measuring devices used in the study will be recorded in the Results. 


\section{RESUL'S}

It is our purpose in this section to present the results obtained according to the procedures previously deseribed. These findings will Include, for the experimental subject of each pair: (1) a developmental record and sumary of the series of therapeutic interviews; and for both the experimental and the control members of each pair of subjects there will be reported pre-test and end-test scores on (2) the Minnesota Multiphasic Personality Inventory, (3) the Califomia Test of Personality, and $(4)$ the Haggerty-0lson-Wlokman Behavior Rating Schedules. The results for each pair will be presented separately, to be followed by a sumary table of data on all eleven pairs together.

It was felt, at the time the measuring instruments used in this test were chosen, that a device was needed that would possibly indicate the supposed change that occurs in an indivicual during successful psychotherapy. Realizing the difficulty of describing this anticipated change and then selecting a single measuring device that would record accurately such a change, it was decided to use a number of instruments covering a wider range of behavior. It was also recognized that a vast uncertainty and difference of oplnion exists regarding the pathology of individuals exhibiting anti-social behavior.

Discussion of the Interviows. The first means used for deternining to what extent a change occurred in the individual during a series of non-directive counseling interviews was the therepeutic objectives. From the subjects' statements and expressions of feeling, it may be determined whether or not these objectives have been reached. The 
successful attainnent of these objectives during the therapeutic process is used by Rogers as criteria for having produced desirable change in the aubject.

It was our aim in this study to determine not only if these objectives could be achieved with institutionalized delinquent individuals, but also, in the event they were achieved, to appraise this change by the use of other devices constructed for the purpose of detecting and measuring certain components of personality.

The chart preceding the account of each interview is designed to point out the particular interview in which responses were made, that In the counselor's opinion, would be indicative of the subject having reached a partioular objective. In some cases this procedure will be subjective in nature because of no verbstum statements to support such an laplication due to the impossibility of taking a complete get of verbatum notes. However, in most instances where many statements were made that would Indieate that the subject has gained one of the objectives, the counselor has indicated such in his notes, and In nost cases recorded verbatum one or more supporting statements.

It w111 be noted, in these interview charts, that the four therapeutic objectives, (1) free expression, (2) insight, (3) positive decision in light of the new insight; and (4) action on the new decision, are listed down the left hand side of the chart. The total number of interviews required by the case are listed across the top of the chart. A mark in the aquare indicates that statements of feelIng were made during the interview as numbered, and with the correspondIne objective. By the use of this device, it is felt that the reader 
may have a more objective and precise viaw of the "success" or "fallure" of a case than could be given in a sumasrizing statement.

A week before starting the interviews, the counselor called all the subjects together who had been selected and informed then of the plans. The relationship of the interviewing situation was explained and its purposes defined.

They were told that if they had disturbing probleras and desired a more satisfactory solution to them, that the counseling situation would give an opportunity to talk snd think about the things that may be causing them to feel unhappy. Further, that in such a situation, It had been found that others had sometimes found satiafying answers to their own problems thet they had been previously unable to solve by themselves.

This type of explanation to the subject of the counseling relationship will be referred to as "structuring the relationship", rather than to describe it on each occasion during the interviews when it seened necessary to do so.

After structuring the relationship to the subjects, they were given a choice as to whether they wished to proceed with the counseling or not. The following week all were called together again to give their decision. Each expressed a desire to be included anong those who were to be interviewed.

The interview series in the case of the first subject, will be given in more detall than the ones that follow. By presenting one case in detail, it is felt that the reader $w 111$ be given a chance to observe more closely the therapeutic process and other aspects of the 
psychotherapeutic situstion.

The subject of the first case presented has reed through all the notes taken during the interviews, and from which this account is Given, and has approved them as expressing the highlights of his feelIngs as he expressed ther to the counselor. After reading then, he sald, "They say just what I have been thinking".

Diecusation of the Minnesota Pultiphasic Personality Inventory. This test was designed especially to detect and measure the degree of maladjustment existing in an individual in nine categories of described neurotic and psychotic disorders. The authors, Hathaway and Wokinley (14), describe it as a psychometric device constructed for the purpose of ultimately providing scores, in a single test, of the major phases of personelity. It atterpts to measure those abnomalities in persons that clinical workers and counselors have cone to know as the rost prychologlcally disebling personslity traits.

The test comprises 550 statements, each on a separate card, cover Ing the physical condition, sorale, and attitudes of the individual being teated. The personality characteristics now in avajible form for scoring are bypochondriasis (Hs), depression (D), psychopsthic personality $(\mathrm{Pd})$, masculinity-fenininity $(\mathrm{MP})$, paranola $(\mathrm{Pa})$, psychasthenia (Pt), schizophrenia (Sc), and hyporania ( $\mathrm{KE}$ ).

In the adninistration of the test, the subject is asked to sort all the cards Into three categories indicated by three gutde cards, True, False, and Cannot Say. The mumber of cards sorted into each group are consldered to be elther normal or abnormal responses to the statement. The abnomal responses indicate the score of the subject 
In any scale, as seasured by the key.

The first four scales listed on the profile shoet (which will be dupliceted in the discussion of the test) are the question (?) score, the lie ( $L$ ) score, the K factor (a check on valioity), and another validity scale, the F score. The raw question score is the number of items classified as Cannot Say. Large question scores invalidate all the others, although it may, in addition, be indicative of psychasthenic and retarded depression patients. The L score is also a validating score. A high I score coes not entirely invalidate other scores, but may indicate that the true values are somewhat higher than actually shown. A high K score may rean the patient was defensive at the time of taking the test, and calls for a faodificstion of some scores in order to secure the true values, The F score serves as a check on the validsty of the whole record. When the $F$ score is high, others are likely to be invalid for one of seversl reasons. A high $F$ score tagy also follow closely certsin abnormal patterns of the profile. It would seem from this account that with certain abnorwal patterns, a high 8 score may be expected. Usually, however, a low $F$ score nay be considered a rellable Indication that the subject's responses were rationel snd relstively pertinent.

Hathaway and Hokinloy (14) present a detailed description of the several categories of personality abnornalities, depression, hoteria, etc.

The pre-test and end-test scores of each pair will be presented on a chart similar to the reguiar profile chart used on the Recording Sheet. Following the profiles in each case is a brief discussion of 
the score impilications.

Discuasion of tho Cals fornte Pest of Personalit:. The third measurm Ing device used in the study is the Callfornis Test of Personality. According to the authors, Clark, Mlegs, and Thorpe (7), "the najor purpose of the test is to reveel the extent to which the student is adjusting to the problems and condtions which confront him and is developing a normal, happy, and socially effective personallty."

The profile of the test is divided into two majos sections. Section 1 Indicates hov the student thinks and feels about hiriself. This section is subdivided linto six categories including the student's self reliance, his esthnate of himself, his sense of personal freedon, his feeling of belonging, his tendencles toward withdrawing, and nervous symptoms. Section 2 is subdivided into six categories composed of social factors. They atterupt to show what the student knows about soc1aJ standards, how apt he is with their use, his freedom from anti-social behavior, and his family, school, and comanity relationships.

As with the Kinnesote Lultiphasic Personality Inventory, the pre-test and end-test acores of esch pair are presented here in the form of a duplication of the sctual test profile.

Discussion of the Hasgerty-01son-wiclonan Behavior llating Schedules.

A fourth maans of mesuring individual change is the Haggerty-01sonWiclanan Behavior Rating Schedules. In recording pre-test and end-test results of this scale, only rav scores will be used. The schedules were standardized on children representing the norwal populetion and to present results of the subjects used in this study on a percentile scale would place the rajority of scores high up in the $90^{\prime}$ s. It is 
felt that raw scores will discriminate the differences in scores on a wider range scale than percentile scores. Although the size of a score does not reveal its significance, it will be incicative of differences in pre-test and end-test results, and this difference is our major concern. The schedules are constructed in such a way that the higher the score the more indicative it is of the presence of numerous and serlous problems, while lower scores point to fewer and less serious problens.

The authors use behavlor problens "to represent the discrepancy between the capacities of the individual to adjust himself, and the demands of his environment." They define a problem child as "one who mantests one or nore behevior problens." The schedules assume that all children are problem children, but in varying degrees (12). The schedule is divided into five major subdivisions representIng problems of various frequencies and degree, as found among a number of school children. In differentiating the nature of the probleas under each division, the authors have described then as behavior, intellectual, physical, social, and enotional.

A table will be used with each pair to show the raw score results of the pre-test and end-test scores in each of the five major divisions of the schedules.

Following is the results of the interviews with the experinental subject of pair 1. 
RESULTS OF THE INTERVIEW

Table 1. Pair 2. Experimental Subject. Interview Results.

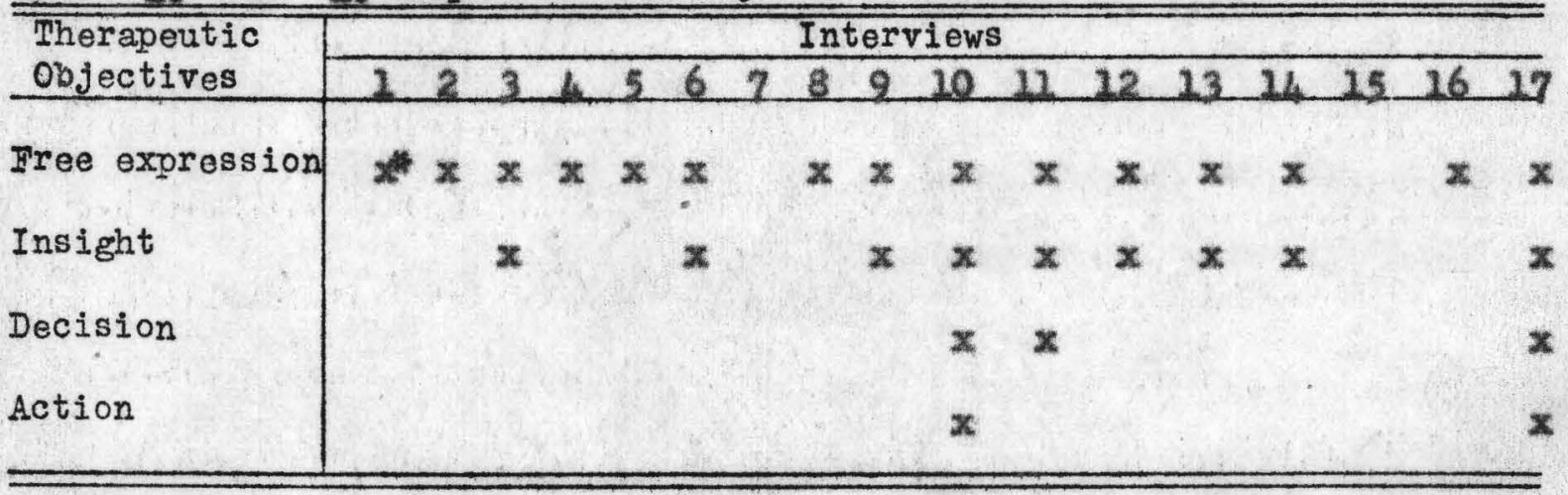

* An $x$ is placed in the square when statements were made indicating the attainment of an objective.

\section{Interview $1 \mathrm{~s}$}

The subject talked freely and inteluigently during the firat inter view. He told of his taking some correspondence work from the University of Utah, and of his aspirations when he is released. He displayed some evidence of being under enotional conflict and went deeply into his own feelings. He analyzed quite ably his feelings regarding his being sent here, his resctions to his environment while being here, and his reections to being released.

He expressed hinself to the effect that he had control of his situation and delinģuent tendencies, but added that he couldn't be right sure because he had felt the same woy twice before and has been returned on each oecasion.

He feels that upon release he would like to stay in Seit Lake, but Is afraid of the bed influenee of the "stigan" and his "former friends". He does not blane them for his "fallures", but recognizes his onn 
weaknesses while in their company.

He says that if he "messes up" again it will mean only one thing: "from one prison to another until shot in the back golng over a wall."

The subject further states that he feels he is "obligated to go straight" because he "owes so much to so many people".

Some negative feelings were expressed in declaring a violent hatred of certain persons.

$S^{*}$ : "I think I would have been OK If I hadn't been sent here the first time, but, then, I shouldn't judge a persor, on a single incident. Let him - how does it go? - who is without gin east the first stone."

Interview 2:

Subject stated that everything "added up" to about the sane as it did the week before.

S: "I've been doing a lot of thinking, but it all adds up to about the same."

He reviewed some of the feelings expressed during the previous interview. He talked about football, wanted to know of the counselor's purpose in talking to him, and talked very little about hisself or his problems.

Subject expressed himself freely.

Interview 3:

c: "Well, how does everything look today?"

S: "I'd give ten gears of my life to get out of here."

C: "It means that much to you?"

S: "Yes. I've sort of had in mind pretty strong these last few * S refers to subject, and $C$ denotes counselor. 
days springing a take-off,"

C: "You mentioned that once before. A little stronger urge this time."

S: "Oh, I'm all mixed up. The more I think, the more mixed up I get."

Subject went from here into a detalled description of his feelings of being afraid of things and being ashawed because he felt others were not concerned over such insignificant problems.

S: "I've sort of been led to belleve I'm smarter, I mean have more intelligence - I guess there's a difference - than most people. Because of this I've sort of got into the hebit of expecting myself to outshine other people. I don't fear my ability mentally, but when I fall physlcally it hurts ay pride I guess, or my expectations of myself. Then I think and worry about it and the next time a physical test comes up the first thing I think of is fallure, and I begin thinking up every excuse available to get out of it. It scares me to death."

The subject continued on in this way for most of the interview. S: "I think I've been rambling on here and wasting your time. You know, this is the first time I've ever told anyone everything. I mean about being scared and everything. It seens like I've always been runing away from things that scare me, things that don't worry other people."

C: "you feel they're such little things that most people wouldn't bother to worry about them."

S: "Yes. Now, take the other night. They brought out the boxing gloves in the gym. Well, I am a good boxer and I love to do 1t, but 
right now I began thinking about everything that was wrong with me that I could use as an excuse to get out of boxing. And I didn't have to box, either, but it scared the hall out of ne for a few minutes. And sonetimes I lay in bed at night just thinking about things like that and get scared to desth. And then the next morning everything looks rosy agaln. I get mad at ryself for it but it doesn't help."

Subject talked freely throughout the interview in this manner. At the end he rentioned agsin that he felt like he would "just have to take off"

S: "I think I could do it without being caught. I could stay good for awhile to show I was on the level and then come back and they might let stay out."

Counselor suspected that the subject may be reaching an uncomfortable phase in the therapeutic process and may be imnediately concerned sbout running away as a means of escaping this growth, which was undoubtedly distasteful to him. Feeling also that he may be serious about running away, the counselor pointed out to him that some people in his present position find it difficult to continue the interviews because of coming face to face with disturbing problems that previously have been avolded, and suggested that his sudien deslre to "take of might $^{\prime}$ unconsclously sten from such a source. Subject showed some anazement at this and wished to talk about it further, but the counselor closed the interview.

Interviow 4:

Some policy changes were made at the school to which the subject expressed a violent dislike. He returned to expressions of a negative nature. 
S: "They have been giving us a going over since last time. They got us going and coming. Took away our own clothing and cut out our smoking. I think there will be a lot of trouble over it."

$$
\text { * * * * }
$$

S: "If some of the guys don't take off, I'll be surprised. Incidentally, that's a question that I had solved for myself. Remerber, lsst week I told you about it. Nell, I had settled it pretty well with tyself that I wouldn't consider leaving and messing up for anytihing, but I'Ii not so sure about it since this has come up."

C: "You had decided derinitely to stick it out here, but now you're not so sure."

S: "It's something - I can't expiain it. It's something that just gets hold of you so strong you can't do anything about it. . . It makes you feel like you just have to flght back somehow, and yet there's no way to flght - there's nothing you can do. Running away is sbout the only weapon - the only way there is to get revenge."

C: "You feel you just have to hit back in some way."

3: "Oh, I gless we'd be hitting ourselves worse than anyone else, but you just can't stand the pressure."

Interview 5:

C: "How does it all look today?"

S: "Things are straightening out a little. It doesn't seen quite as tough as it did. At least I know now that we don't know what to expect here any wore."

C: "Everything seens cquite uncertain."

After an atteript to assure the counselor that he was less disturbed 
than before, the subject continued:

S: "You know, I thought at first that I wouldn't say anything about this, but I've told you about everything else so far. I've decided the only thing to do is to get away from this place."

C: "You've pretty definitely decided to take off."

S: "That's the general 1clea. I'm just not getting any where here. I've reached the peak of good treatment. I mean from here on all the good that's come from being here has already had its effect. From now on I'm going down hill. I've hit the crest of being benefited or helped, and now it's having an opposite effect. I can see that if I stay my time, It might be worse for me than if I hadn't come in the I1rst place. It's difficult to explain, but I feel that I could make a clean go of it on the outs now, where if I stay longer, feeling like I know I will, why I'll surely be headed for the pen. Do you get what I'm trying to say? It's all stated in a zalxed -up way."

C: wou feel that for your own welfare, your own good, that you have to get out now."

S: "Yeah, I guess that is it. Yeah, that's just about what I was trying to say."

The subject spent most of the interview explaining why he had decided he must run away.

St "I had decided that my obligations to some others were so great that I had to make good for their sake. Now it seems that ny obligation to ayself is raore important."

C: "Your obligation to save yourself while you can seens more important now than your obligation to others which, you feel, you would 
fulfill by not running away from here."

S: TYes. And I've been thinking about maybe they would blsme you for ny going - that 18, the fact that you knew about it and didn't say anything. But in case I don't see you any more, I'd like to say to you that I would have probably been gone by now if it hadn't been for talkIng here. I mean, I've sort of looked forward to coming in here each week."

Ca "You're afraid they may blame we for your going, but you don't feel that I an responsible for it."

S: MThis is all a result of ry own thinking and figuring out on the basis of what I think is best for me. I may be influenced by conditions here and how I feel about it all, but the decision is any own and I wouldn't want aryone else to take the blane for 1t."

The subject continued to give reasons why he felt he must run away. S: "It's such a waste - a total waste of time here." Subject's last remark in this interview: "It might be a mistake. Maybe I've got it all figured wrong, but from where I sit there just 1sn't another answer."

C: "In case you decide to stay another week, I'Il be looking forward to talking to you again."

\section{Interview 6:}

The subject at first didn't mention his plans to run away the previous week. He talked some of others who had run sway during the week.

S: "The clothes and no smoking might have caused the runaways, but then it may have been an 'any port will do in a storm' reaction; 
an excuse to do what they would like to have done anyway. . I'm getting fed up with it all. I mean this 'cop-and-catch-him' stuff. That one group should alweys be being chased by another group. It don't make sense. I know we're to blame, but I just can't stand to hear it discussed. I heard two men talking about different wethods used for catching criminals. It alnost sent we cragy."

The subject expressed guite violent negative responses. These were aimed at (1) the common policenan, and (2) authority, when "it scts on euthority alone."

S: "I know I'II have to go. It kity not be right away, but I can't stand it here any longer. I'm sort of losing control of nyself as far as same authority around here is concerned, tand I'b afreid it might have some serlous outcomes."

The subject asked to sew the notes of previous interviews.

S: "How come I'm so wuch more all mixed up than other guys?"

C: "You think you ere more mixed up than others."

S: Magbe they just don't show it. Myg be I con't show it to then."

He talked more on this subject and indicated sone insight, although he was unable to reach a definite decision.

Getting around to the subject of intelligence, he continued

S: Mlaybe it 1sn't what you know thet counts, but how you use 1t. The trouble with me is, I've got too many brains, and not enough sense. Maybe I'b just kidaing myself. I mean making an issue of all these things I've been talking about. They might not be that inportant after all. I might just be looking for a loophole to hide in. I wish 
I knew the answer. I hadn't thought of It like that before. Tell me this, do you think I play myself up to myself too much? I mean, an I too concerned about wyself"

C: "I'll answer you thls way: suppose I did and told you so. Do you think that would mak you any less concerned about yourself?" S: "No, I Guess not."

Subject seemed to Eet quite a shock of sudden Insight at this point. He became excectingly exotional in his apparently confused condition and seened to be attenpting to mediate his previously expressed feelings with the fact that "maybe I'm Just kidding myself." He breathed quite heavily and persplred freely. He sat with his head lowered without nakIng a single response for a period of approximately five minutes. This was the first time he had hesitated in his conversation.

The counselor closed the interview at this point and the subject left with no renarks.

\section{Interview 7:}

The subject was locked up for smoking. Counselor talked to him for a few minutes. His responses were 2.11 negative.

S: II would rsther wait until next week to talk. I'll be out of here by then."

Interview 8:

The subject had baen let out, but was locked up again for the same Infraction of rules.

Counselor talked to him for a while, but felt it was not too profitable because of others who could hear what was said.

S: "It seem like they single me out to punish. I haven't done 
anthing afferent from the other fellows."

Interview $9:$

Subject began this interviow with responses indicative of negative feelings. He expressed a dislike for some of the staff nembers.

During the latter part of the lnterview, he faced his problens more adequte but with much indecision and probably a little inaight. S: "I can figure things out pretty good for a while. I can figure that it's better for to stay here and not mess up, even from a selfish angle, than to take of $\hat{f}$ or mess up in sone way. Eut then I get feeling at times that I've just got to mess up in sore wry. It's the excitement of 1t, I guess. I guess that's the reason I got here in the flrst place.

He continued on this subject for awhie, and then:

S: "I guess, though, it all adds up to taking a bird in the hand and fiving up a thousand birds in the bush. It's a matter of sacrificIng six, efght, or ten wonths of freectox for one night of fun. It doesn't make much sense, does it? No, It coesn't. I hadn't thought of it quite like chat before."

He generalized this idea in severel diferent ways.

S: "But then messing up might be tho only thing that gives us gugs here any excitement. Defying suthority. Yeah, maybe that's where the fun cones from. But I don't know if that's right or not. I'11 think about that some more. It doesn't scem right, but it could be. You can have things like that in your systen and not know it, can't you? Haybe that's it. 
Subject remarked that he would tell how it plgured out by next interview.

Interview 10 :

Subject talked freely. His conversation was very similar to what it was last week. He showed no further inslght, but probed his problems as usuel.

Interview 11:

Some insight was apparently gained during this interview. New decision is implied throughout the interview and sone action has apparently been taken, as the following expressions indicate.

S: "Part of me wants to make something out of itself. The other part is just a bux. It wants to take it easy and sort of fool around all the time. The weight shifts occasionally on the surface, but underneath I guess the majority of the welght lies on the side of improvement."

S: "I seem to be integrating ny thinking much better than I did before we started talking. Before, I had no direction: I wasn't going any place in ny thinking, but now I think I can see the relationship of things more clearly."

\section{*ै* * *}

S: "I used to blow up on the least provocation and worry and be afraid of things all the time, but I'm doing better lately. I've got myself considerably more under control, as far as my temper is concerned,"

\section{$*$ * *}

S: "I'm trying now to map out a college course and gathering high achool credits together to see how they stack up." 
These sre statanents quite typical of the entire interview. Interview 12:

Today the subject enthusiastically explored himself for the answer to his confusion and snti-sociel behavior. Last interview he set up and discussed the possibility of selecting a goal, important enough to hiroself, on which all minor dectsions could be made.

S: nThis might serve to help me make 11ttle decisions in a way that will keep me out of trouble here so that the big goal cen be reached in the quickest possible time."

Today he discarded this as the most important answer to his probleme, because he sald he felt that it couldin't, or wouldn't, be carried out successfully until the nore "disturbing things" had been relseved.

He talked further of the possibility of these "worries and conflictIng drives" as possibly originating from his having "get up ideals and then trying to stretch reality to meet ther." In falling to reconcile the two in his om mind and "being uneble to bring then together," he had possibly come to blame and hate cortain individuals who mey be violating his 1deals, and in an unconscious way "seeking revenge in the form of anti-social behavior"

S: Maybe I place too nuch emphasis on feeling badly because these Ideris are violated and not enough on eccepting reality as it is." Interview 13:

Subject talked sbout the weather, the other boys at the school, his parents, and other things. He did not spproach his own problems until the end of the hour.

S: "You know, something mighty strange is happening to uce" 
C: "Would you care to tell me about it?"

S: "well, you know, maybe you've noticed that todey is the first time I haven't griped about something or been all mixed up. I't still sort of mixed up but it seems to be more over what's going on insice of me. I can't think of a thing to say today except maybe that the things I mean the things I've talked about before and a hundred others - somehow are losing their Importance. It all seems not to bother me so much. Everything has worried me so much. I've always been all mixed up.

\section{*** *}

S: "I con't a.ean I've found any solution to it all, it just coesn't sees so all-important."

c) "You mean nothing seems 1mportant, sort of a defeatest attitude, or that the enotional tone is sort of letting up some?"

St "Yes, that seems to be it. I don't feel defeated; it may be just the opposite. Things seam important, maybe just as important as over, but - it's pretty herd to explain. It's something I can't get hold of, something I'm not sure of myself." (long pause)

C: "Suppose you consider it further during the woek and tell me how it looks then."

S: ryeah, maybe it's just a temporary mood, or maybe if it isn't, it might clea $r$ up a little by then. Maybe I can Plgure it out."

Interview 14 :

Similar to the previous interview, the subject talked frcely, but did not approach his own problems until the last few minutes of the interview.

S: "I suppose 1t looks to you like I's sort of laying down on the 
job. I mean by not discussing my own situation like I have before." C: What ever you feel like discussing or talking about is more important than what jou feel you ought to talk about. Do you mean that you feel obligated to say the things you think I would like to hear?" S: "No, it isn't that. I've never felt that way. In fact, what I think I want to say - what I was trying to say last week - I think you wight like to hear, but I can't seen to get it into words yet, or even tell definitely what it is all about ayself."

C: "You are still trying to get hold of it."

S: "I can't seem to underatand it all." (pause)

C: "Do you feel that it makes any difference to me what you say? Do you feel that I w1I pass judgment on the things you finally decide and the decistions that you may make?"

S: "No. I didn't mean to give you that impression. I should know better than that by now, after all that's been talked about. No, it isn't that, but it's just that I hesitate to start talking now because I'd like to figure it out a little more. I'n afraid I'll get so involved when I do try to explain everything that it will be all mixed up and you won't know what it is I'm trying to say."

C: "You want to talk about it but don't feel ouite reacy to go into a lengthy discussion."

S: "That's about the way it is."

C: "Suppose you look at it for another week, or for that matter, as long as you feel is necessary."

The counselor, on one occssion here, purposely violated a strictly non-directive technique, but he wanted to be sure that the subject was entirely on his own in developing insight and raking decisions. 


\section{Interview 15:}

The subject was locked up when the counselor arrived this week. He had been locked up two days after the previous lnterview. It was reported that he had sade a threatening statement against a smaller bog.

Counselor talked to him for only a short time. His expressions were quite violently negative, and almed chiefly at the "injustice" of his being punished.

Interview 16:

Subject was atill locked up for the same offense. His expressions were of a negative nature and quite similar to those of the preceding interview.

Si I don't know when I will get out of here. I hope before long. I still can't see why I was locked up for threatening that kid. There are a thousand threats wade around here every day, but they don't lead to any serious results,"

C: "You don't feel your offense should justify being locked up." S: "well, maybe it wos violating the rules, but why pick ate out of fifty others dolng the same thing? I told them locking someone up wouldn't change them even if they had broken rules. I could get out now, I guess, if I was to tell them I was sorry and promise not to do It again, or ever break another rule."

C: "You don't feel like promising that?"

St "Oh, I wouldn't mind promising to try not to. But there's so many rules that you don't know what not to do half the tine, and then it would mean back in here again." 
These expressions denote the general tone of the interview and are representative of other statenents expressed.

Interview 17:

S: Well, I might gripe today about having been locked up but in the firat place I con't feel like it, and in the second place I've already moened the blues to you twice about it."

C: "I hope you wLII telk about the things thet seem most Important to you."

S: "That's just what I'm going to do. After I got it off my chest last time you were here, it seemed like everything began to clear up and I even dicn't mind being locked up, because it gave me a real chance to look at the situation and really get hold of how I feel."

$$
\text { ** * * }
$$

S: "I can't just tell exactly if I've reformed yet, that is, I don't know if I want to be good or not, but I don't feel any more that compulsion to iness up - I mean, it's sort of in ay own hands now. I can take it or Leave 1t. The drive to fight back len't so strong; I can choose one wey or the other. I don't just have to do things because there's nothing else I can do sbout 1t... Gee, I hope I'm not just saying these things because they sound good, or because that's the way I'd like to have 1t. No, I don't think I am."

$$
\text { *** }
$$

S: "I've been working at the barns the last couple of days and have had plenty of chance to run away. After threatening to leave and overything, ordinarily I would have just had to mess up sone way, but 
it just didn't seem 13ke I had to go - that 1s, I could think about it and then decide either way without feeling forced into it one way or another against what I know to be the best course."

$$
\text { *** } *
$$

S: "rhat's a strange way to have 811 this talking turn out, isn't it? Who would have guessed the answer to be that? Is it just a compulsion or something to mess up that I didn't have any control over? Have I reslly got the answer to ay difficulties? Did you know that was going to heppen? Did you know it would tum out this way? I wish you'd tell me whet you know about it all. Do you know why all us guys are here; what nekes us act like we do?"

These ropresent some of the expressions made by this subject in his apparent enthusiasn over the insight he hes gained, and in his resching out for additional Lnsight.

A.1 of these responses are not copied verbatun, but as nearly so as the counselor could recall then immediately following the interview. The counselor regrets having been so occupled during this interviow to have failed to record nore verbatum responses made by the subject. The counselor felt this to be an important interview, as much insight and some evidence of new decision and action besed on this new insight wss epperent.

Although the interviews were not teminatad th this point, this is the last counseling situation in which the counselor contacted the subject. The following week the subject was released from the institution and allowed to return to his home. 
RBSULIS OF THE MMPI *

Standard

Scoros

100

90

80

70

60

50

40

30

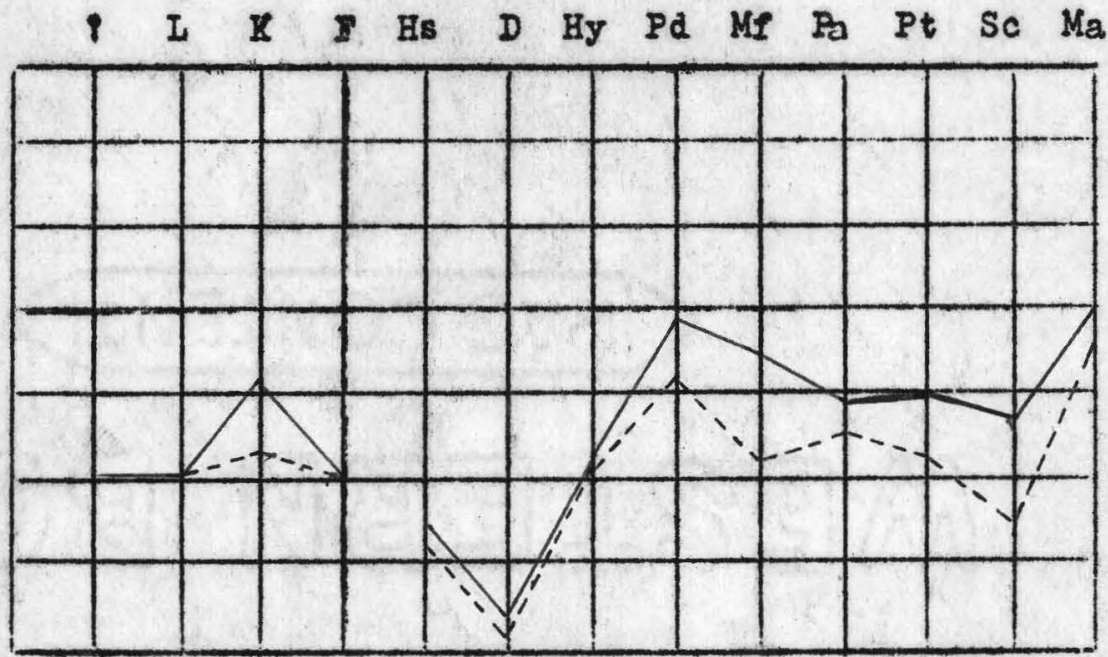

Fig. 2. Pair 2. Pre-test and end-test profiles of the experimental and control subjects. Key: Bxperimentel subject pre-test _, endtest - _ - ; control subject pre-test__ . end-test_ _ _.

The end-test was given to this subject before the interviews were completed, because of the time elenent. It was administered following the seventeenth interview.

The control subject of this pair left the school unexpectedly and, although efforts were made to contact $\mathrm{him}$, the results of an end-test were not obtained.

The experimental subject has demonstrated some tendency to more normal responses on the end-test scores in the two scales that approach the aree of poor adjustment.

- MuPI will be used to designate Minnesota liultiphasic Personality

Inventory. *wNo end-test was recorded for the control subject in pair 1. 


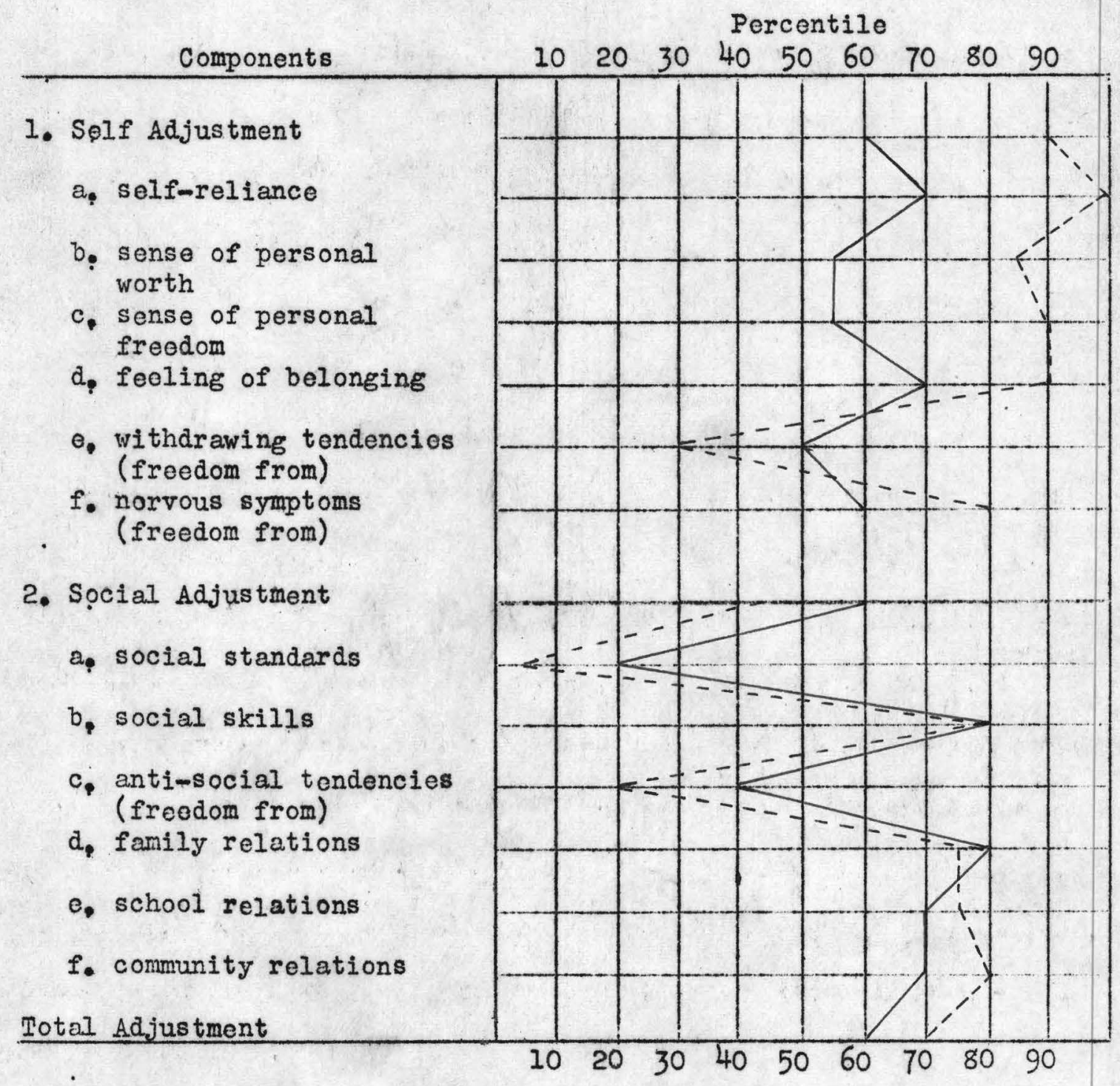

Fig. 2. Pair 1. Pre-test and end-test profiles of the oxperimental and control subjects. Key: Experimental subject premtest-, endtest _. - ; control subject pre-test__ end-test_....

In some ways, this is an interesting profile. The low score in withdraving tendencles, the low scores in social standerds and antisoeial tencencies, present quite a moaningful contrast to the subject's - C I P will be used to designate California Test of Personality. * No ond-test ws.s recorded for the control subject in pair I. 
knowledge of social skills.

It w1ll be noted that the subject has shown by test scores to have improved his self adjustment component, but at the same time he has indicated no improvement in social response. His total adjustment has improved on the proflle by ten percentile points.

The control subject was not available at the time the end-test was given. 
Resuits of the Hazgerty-0lson-Vickman Behavior Rating Schedule. Collecting data on the Haggerty-01son wickwan Bohavior Rating Schedules was sowewhat disappointing. Due to unavoldable circumstances, the execution of the scales on some subjects was delayed to the point where the reliability of results may be cuestioned. In some instances the schedules were executed promptly, while in other inatances the preratings were executed aimultaneoualy with the end-ratings. In the latter cases the best that could be accomplished was an attempt to rate the individual on the basis of his recalled behavior before the interviews began and then to record any noticeable change in the subject observed during the tine the interviewing was in progress. This procedure violates the suggested method of scoring as given in the samul of Instructions.

It would be impossible, under the circumstances to differentiato between those subjects who were scored prior to and following the interviews (which is auggested as the nost reliable procedure) and those in which both scorings were delayed until after the interviews. Rather than to attenpt what would amount to a probable inaccurate differentiation of the two deseribed conditions, the results of $211 \mathrm{H}-0$ m schedules that were completed are presented exactly as they were scored with no atternt to evsluate the rellability of different scoring procedures. As originally planned, each subject was to be rated by two individuals who, it was felt, would be able and quallfled to make such a rating. But, due to circumstances out of our control, some ratings were never completed and others, as described above, were not accomplished with the recomended objectivity. The ones thst were completed are presented, In their appropriate places, following this brief explanation. 
RBSULTS OF THE H-OLW *

Table 2. Pair 1. E-O-W Raw Scores.*

\begin{tabular}{l|c|c|c|c}
\hline \multirow{2}{*}{ Problem } & \multicolumn{2}{|c|}{ Experimental Subject } & \multicolumn{2}{c}{ Control Subject } \\
\cline { 2 - 5 } Pre-tost & Bnd-test & Pro-test & Ind-test \\
\hline Behavior & - & - & - & - \\
Intollectual & 11 & 21 & 22 & 22 \\
Physical & 12 & 12 & 14 & 14 \\
Social & 26 & 24 & 30 & 30 \\
Bmotional & 25 & 15 & 35 & 35 \\
\hline Total & 74 & 62 & 102 & 102 \\
\hline \hline
\end{tabular}

* The higher scores are indicative of maladjus tment.

With scores recorded in four of the five problem categories, the experimental subjeet was shown to have inproved in general behavior indicative of better adjustment, as measured by this instrument. The control subject has been scored to Indicate that his general adjustment has remained about the asme during the interval between the pre-rating and the end-rating.

Sumary, Peir 1. Although the interviews were not completed and there were some roversions to negative responses during the contacts, statements Indicative of the attainment of all therspeutic objectives were observed. A comparison of scores on the AMPI, on the CrP, and on the H-O-II are supporting evidence of improved adjustment from the pre-test to the end-test.

All messuring devices used in this case show consistency in recording Improvenent.

* H-OWW will be used to designate the Haggerty-01son-Wiekman Behavior Rating Schedules. 
RBSULIS OF THE INTWRVIBW

Table 3. Pair 2. Ixperimental Subject. Interviey Results.

\begin{tabular}{|c|c|c|c|c|c|c|c|c|c|c|}
\hline \multirow{2}{*}{$\begin{array}{l}\text { Therapeutic } \\
\text { objectives }\end{array}$} & \multicolumn{10}{|c|}{ Interviews } \\
\hline & 1 & 2 & 3 & 4 & 5 & 6 & 7 & 8 & 9 & 10 \\
\hline Free expression & & $x^{*}$ & $x$ & $x$ & $\mathrm{x}$ & $x$ & $x$ & $\mathbf{x}$ & $\mathbf{x}$ & $x$ \\
\hline Insight & & & & $x$ & $x$ & $x$ & $x$ & $x$ & $x$ & $\mathrm{x}$ \\
\hline Decision & & & & $x$ & $x$ & $x$ & $x$ & $\mathbf{x}$ & $\mathbf{x}$ & \\
\hline Action & & & & & $x$ & $x$ & $x$ & $x$ & $x$ & \\
\hline
\end{tabular}

*An $x$ is placed in the square when statements were made indicating the attainment of an objective.

This subject talked freely during all the interviews but the first. Her expressions during the first two or three interviews were of a violent negetive nature. It was during the fourth interview that some expresstons Indicative of Insight were made.

Interview $4^{2}$

St "You know, sometimes lately I think that if I wovlan't do so much talking back, I wouldn't get into so much trouble."

St "Sometimes I think I've always had too much, and now I still think I should have my own way about everything,"

St "I'm golng to try awful hard to do better,"

Interview 5:

St "Yesterday I heard Mrs. enswer the phone whan ay mother called to ask about me, and she told her that I was a hundred percent better. . . Urs* _ told me that I had Improved a lot. I don't know where all this change is coming from. It's something I can't 
Iigure out myself, but I know I feel a lot different about things than I did."

The subject is the third of the four girls being interviewed who has expressed amazement and an inability to understand the change takIng place in her.

Interview 6:

Mrs, _ comnented on the subject, and the big change that had come in her behavior. Relating an Incident that took place in her office the night before, Mrs. stated that Miss a girl that is about ready to leave, had commented on the recent change that had taken place in the subject. In a playful way, the subject said, accordIng to Mrs. I didn't know that I hed changed so much." Miss replied, "You know that you have changed a lot."

Interview 7:

Subject asked to hear the notes of the previous interviews. After the counselor had finished reading then to her, she said:

St "You know, what those notes say are the things I wanted to say to you today. I've felt all week like I wanted to tell you more about how I feel. I've changed."

$$
\text { *** }
$$

St "I used to feel like, well, what's the use, I've been in so much trouble that a little more won't matter. Bverything seems differ ent now. Oh, I taight get into trouble again, but I feel a lot changed about it all any way."

C: "How do you feel about coming in next week?"

S: "Well, I'd like to keep taiking to you, but I've been thinking maybe it would be better if you used your time talking to some of the 
other girls than to keep on with me."

C: "Suppose we say, then, that next time $w_{111}$ be the last for you." Interview 8:

Subject had experienced a disturbing incident with a member of the staff.

S: "I'm glad I dich't talk back. . . I only said one thing that I shouldn't have said. . . It suraly has left me all upset. . . What should girls do in a situation like that?"

The counselor belleves that her related action to this sltuation presents some evidence of insight and perhaps more integrated behavior.

Interview 10:

St "I have a lot of confldence in ayself now. That is, I feel that I know how to get along without sny help now. These interviews have helped me over some bad places." 


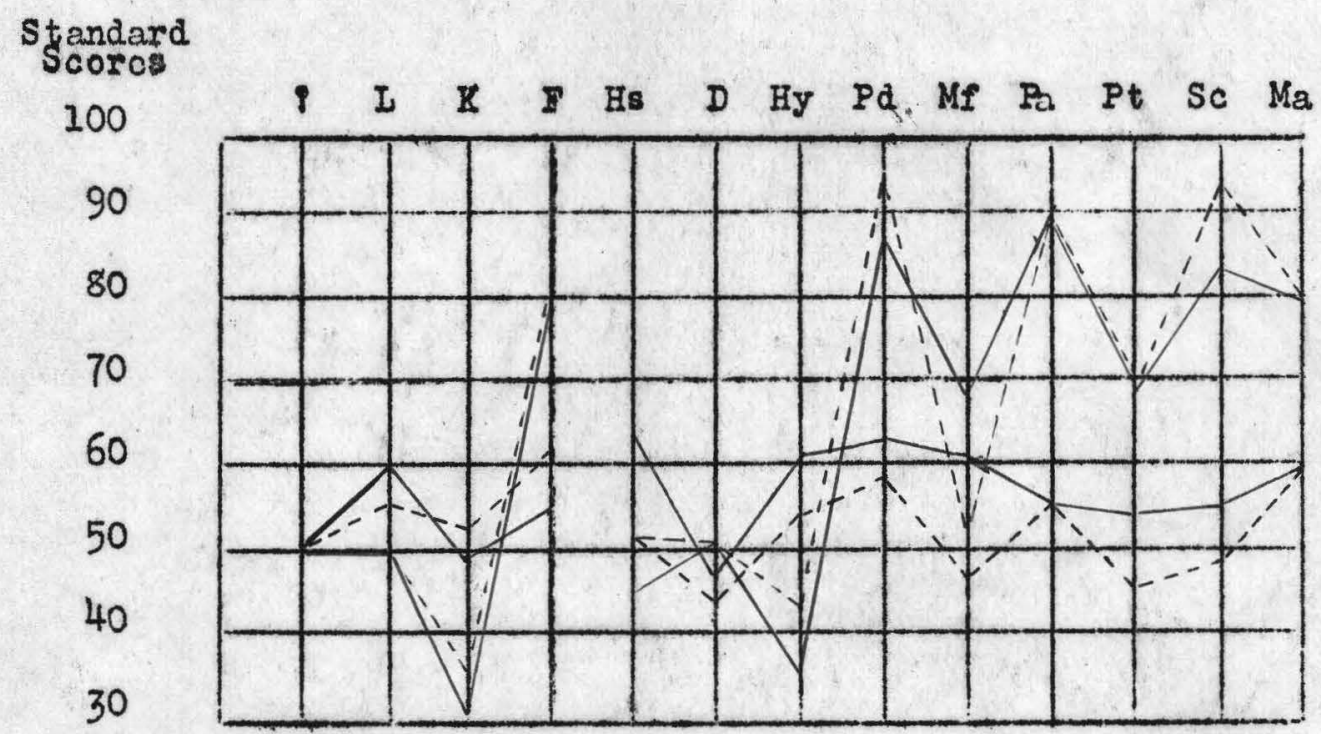

Fig. 3. Pair 2. Pre-test and end-test profiles of the experimental and control subjects. Key: Experimental subject pre-test _ , endw test _- - ; control subject premtest__, end-test _ _ -

It will be noted in IIgure 3 that the experimental subject measured within the nomal range on both the pre-test and the end-test. The scores that approsched more elosely to the abnormal were on the scales of hypochondrissis and psychopathle deviate. The end-test scores Indicate a lendency toward more nomal responses in these and some othar traits.

The control subject, with exceptionally high scores on the $F$ scale and the $\mathrm{Pd}, \mathrm{Pa}$, and $\mathrm{Se}$ scales, showed an even more abnomal tendency on two of the last three on the end-test, and no Improvenent on the other two scales. However, the scores indicate a considerable growth toward. more nomal responses on the uf scale.

In this case the test results for the experimental subject indicates sone improverent on the seales mentioned, while the control subject 
presents no general improvement on the extremely ebnormsi scores. Gough's (11) studies show a tendency for the F scale to score high in cases of abnomality on the psychotic end of the profile. 


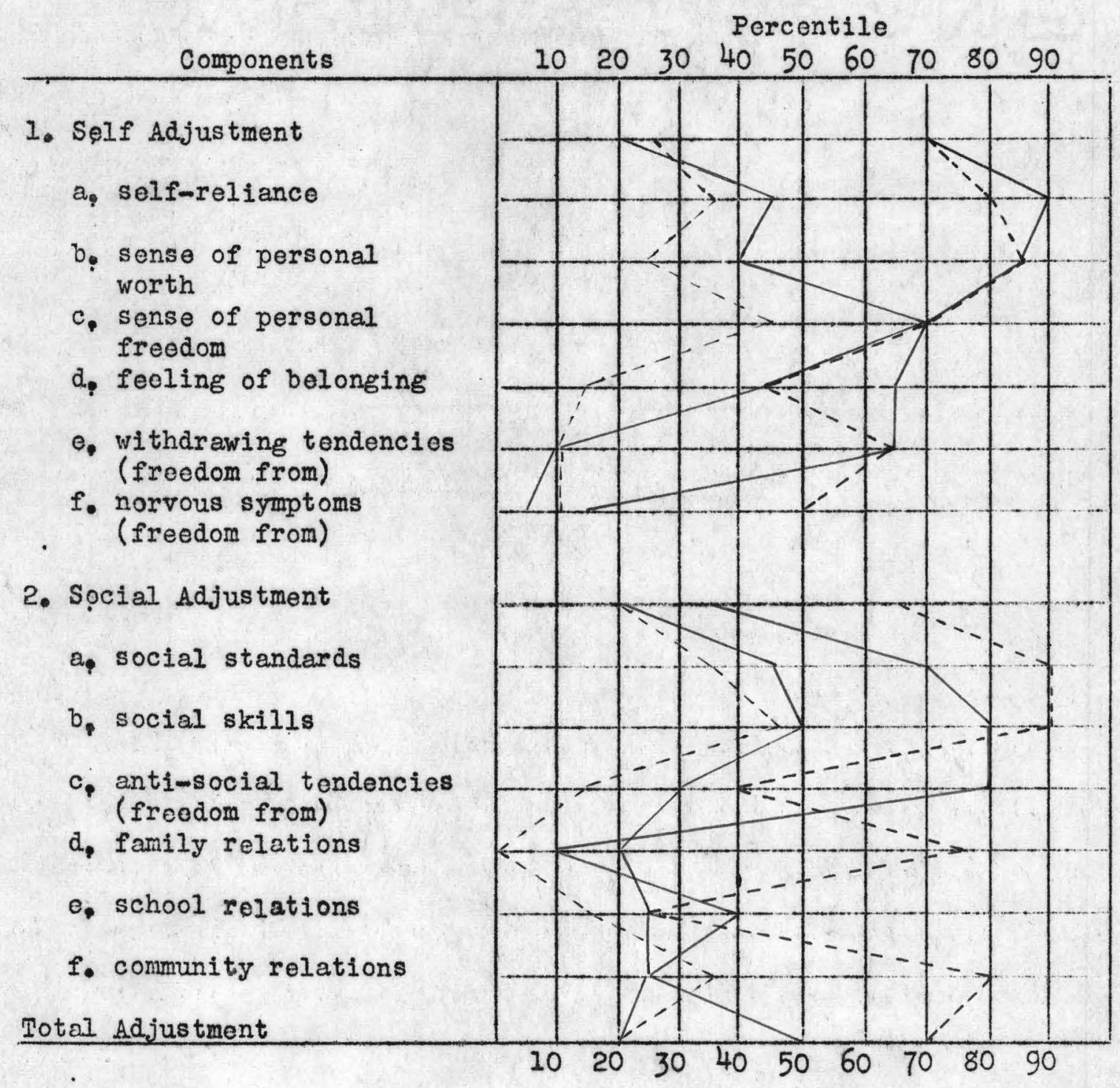

Fig. 40. Pair 2. Prentest and end-test profiles of the experimental and control subjects, Key: Experimental subject pro-test_, endm test_. - ; control subject pre-test _ end-test _...

The experimental subject has gained a higher percentile rank in social adjustment and an equal rank in personal adjustment on the endtest scores.

The control subject shows a five percentile increase in self adjustment and no increase in social and total adjustment on the end-test. 
The two scores indicate an increase in total adjustment in the case of the experimental subject, and no improvement in the control subject. 
RHSULTS OF THE H-O-W

Table 4* Pair 2. E-OW Raw Scores.*

\begin{tabular}{|c|c|c|c|c|}
\hline \multirow[b]{2}{*}{ Problem } & \multicolumn{2}{|c|}{ Fxperimental Subject } & \multicolumn{2}{|c|}{ Control Subject } \\
\hline & Pre-test & Ind-test & Pro-test & End-test \\
\hline Behavior & 110 & 87 & 100 & 72 \\
\hline Intollectual & 17 & 20 & 15 & 18 \\
\hline Physical & 17 & 25 & 17 & 13 \\
\hline Social & 38 & 24 & 26 & 22 \\
\hline Enotional & 32 & 25 & 22 & 29 \\
\hline Totel & 214 & 17 & .180 & 154 \\
\hline
\end{tabular}

* The higher scores are indicative of maladjustment.

The end-test scores of the experimental subject indicate some inprovement in behavior and also in social and emotional problems.

The control subject hes also been shown to have improved in general behavior during the time the interviews were in progress.

In the opinion of the person making the ratings, sone improverent was observed in both subjects between the first and second ratings, with a seventeen point difference of improvenent shown in favor of the experimental subject.

Summary. Palr 2. Example statements show all therapeutic objectives. to have been reached with the experinental subject in this case. Comparative profiles on the WuPI and on the CIP Indicate a greater degree of improvement with the experimental subject than wes found with the control subject. The total scores of the H-O-ll schedules are also in line with the general results of the other tests, 
All four measuring instruments show a consistency in registering generally more improvesent in the experimental subject than in the control subject during the interval from the pre-test to the end-test. 
RISULTS OF THE INTERVIIEN

Table 5. Pair 3. mxperimental Subject. Interview Results.

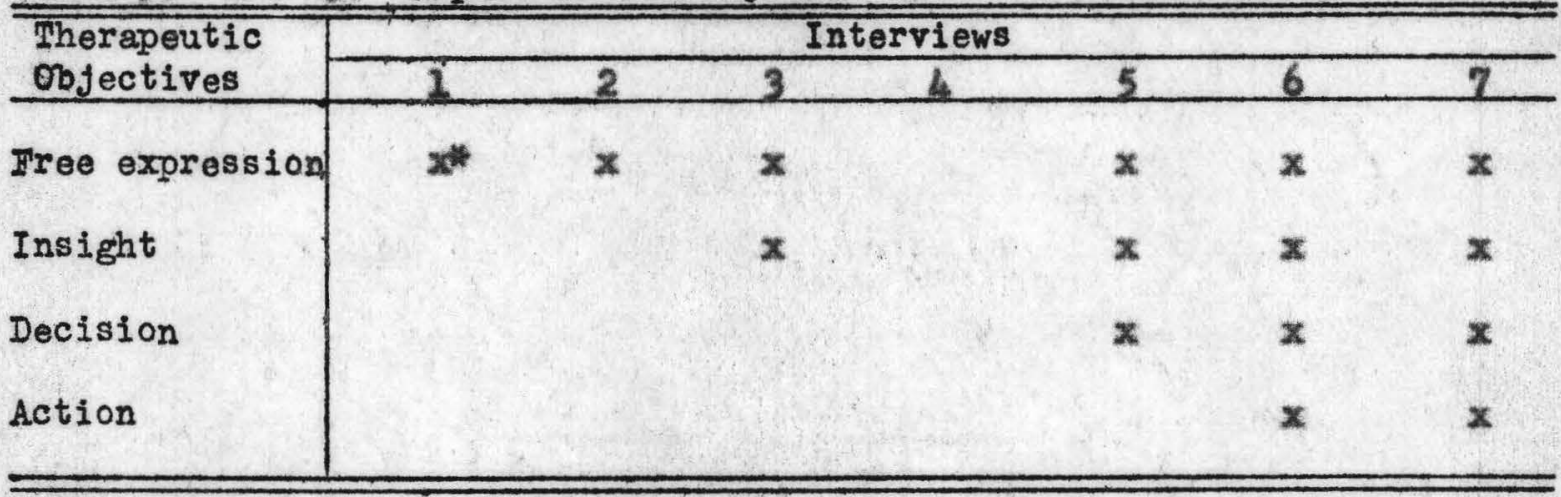

*An $x$ is placed in the square when statements were made indicating the attainment of an objective.

\section{Interview $2:$}

C: "You have expressed an extrene dissatisfaction wh the way you are treated here."

S: myes. We all feel that way. It's gettling worse. I mean all the new rules and everything "

C. "You feel that things are not Improving any?"

st Wo. They're worse all the time."

Interview $3:$

Towerd end of interview:

S: "I've told you before about how bad the matrons are to us. But sometimes now I believe they are trying to help us."

Interview 48

The subject expressed a dealre to miss this interview.

S: "I feel about the same as I told you last time. I would like to talk to you again next week. I Just haven't arything to sey. I' 
thinkling about the things we have talked about before, but I'd rather walt another week,"

This desire to miss one or two interviews, at this point in the therepeutic process, has been expressed in sevoral cases. On some occasions the subject, after expresaing a desire to miss the interview, will spontaneously continue to talk. On other occasions he will leave, expressing a desire to come next tine.

Interview 5:

S: "Would you talk to H__ ?"

C: "Do you think it would help H__ to talk as you have done?"

St Wes. She is my best friend and I'd like her to talk to you if you have time."

Interview 6:

Subject brought her friend $\mathbb{H}_{\text {_ }}$ and ssked if she rafght stay during the interview. She asked if she might hear the notes of the previous interviews.

Addressing the statement to $\mathrm{H}$

C: "Had you noticed all this happen to ____(subject)?"

IL_: "She has aurely changed a lot. I feel better just talking to her. I would like to come in and telk to you like she has,"

Iaterview 7:

S: "I see everything quite a lot different than I ever did before. I believe I know what to do now"

C: "You feel capable of handling everything by yourself now?"

S: WYes. At least, I think so. I'd like to try awful herd, because there are a lot of things I want to do now that haven't semed Important to we before." 


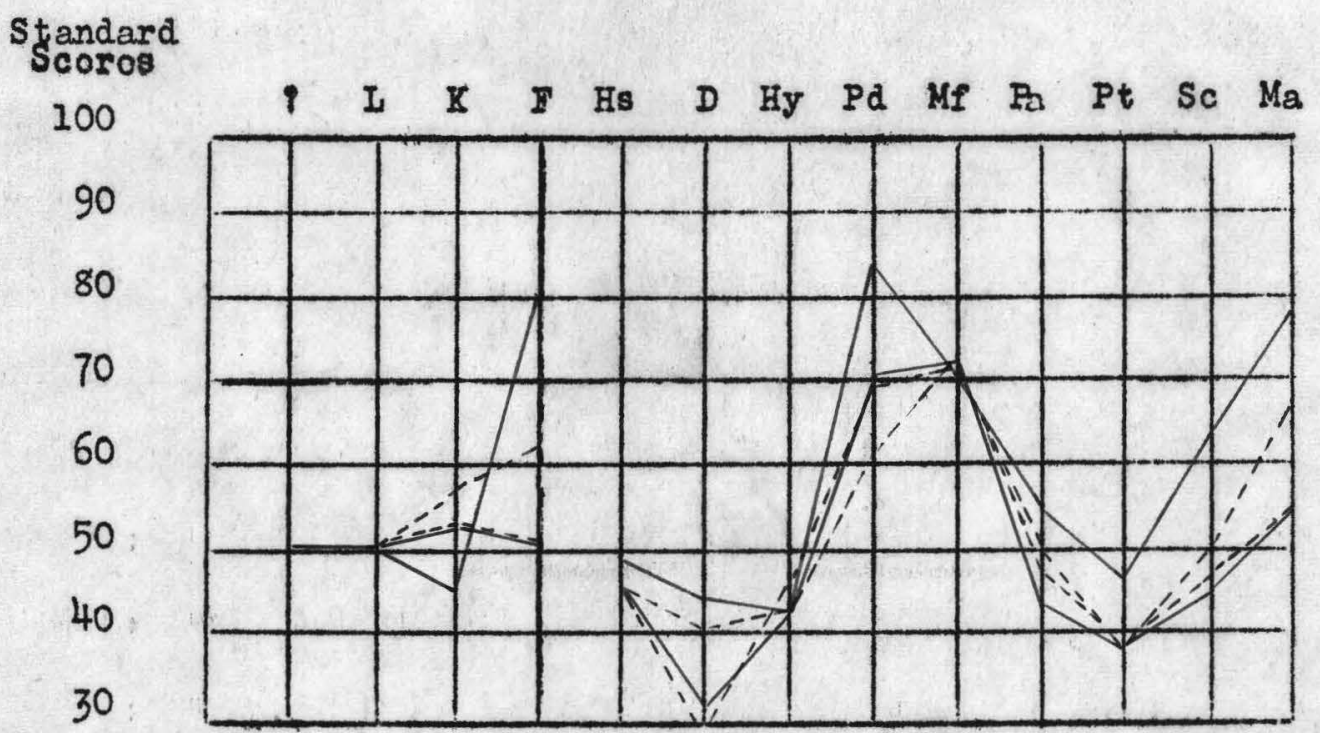

Fig. 5. Pair 3. Premtest and end-test profiles of the experimental and control subjects. Key: Bxperimental subject pre-test _, endtest _- - ; control subject pro-test __, end-test_- _.

The scores of this pair shows the experimental subject as giving more abnomal responses on certain scales than the control subject. On three scales, the F, Pd, and $\mathrm{Ka}$, the experimental subjeet is shown to have given a comparatively large number of abnormal responses.

The Pd and Ya tendencies seem to be considerably relleved, as indicated $\mathrm{ky}$ the results of the end-test. The F score is similarly shown to be approaching the normal.

The scores also suggest the control subject to have improved on the Pd and Mf seales.

A general summary would indicate improvement in both subjects on the end-test, with the experimental subject presenting a greater difference of improvement on a comparison of scores. 


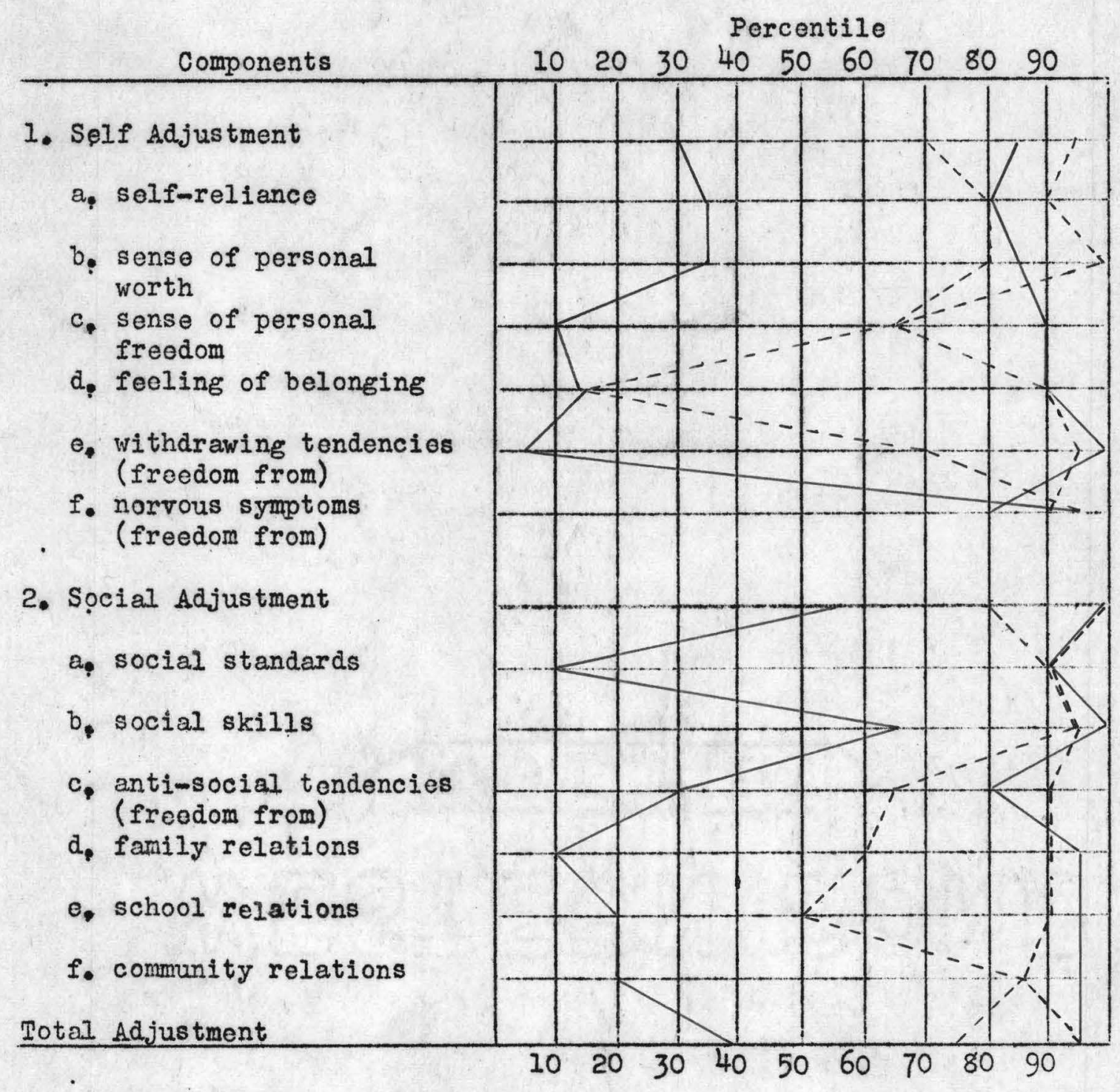

Fig. 6. Pair 3. Pro-test and end-test profiles of the oxperinental and control subjects. Key: Experimental subject premtest-, endm test - - - ; control subject premtest _ ond-test_ $\rightarrow-$.

The experimental subject in this case, as indicated by both scores, has isproved in both self adjustment and social adjustment.

Scores of the control subject show her to be well adjusted in both tests. She has shown consistently good adjustment in each of the weasuring devices used in the study. 
RESULTS OF THE H-O-W

Table 6. Pair 3. H-O-W Raw Scores.*

\begin{tabular}{l|c|c|c|c}
\hline \hline Problem & \multicolumn{2}{|c|}{ Experimental Subject } & \multicolumn{2}{c}{ Control Sub,ject } \\
\cline { 2 - 5 } & Pre-tost & End-test & Pre-test & End-test \\
\hline Behavior & 60 & 73 & 40 & 34 \\
Intollectual & 15 & 16 & 12 & 13 \\
Physical & 10 & 10 & 13 & 11 \\
Social & 23 & 23 & 22 & 22 \\
Bmotional & 22 & 20 & 17 & 16 \\
\hline Total & 120 & 142 & 103 & 96 \\
\hline \hline
\end{tabular}

* The higher scores are indicative of maladjus tment.

The totel score results are indicetive of increased behavior probless observed in the experimental subject while the control subject has shown some improvement. In the former, enotional probleras are shown to be two points less serious on the end-test. At the saxe time, general behevior shows some decrement, according to the observer who executed the schedules.

Sumsary, Pair 3. The interviews were completed and stateants were given to confirm the fact that all therapeutic objectives were attained. The general patterns of profiles on the WPI and on the CIP indicate more inproved adjustment from the pre-test to the end-test, with the experimental subject than with the control subject. Results of the H-O-lif schedules show the control subject to have gained the better adjustment. Three of the four weasuring instruments are consistent in giving some evidence of more genorally improved adjustment with the experimental subject. 
RWSULTS OF THE INTHRVIFW

Table 7. Pair 4e Irperimental Subject. Interview Results.

\begin{tabular}{l|ccccccc}
\hline Therapeutic & & \multicolumn{4}{c}{ Interviews } & & \\
\cline { 2 - 6 } Objectives & 1 & 2 & 3 & 4 & 5 & 6 & 7 \\
\hline Iree expression & $x$ & $x$ & $x$ & $x$ & $x$ & $x$ & $x$ \\
Insight & & & & $x$ & $x$ & $x$ & $x$ \\
Decision & & & $x$ & & & $x$ \\
Action & & & $x$ & & & \\
\hline
\end{tabular}

*An $x$ is placed in the square when statements were made indicating the attainment of an objective.

Bxpresslons of negative feelings Seatured the first two interviows, Interviow $1:$

S: "It is so bad here, you sometimes feel like running away. They treat us as if we are eriminals, and make us do work over and over just to keep us busy,"

Following the second Interview expressions of positive feelings were given and in the fourth interview some insight was indicated.

\section{Interview 4:}

St "I've declded I want to go with my wother when I get out,"

$\mathrm{C}_{8}$ wou were undecided where to go"

St wes. I thought I would have a better chence of being good with my father, but I've decided it isn't where you are that maikes you good or bad, It's whether you want to be. You could be bad any place if that's what you wanted to be" 
S: "It's a new experience for me to make up my own mind about things like that."

C: "You find this new experience of trying to figure out the solutions to your own problems to be an enjoyable one?"

S: "Well, it isn't very easy at times. Sometimes I don't know whether I can or not."

\section{Interview 5:}

S: "I've had a bad week. I got in an argument and was given ten demerits. . . I haven't felt like that for quite awhile."

C: "It was sort of a new experience then?"

S: "Oh, I used to feel mean like that all the time."

Interview 6:

S: "It seers good to be able to think and decide for myself whether I want to really do some things now. I used to sort of do a lot of things kind of elther because I felt I had to do it anyhow, no matter how I felt about it."

C: "You are more able to sort of think and decide for yourself what you do and what you don't do, whthout feeling you just have to do certain things, or may be without ever thinking about them at all."

S: "Yes. I guess this is about the first time I've ever really thought about myself and the way I act. I've always sort of blamed others for what I do, but I guess it might be mostly my own fault."

Interview 7 :

The subject talked nostly of her new plans after she is released and suggested that she felt able to get along without coraing in again. 


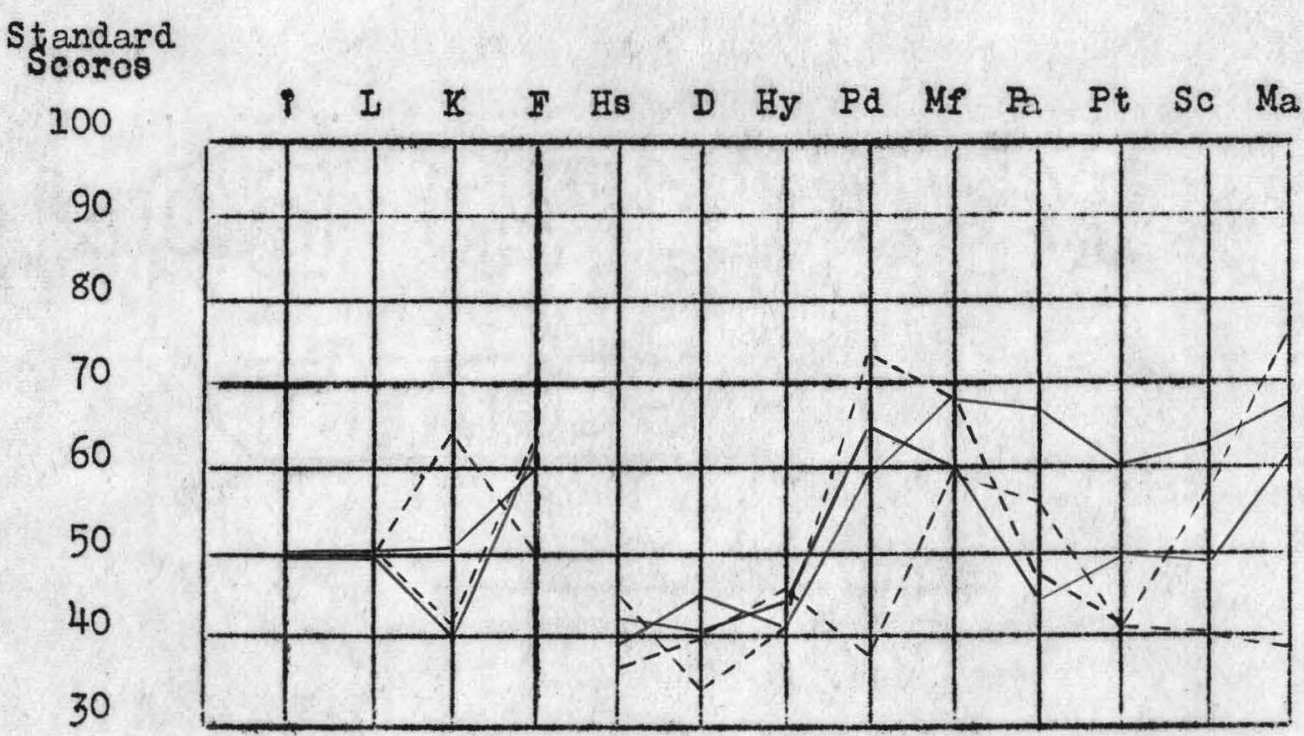

Fig. 7. Pair 4. Pre-test and end-test profiles of the experimental and control subjects. Key: Bxperimental subject pre-test _, endm test _ _ - ; control subject promtest__, end-test _ _ .

Both subjects remained generally within the normal range of scores. It may be noted that on the most extreme scale, the experimental subject, on the end-test score, has given less abnormal responses than on the pre-test.

Contrasted to these results, the control subject gave more abnormal responses in the scales of most extreme deviation on the end-test.

While scores on all scales but two remained within the normal range, the experimental subject tended toward a more normal score on the endtest, with the control subject tending toward a more abnormal score on the same test. 


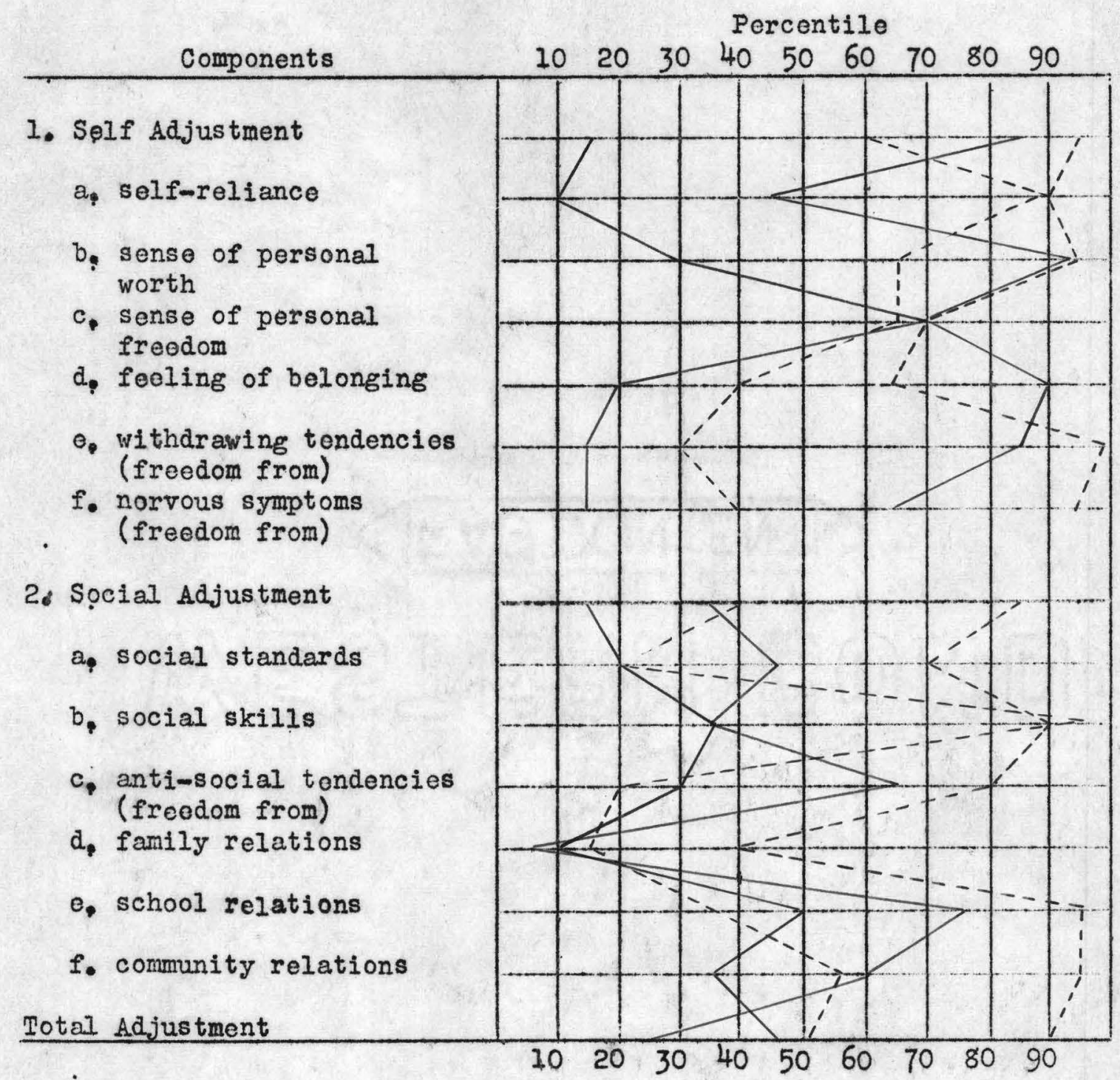

Fig. 8. Pair 40 Pre-test and end-test profiles of the experimental and control subjects, Key: Experimental subject pre-test-, endm test_- - ; control subject pre-test _

The pre-test scores of the experimental subject are relatively low In self adjustment. Her ninety $\mathrm{rive}$ percentile seore on the end-test Indicates marked Improvenent. Signifleant improvenent is also indicated In the conponent of sochal adjustnent. 
The scores of the control subject denote sowe decrenent in self adjustment and improvenent in sociel adjustment.

Both subjects have better scores in total sdjustment on the endtest, with the experimental subject showing a wider difference of Improvement. 
RTSULTS OF THE H-O-W

Table 8. Pair 4e H-O-W Raw Scores。*

\begin{tabular}{|c|c|c|c|c|}
\hline \multirow[b]{2}{*}{ Problem } & \multicolumn{2}{|c|}{ Experimental Subject } & \multicolumn{2}{|c|}{ Control Subject } \\
\hline & Pro-test & Fnd-test & Pre-test & End-test \\
\hline Behavior & 32 & 52 & 34 & 44 \\
\hline Intellectual & 16 & 21. & 13 & 14 \\
\hline Physical & 19 & 13 & 10 & 10 \\
\hline Social & 22 & 22 & 21 & 23 \\
\hline Emotional & 24 & 32. & 37 & 18. \\
\hline Totel & 112 & 129 & 25 & 109 \\
\hline
\end{tabular}

* The higher scores are indicative of maladjus tment.

The higher seores of the experimental subject's rating on the endtest denotes sone incresse in maladjustment, in the opinion of the scorer. Behavior probleas, especially, are thought by the person rating this subject to have increased elther in number or degree during the interview series.

The control subject, 11kevise, hes been shown, according to the scores, to heve evidenced sone degree of decrement in general behavior during the time the interviews were being conducted. The ratings suggest the greatest deerement to heve been observed in behavior problems.

Sumarr. Pair 4. Supporting statements are indicative of all objectives having been attained during the series of interviews. Both the MUPI and the CIP show, by general pattem, wore 1mprovenent of adjustment in the experimental subject than was shown in the control subject. The HLO-W schedules present no appreciable difference for 
either subject during the experimental interval.

Three measuring instruments are consistent with more Laproved endtest scores in favor of the experimental subject, with the fourth measuring device giving little score differences in favor of either subject. 
RISULTS OF THE INTERVIHW

Table 9. Pair 5. Ixperimental Subject. Interview Results.

\begin{tabular}{|c|c|c|c|c|c|c|c|}
\hline \multirow{2}{*}{$\begin{array}{l}\text { Therapeutic } \\
\text { objectives }\end{array}$} & \multicolumn{7}{|c|}{ Interviews } \\
\hline & I & 2 & 3 & 4 & 5 & 6 & 7 \\
\hline Free expression & $x$ & $x$ & $\mathbf{x}$ & $x$ & $x$ & $x$ & $x$ \\
\hline Insight & & & & $x$ & $x$ & $\mathbf{x}$ & $x$ \\
\hline Decision & 4 & & & $x$ & $x$ & $\mathbf{x}$ & $x$ \\
\hline Action & & & & & & & $x$ \\
\hline
\end{tabular}

*An $x$ is placed in the square when statements were made indicating the attainment of an objective.

Free expression was attained throughout the serles of Interviews. During the fourth interview some Inalght was apparent with regard to a problem that had been talked about at some length in provious interviews.

\section{Interview 4:}

St uI have solved - I have Plgured out the answer to one thing that has bothered for guite a while. You remember when I asked you what I should do when any one asked me, or made any cracks about being here. Well, I've II gured out how to handle that. In the flrst place It don't worry me as rauch as it did. Just talking about it and thinkIng makes it so $1 t$ don't seen so big as it did."

\section{Interview 5 :}

Ss "I feel bad at tirses, but It's not as bad as it used to be because I can think, well, tomorrow I'II feel better, and I usually do. I don't feel so bad about being here, elther, as I have done. I want to stay here now, I don't went to go to Inglewood. That's another 
thing that I have worried a lot about."

\section{Interview 7:}

3: One thing I can do now is solve ny own problems. I always used to ask someone else what to do, but I don't have to any more with most things,"

\section{* * * *}

S: "It doesn't bother me to be here any more. I know it is necessary for me to flnish my ters here. I'b not afraid of getting out, elther. It used to worry me about what people would say. I don't worry about these things like I used to... I have had lots of chances to run away, but I've decided to stay." 


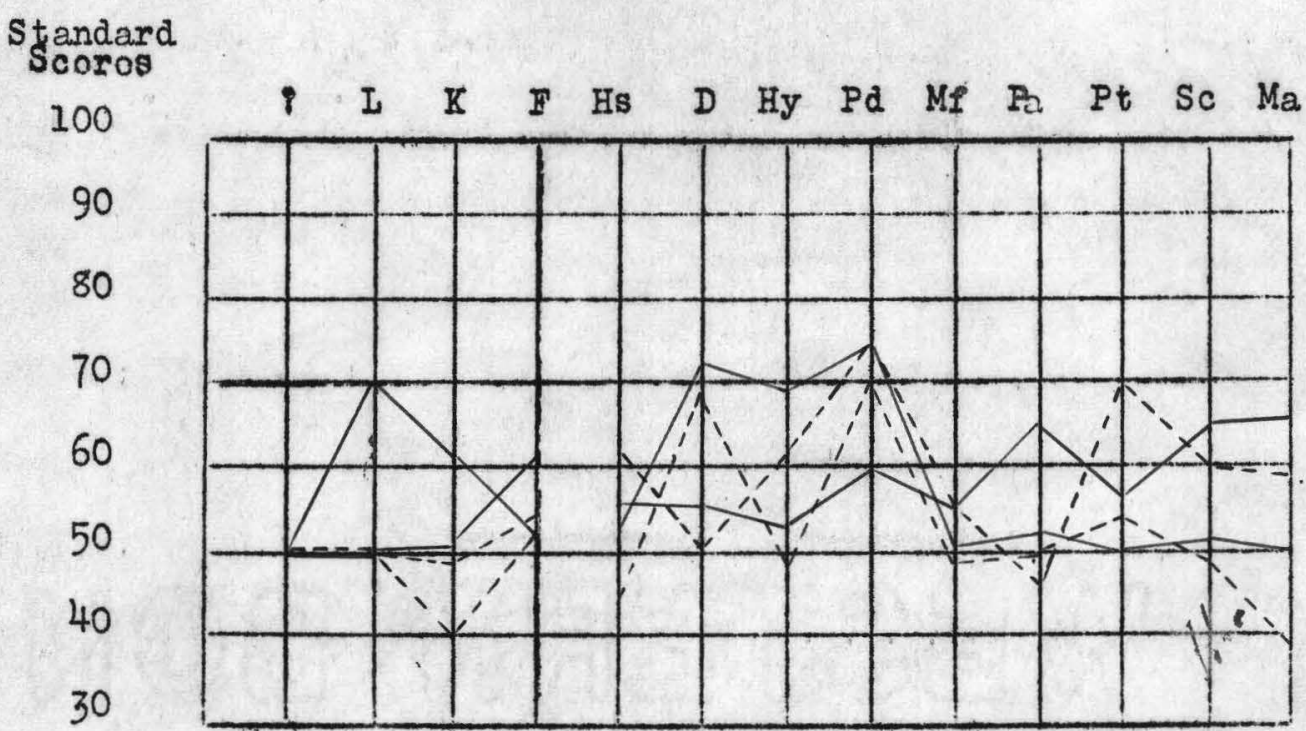

Fig. 9. Pair 5. Pre-test and end-test profiles of the experimental and control subjects. Key: Ixperimental subject pre-test _ , endtest _ - - ; control subject pro-test__, end-test__ _.

The scales in which the most abnormal responses were given, by the experimental subject, are the $D$ and Pd on the pre-test. The endtest indicates a decreased number of abnormal responses on the same two scales, ALI other scores, with the exception of L, which may tend to invalidate all the seales, appear to be well within the range of normal responses.

The control subject has scored within the norral range on all seales in both tests, with one exception. This is the end-test score on the Pd scale. One other score, on the Pt scale, approaches the abnormal ares.

It would seen safe to conclude, according to the two scores of both subjects, that the counseled subject has shown some improvement in the abnomelly indicated areas, while the control subject, in these seme areas, has shown some decrement. 


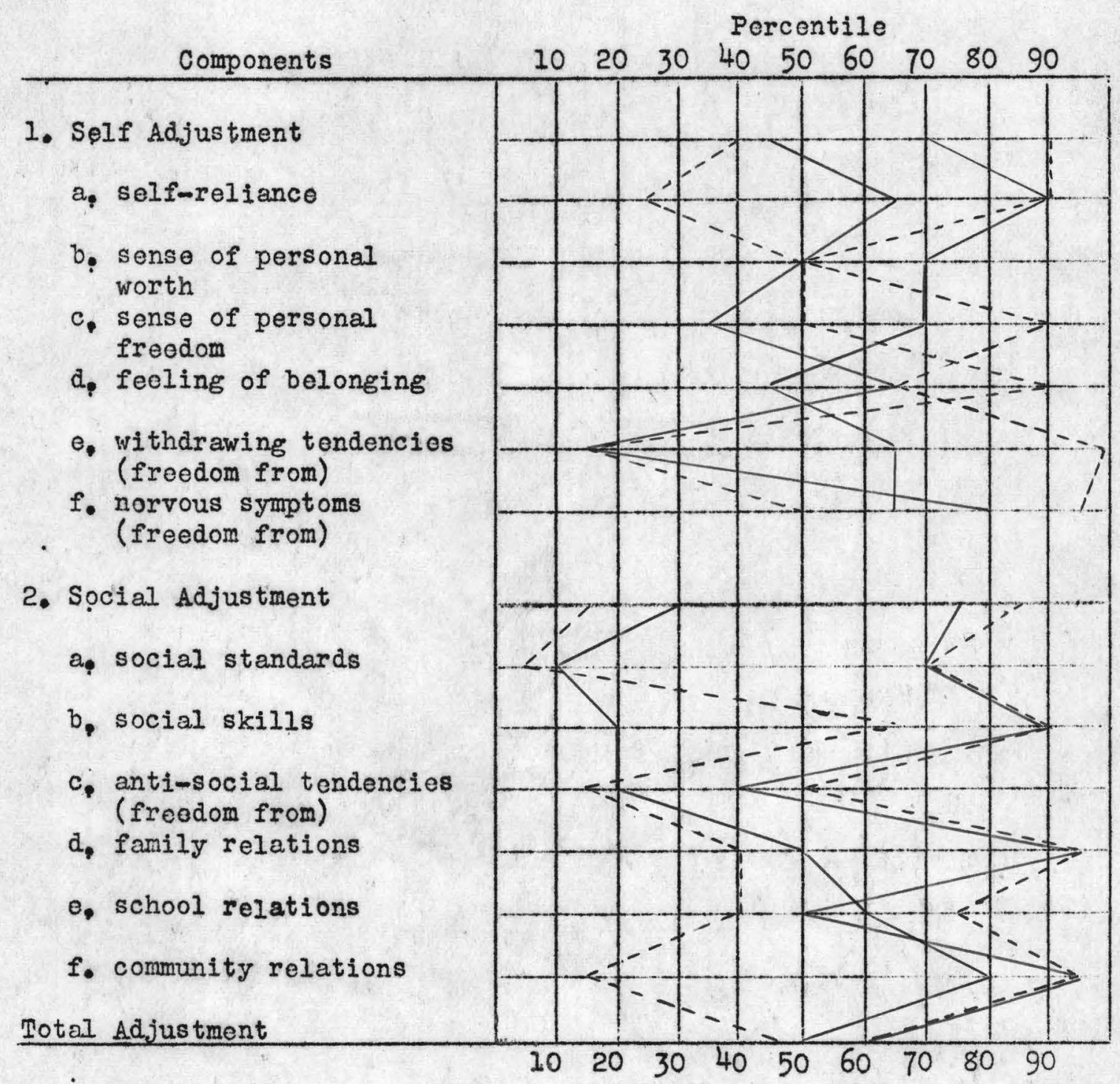

Fig. 10. Pair 5. Promtest and end-test profiles of the oxperimental and control subjects, Key: Experimental subject pre-test_-, endmtest_- - ; control subject pre-test__, ond-test_- -.

The pre-test and end-test scores of the counseled subject Indieste a five percentile decrement in hie self adjustaent during the two wonth period while the interviews were being conducted. The promtest and andtest scores In secial adjustment indicste a 10 percentile improvement over the same period of tine. 
The same scores of the control subject show a 15 percentile increase in self adjustment and a 15 percentile decrease in social adjustm ment.

The pre-test and end-test scores in total adjustment are the same In the case of the experimental subject and indicate a 5 percentile decrement during the experimental interval for the non-counseled subject. 
RHSULTS OF THE H-OM

Table 10. Pair 5. HuOW Raw Scores.*

\begin{tabular}{l|c|c|c|c}
\hline Problom & \multicolumn{2}{|c|}{ Experimental Subject } & Control Subject \\
\cline { 2 - 5 } Pre-tost & End-test & Pro-test & Bnd-test \\
\hline Behavior & - & - & - & - \\
Intollectual & 12 & 12 & 27 & 27 \\
Physical & 11 & 11 & 15 & 15 \\
Social & 19 & 12 & 32 & 30 \\
Enotional & 16 & 12 & 35 & 35 \\
\hline Total & 58 & 47 & 109 & 107 \\
\hline
\end{tabular}

* The higher scores are indicative of maladjustment.

Both pre-test and end-test scores indicate the experimental subject to be comparatively well adjusted. The difference of the two scores points to the fact that the observer believed the subject attained even better adjustment during the experimental interval. The control subject, as shown by total scores, was thought to have made little, if any, significantly improved general adjustment.

Summary, Pair 5. Statements were given during the series of therapeutic interviews that gave evidence of the attainment of all the objectives. The CIP was the only measuring instrument that gave no supporting evidence of generally improved adjustment during the experimental process. End-test total scores, both on the MPI and on the H-O-W schedules, along with the attainment of the therapeutic objectives during the interviews, support the assumption that the experinental subject showed. a greater difference of improved general adjustment from the pre-tests to the end-tests. 
RTSULTS OF THE INTERVIEW

Table 11. Pair 6. Ixperimental Subject. Interview Results.

\begin{tabular}{|c|c|c|c|c|c|c|c|c|c|c|}
\hline \multirow{2}{*}{$\begin{array}{l}\text { Therapeutic } \\
\text { objectives }\end{array}$} & \multicolumn{10}{|c|}{ Interviews } \\
\hline & 1 & 2 & 3 & 4 & 5 & 6 & 7 & 8 & 9 & 10 \\
\hline Free expression & & $x^{t}$ & $x$ & & & & $x$ & $\mathrm{x}$ & $x$ & $x$ \\
\hline Insight & & & & & & & & & $x$ & $x$ \\
\hline Decision & & & & & & & & & $x$ & $x$ \\
\hline Action & & & & & & & & & $x$ & $\mathbf{x}$ \\
\hline
\end{tabular}

*An $x$ is placed in the square when statements were made indicating the attainment of an objective.

A considerable portion of this subject's responses during most of the interviews were of a violently revengeful, negative nature. His expressions indicated an attitude of having been dealt with unjustly, along with the feeling of a need to strike back.

Interview 2:

S: "I'm still getting a dirty deal."

C: "Things haven't seaned to change much,"

S: "I got to miss eight shows now; two for stealing pies, two for smacking , two for smoking in the school house, and two for sleepIng in church."

The subject spent the first several interviews conplaining about everything with which he came incontact, including the school, the fellows, the food, the administration, teachers, company comnanders, policy, the state boys getting all the breaks, etc. 


\section{Interview 3:}

C: "You don't feel that things are any better."

S: "Worse. It doesn't get better, It gets worse,"

Following the fourth interview, the subject ran away, was found and brought back, and the negative responses continued until the ninth interview.

Interview $9:$

3: "I sure cen see things a lot different. It happened all at once. I'm satisfied to stay here now. I feel different about the place and all the guys here. I guess it was just me. . . It makes me feel a little silly to look back on what I've said before."

The following is a quotation from one of the instructors at the school: "_._. (subject) has been a hard boy to handle, but something has helped him lately. He is doing a good job of things now." 
RESULTS OF THE MMPI

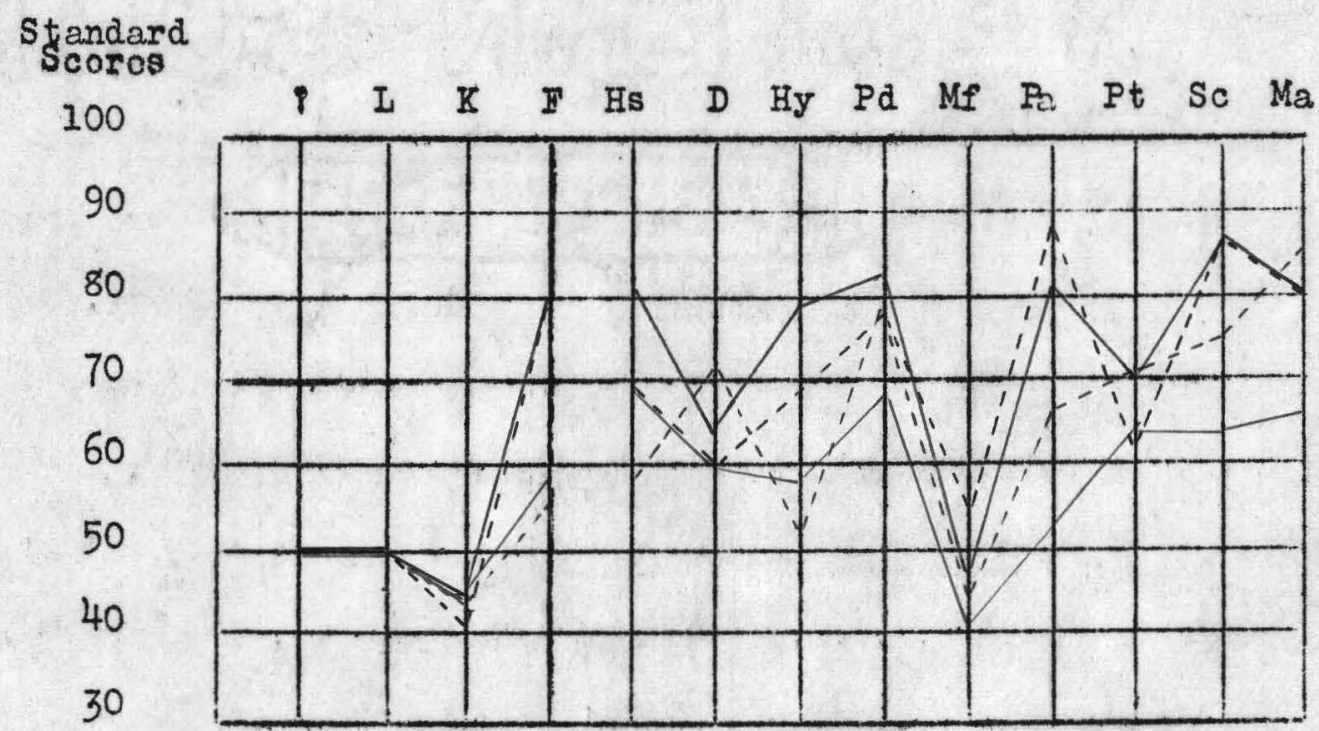

Fig. 11. Pair 6. Pre-test and end-test profiles of the experimental and control subjects. Key: Ixperimental subject pre-test _, endm test - _ - ; control subject prentest _ _, end-test _ _ - .

The pre-test seores of the experimental subject show a large proportion of abnormal responses made on most of the psychotic and prychoneurotic scales. The ond-test scores Indicate fewer abnornal responses in all but three scales, two of which remain the same. The end-test results show more abnormal responses on the $\mathrm{Pa}$ scale than were sade on the first test.

On the pre-test, the control subject scored within the nomal range of responses on all scales, The second scores indicate more abnomal responses made, especially in the psychotic scales.

With one exception, the end-test scores of the experimental subject recorded improvement, where the results tended to be extreme. The control subject has made fewer nomal responses on the psychotic scales in the end-test. On the psychoneurotic end of the profile the second test scores Indicate more abnornal responses on the $\mathrm{Pd}$ and $\mathrm{D}$ scales and norral responses on the His scale. 


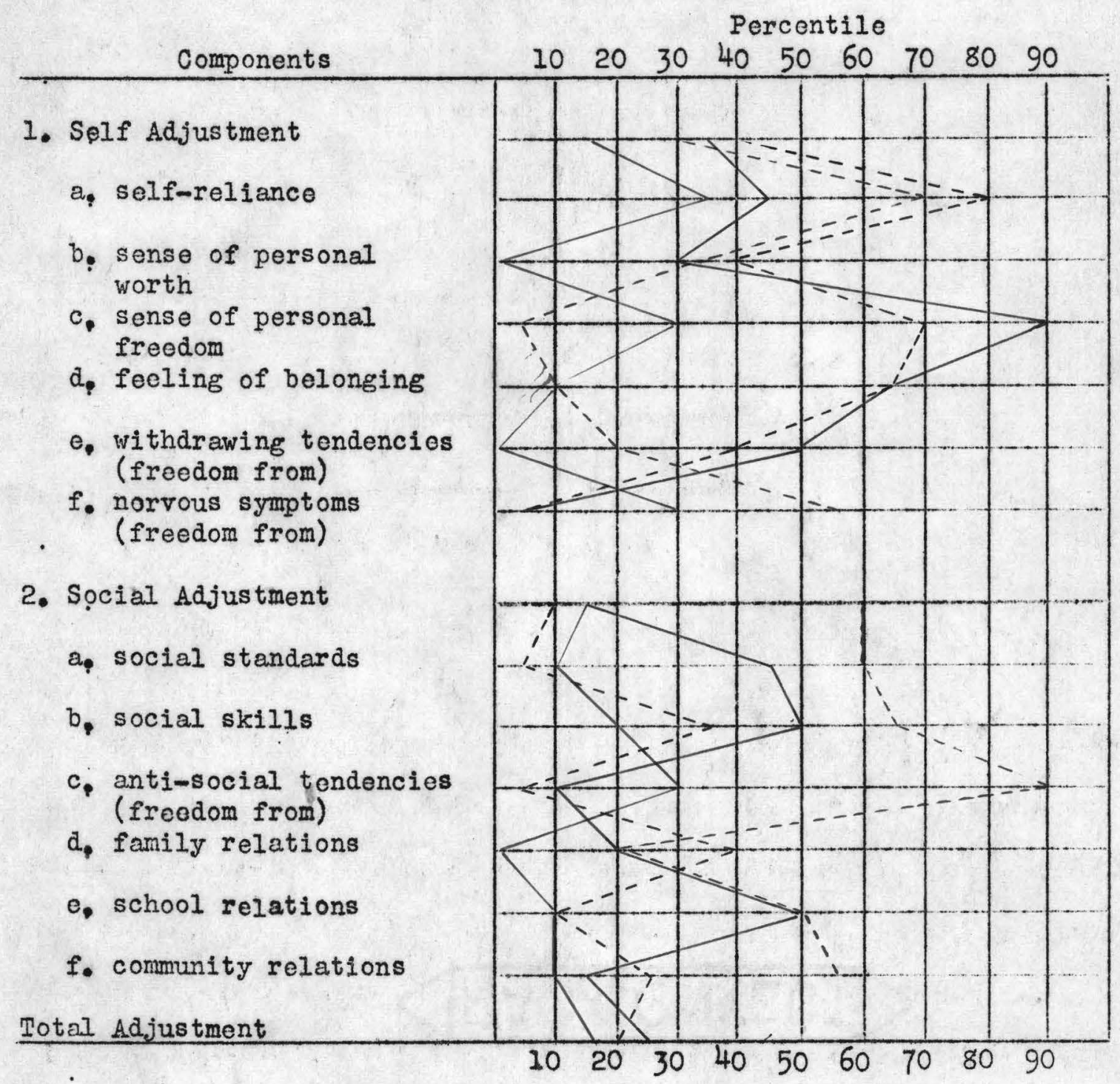

Fig. 12. Pair 6. Premtest and end-test profiles of the experimental and control subjects. Key: Bxperimental subject pre-test -, endm test _ _ - ; control subject pre-test _ , end-test ....

The experimental subject's end-seores show a 5 percentile increase in self adjustment and a 5 percentile decrease in soelal adjustment cospared with the pre-test scores. Component $c$, sense of personal freedom, exhibits the most extreme decrenent deviation of any component 
listed under self adjustrent.

The control subject, by the indication of scores, shows an increase in general adjuatment on both the self and social scales.

The total adjustment scores indicate a 5 percentile decrement in the case of the experinental subject and a 30 percentile improvement in the case of the control subject. 
RBSULTS OF THE H-O-W

Table 12. Pair 6. E-O-W Raw Scores.*

\begin{tabular}{l|c|c|c|c|}
\hline Problem & \multicolumn{2}{|c|}{ Experimental Sub.ject } & \multicolumn{2}{|c}{ Control sub.ject } \\
\cline { 2 - 5 } Pre-tost & Ind-test & Pre-test & Ind-test \\
\hline Behavior & - & - & - & - \\
Intollectual & 25 & 25 & 15 & 15 \\
Physical & 13 & 13 & 12 & 11 \\
Social & 32 & 21 & 18 & 18 \\
Bmotional & 23 & 17 & 16 & 16 \\
\hline Total & 93 & 76 & 60 & 60 \\
\hline \hline
\end{tabular}

* The higher scores are indicative of maladjus tment.

In the four categories of adjustment that were scored by the person making the observation, the total scores are indicative of some general Improvement in the experimental subject. The control subject was observed to have made no improved adjustment.

It way be of interest to note that in this rating, as with some others, the changes that are recorded to have occurred, are primarily in the social and emotionel phases of adjustment.

Suwnary. Palr 6. Statements were given during the interviews that were indicative of the subject having attained all the therapeutic objectives. Pre-test and end-test total scores on the MMPI and on the B-O-W supported the interview statenents indicating iaproved general adjustmert, Results of the CTP failed to lend supporting evidence to the sssumption that the experinental subjeet showed a greater difference of improved adjustment. 
Table 13. Pair 7. Ixperimental Subject. Interview Results.

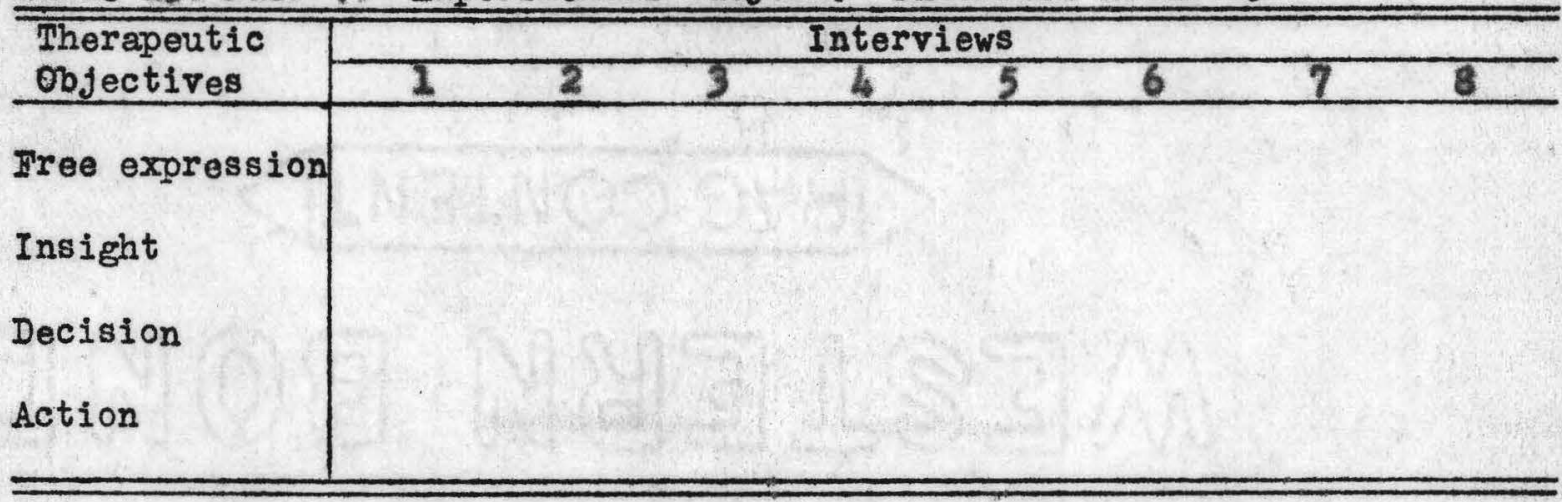

*An $x$ is placed in the square when statements were made indicating the attainment of an objective.

This subject was unique in that he brought no probleras to the interviews. He was apparently well adjusted at the institution and in no way during the interviews approached his anti-social behavior problens. No problems of concern to him, if he had ary, were discussed or even mentloned during the entire series. Whether this subject had already conpleted the task of adjustment, or just didn't recogaize or wish to discuss his situation, the counselor was unable to determine. At any rate It may be safely concluded that none of the objectives, as outlined, were achieved during the lnterviews. His expresalon was free only for short intervals, and almost never in relation to his own problems. 
RESULTS OF THE MMPI

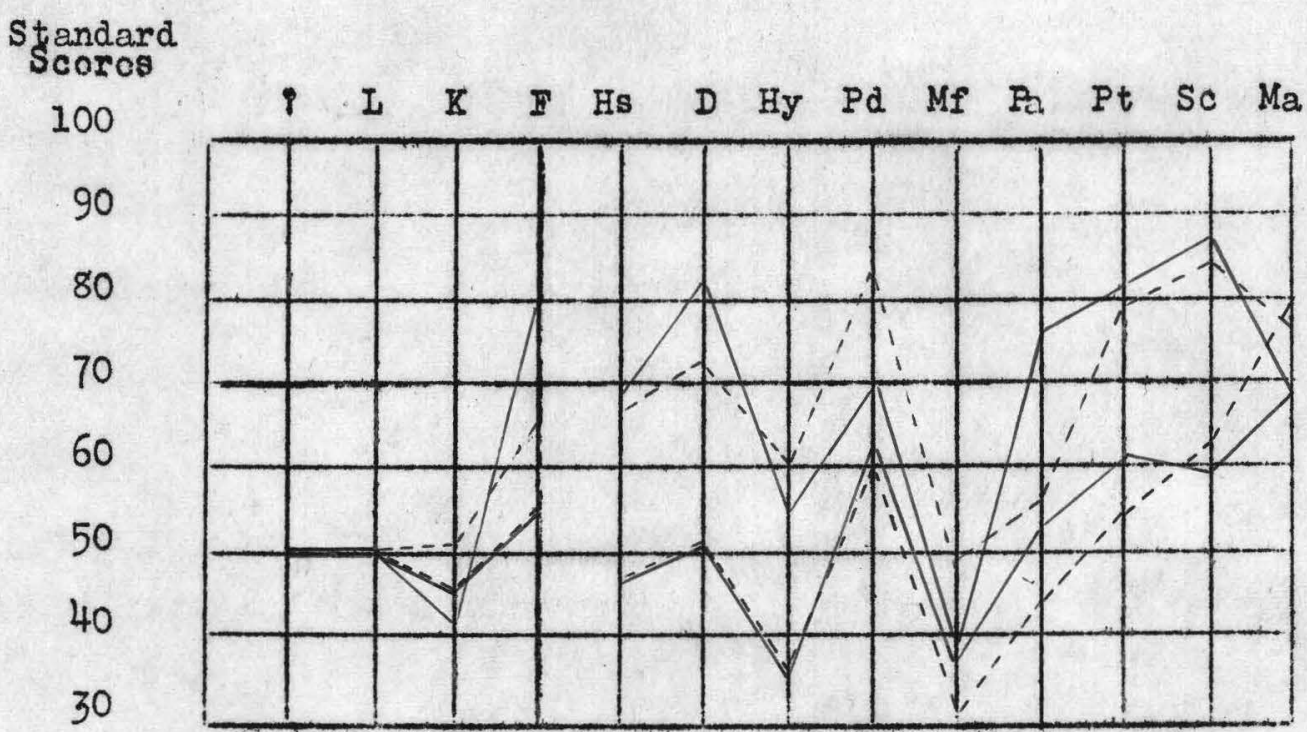

Fig. 13. Pair 7. Premest and end-test profiles of the experimental and control subjects. Key: Experimental subject pre-test _, endtest _ - ; control subject premtest __, endatest__. .

A21 responses in the case of the experimental subject on both tests, are dithin the normal range, with the exception of those made on the Ia scale in the end-test. In this ease the end-test indicates more abnormal responses on the Ma scale than were recorded in the pre-test.

The control subject shows a more normal trend on the D scale and a more abnormal trend on the Pd scale on the end-test than was shown on the first test. The psychotic end of the profile indieates some improvement on all except the Ma seale.

It would seen that the total results indleate some decrement for the experimental subject on the Wa scale in the end-test results. The two scores of the control subject show improvement on the $\mathrm{D}, \mathrm{Ps}, \mathrm{Pt}$, and Sc scales, and a decrement on the Pd and Ma scales. 


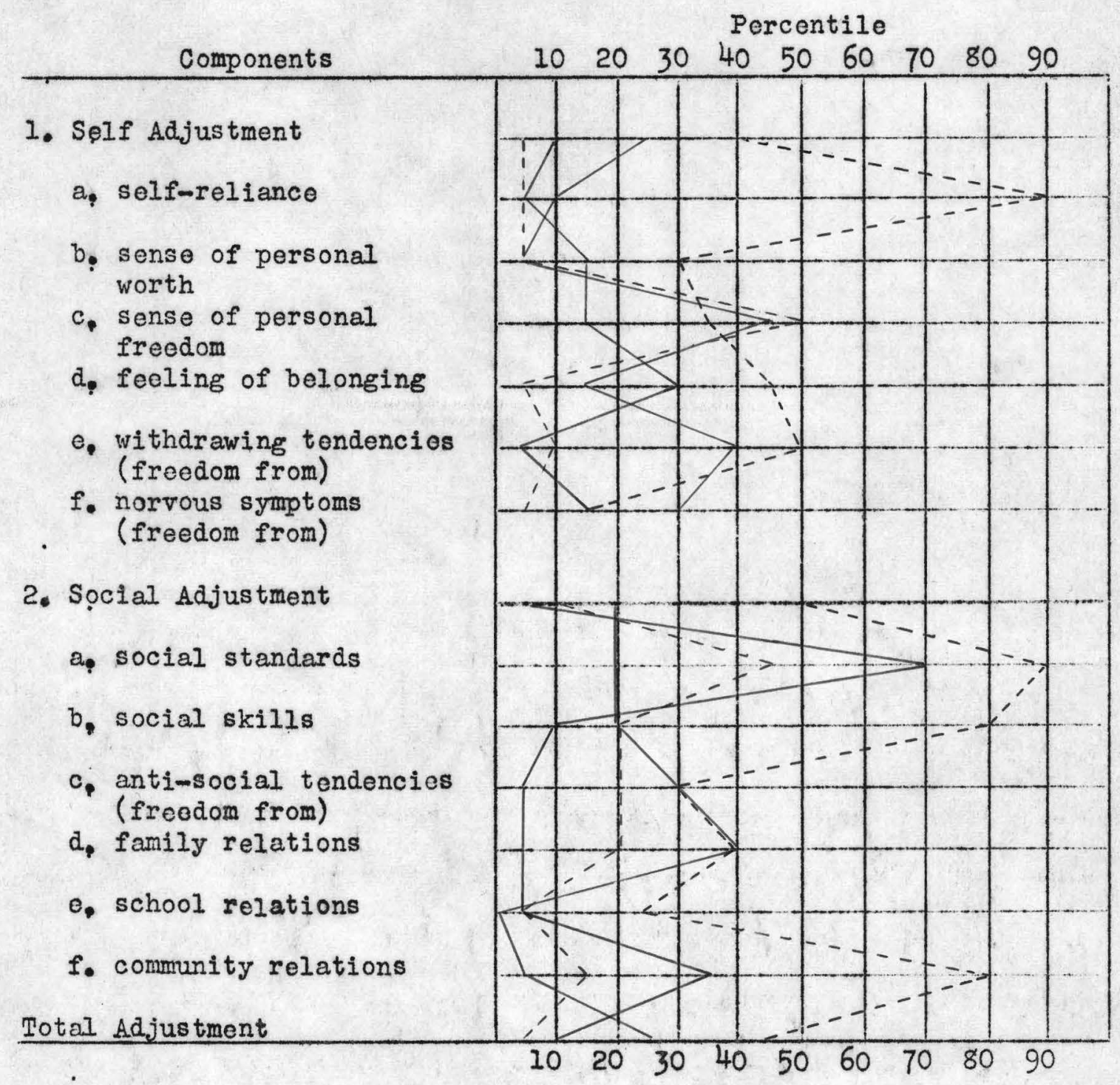

Fig. 24. Pair 7. Pre-test and end-test profiles of the experinental and control subjects. Key: Nxperimental subject pre-test - endtest_- - ; control subject premtest___ end-test_. - .

The two test scores of the experimental subject represent an inerease in better self adjustment of 30 percentile points. Host improvement is indicated in the personality component of self reliance. An even greater improvement, as indicated by total scores, was made in social adjustment. 
The control subject received a decrease in percentile scores on the end-test in both self and social adjustment.

The total adjustrent end-scores of the experimental subject show a 40 percentile higher score than the pre-test. With the control subject, the corresponding end-score shows a 20 percentile decrease. 
RESULTS OF THE H-OMW

Table 14. Pair 7. E-O-W Raw Scores.*

\begin{tabular}{l|c|c|c|c}
\hline \hline Problon & \multicolumn{2}{c|}{ Experimental Subject } & Control Subject \\
\cline { 2 - 5 } Behavior & Pre-tost & Bnd-test & Pro-test & Bnd-test \\
\hline Intollectual & - & - & - & - \\
Physical & 14 & 16 & 22 & 14 \\
Social & 10 & 10 & 10 & 11 \\
Bmotional & 19 & 21 & 18 & 16 \\
\hline Total & 21 & 22 & 17 & 17 \\
\hline \hline
\end{tabular}

* The higher scores are indicative of maladjustment.

Total scores are conslatent in ahowing very 1ittle deviation in either subject. Both subjects are Indicated as having slightly increased maledjustments, but the differences of pre-test and end-test scores are not significant in elther cese.

The person making the observation, in this case, did not score either subject on the behavior scale.

Sumary. Pair 2. The CIP was the only measuring instrument that Incleated axy difference of Improvement in the experimental subject. No objectives were attained during the interviews and scores on both the MPI and the Ha-li schedules are consistent in showing no signifleant difference of improved adjustment in the experimental subject over the control subject. 
RESULTS OF THE INTERVIEW

Table 15. Pair 8. Ixperimental Subject. Interview Results.

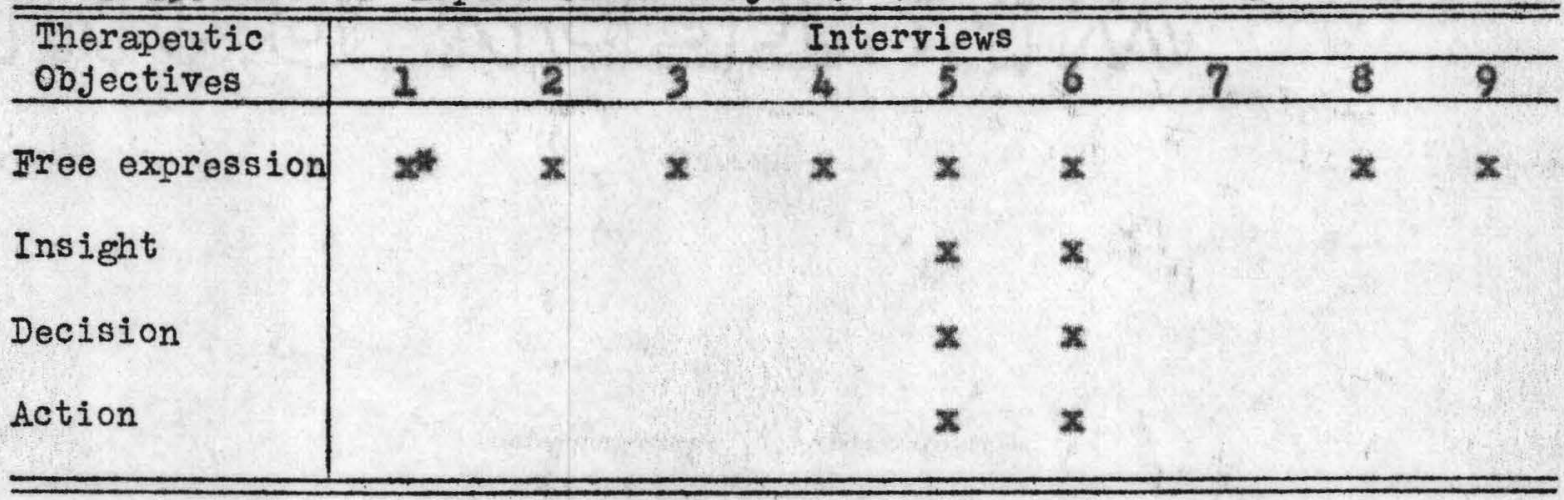

* An $x$ is placed in the square when statements were made indicating the attainment of an objective.

This case Is somewhat unique in that the subject showed considerable Insight during the fifth and sixth interviews, only to regress to negative expressions during the remaining interviews. Complete insight was never galned and the subject terminated the interviews by expressing a desire to discontinue. He freely expressed himself throughout the series and repport was seeningly good.

\section{Interview 5:}

S: II find myself quite often now stopping and thinking about things before I do sonething that might get ne into trouble."

The following sccount was expressed by the case worker at the school: "I had a talk with one of your boys. Youtve surely done him some good. He told me he had changed his way of thinking and that it had done $\mathrm{hm}$ a lot of good to come in and talk."

Interview 6 :

Subject told of some boys running away the previous night. 
S: "I had a chance to go wh then, but I thought about it for awhile and then I knew I didn't want to go. If I had done that some of the times before, I might not even be here."

Interview $7 t$

S: "Something's happened that I don't think I'm going hose so soon. Haybe Mr. had something to do with 1t. I can't get along with him. If I'm not out by Fobruary, I'm going to run away. Then I don't care what happens,"

Interview 8:

S: "I felt better for awhile, but now I feel just like I used to. They blame me for everything that happens. Like if something's taken, I always get the blane."

$$
* * *
$$

S: "I haven't got any reasons for foeling 2lke that, but I just don't want to stay here any longer."

Interview $9:$

S2 "I' golng right on messing up as long as I feel this way. It's no use trying to get along as long as they treat you that way." This feeling of being unjustly treated and of being singled out for punishment seems, in most cases, to decrease in proportion to the amount of insight attained. 
RESULTS OF THE MMPI

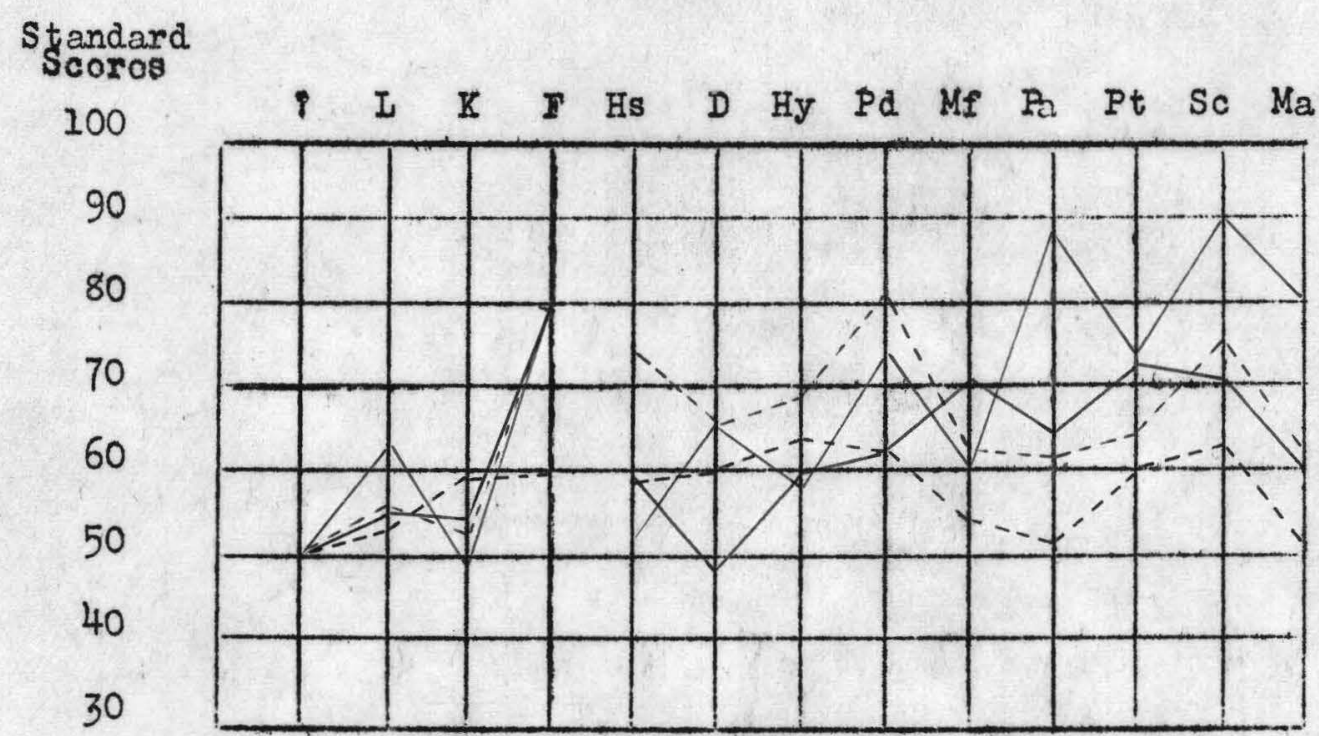

Fig. 15. Pair 8. Pre-test and end-test profiles of the experimental and control subjects. Key: Bxperimental subject pre-test _, endm test _ _ - ; control subject premtest __, end-test _ _ -

The responses of the experimental subject approached the abnornal area only on the psychotic end of the profile. End-test scores 1ndicate a greater number of nomal responses on these scales.

The control subject exhibits some extrene abnormality in some of the psychotic scales on the pre-test. The end-test scores indicate a trend toward more abnormal responses in the psychoneuroses and fewer in the psychoses.

The scores show the experimental subject to have given fewer abnorasl responses in the psychoses, while the control subject shows Improvement in the psychotic seales and a decrement in sone of the psychoneurotic conponents.

The high F scores, in both cases, are consistent with abnormel tendencles exhibited in the psychotic scales. 


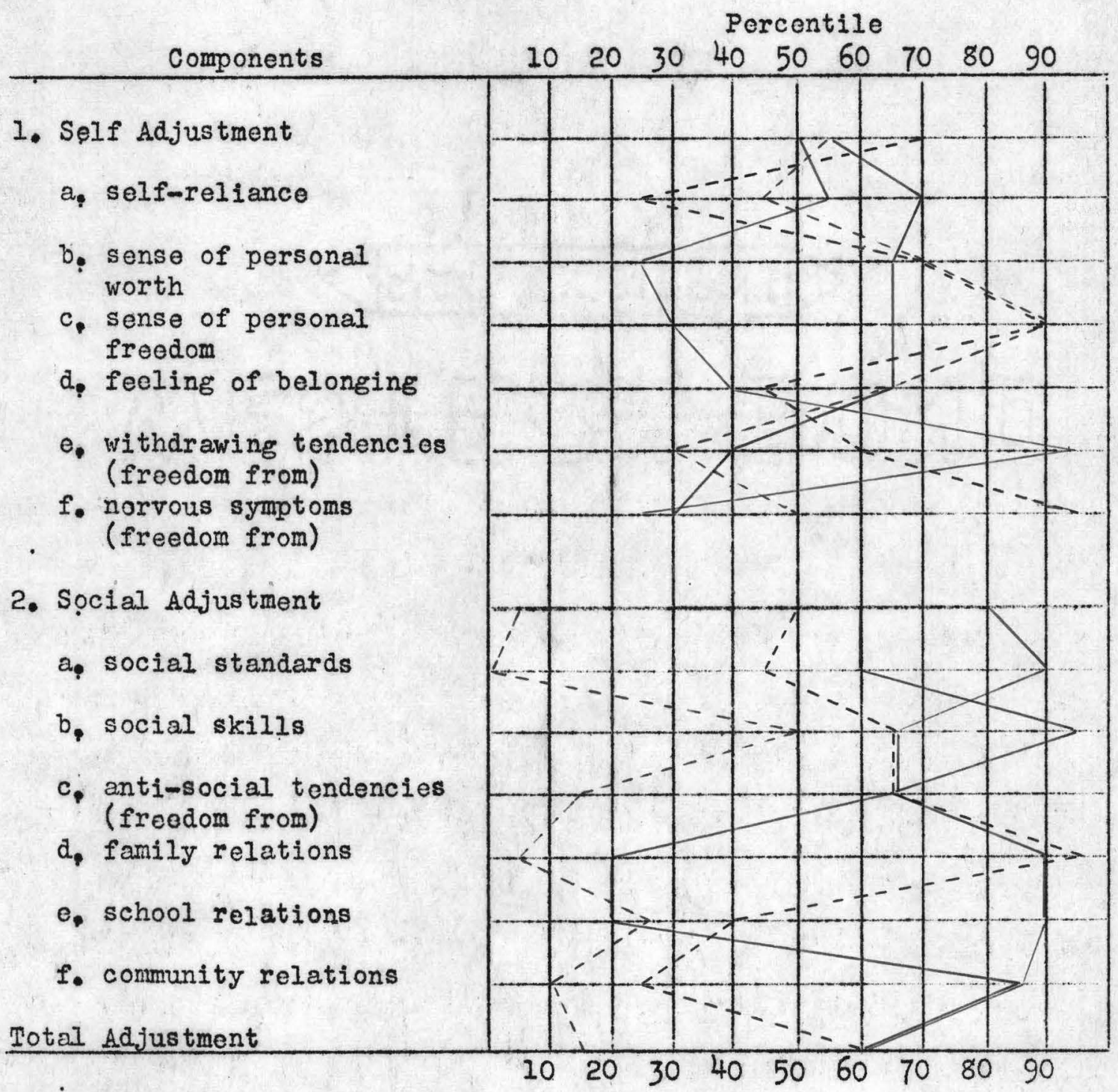

Fig. 16. Pair 8. Premest and end-test profiles of the experimental and control subjects. Key: Exporimental subject pre-test - endm test__ _ ; control subject pro-test___ end-test _. - .

Some improvenent is Indicated in self adjustnent and sone decrement in social adjustwent with the experimental subject.

In the case of the control subject, the end-test scores show a 5 percent1le Improvement. In social adjustment the same scores denote considerable decresunt. 
The total adjustaent score remained the sane with the experimental subject. The control subject scored sone decrement on the end-test. 
RESULTS OF THE H-O-W

Table 26. Pair 8. H-O-W Raw Scores.*

\begin{tabular}{l|c|c|c|c}
\hline Problem & \multicolumn{2}{|c|}{ Experimental Sub.ject } & \multicolumn{2}{|c}{ Control Subject } \\
\cline { 2 - 5 } & Pre-tost & End-test & Pro-test & End-test \\
\hline Behavior & - & - & - & - \\
Intollectual & 22 & 15 & 22 & 17 \\
Physical & 18 & 16 & 15 & 13 \\
Social & 32 & 35 & 20 & 22 \\
Emotional & 38 & 40 & 27 & 24 \\
\hline Total & 109 & 106 & 83 & 75 \\
\hline \hline
\end{tabular}

* The higher scores are indicative of maladjustment.

Although both of the end-test scores indicate a greater degree of improved adjustment in both subjects, the difference is small in both cases. Seores show the control subject of this pair to have a slight advantage of improverent during the experimental interval.

The person rating in this ease gave no scores on behavior problens.

Summaxz. Pair 8. Although some statements were made during the interviews that would suggest the subject had attained the therapeutic objectives, a regression was made in the final interviews to negative responses. It was felt that the subject could not be assuned to have finally attained the objectives. All measuring instrunents supported this contention and all were consistent in showing by total scores that no difference of Improved edjustanent was ovidenced In the experimental subject. 
RESULTS OF THE INTERVIEW

Table 17. Pair 9. Ixperimental Subject. Interview Results.

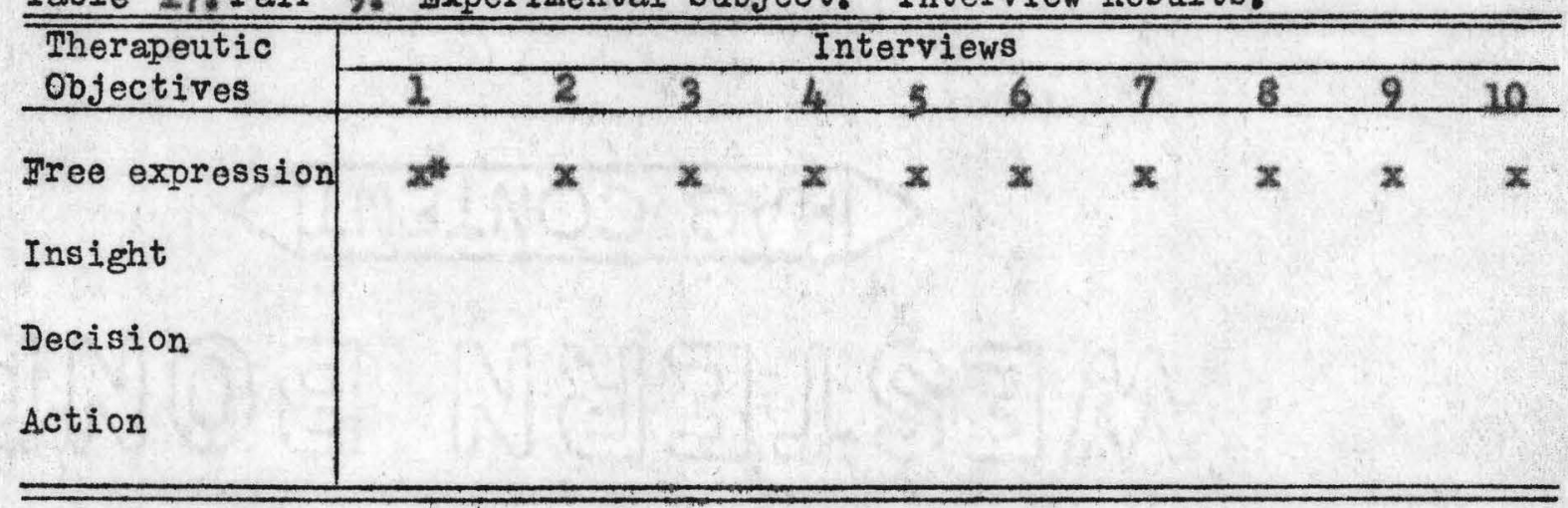

* An $x$ is placed in the square when statements were made indicating the attainment of an objective.

The outcones of this interview serles were different in some respects from the others. The subject expressed himself freely nost of the time, but at no time during the series did he indicete by his reaponses that any Insight was gained. Duxing the final four interviews, no reference was made to himself in the form of recognizing his ow situation.

His expresslons revealed that his najor interest wes "outsmarting" the staff members "ixithout getting caught". This attitude was carried through to the last intervlew.

His general attLtude of Indifference was never threatened or changed. Interview 10 t

St "I've got a new Job now, I like 1t too. You have more chance to play around."

$$
\text { ** * }
$$

S: Milabe I'II think about how to stay out of this place sometime." After taking some article from his poeket, the subject remarked: 
"Look, you're not supposed to have these things. It's against the rules,"

The counselor suegested that the interviews be discontinued. 


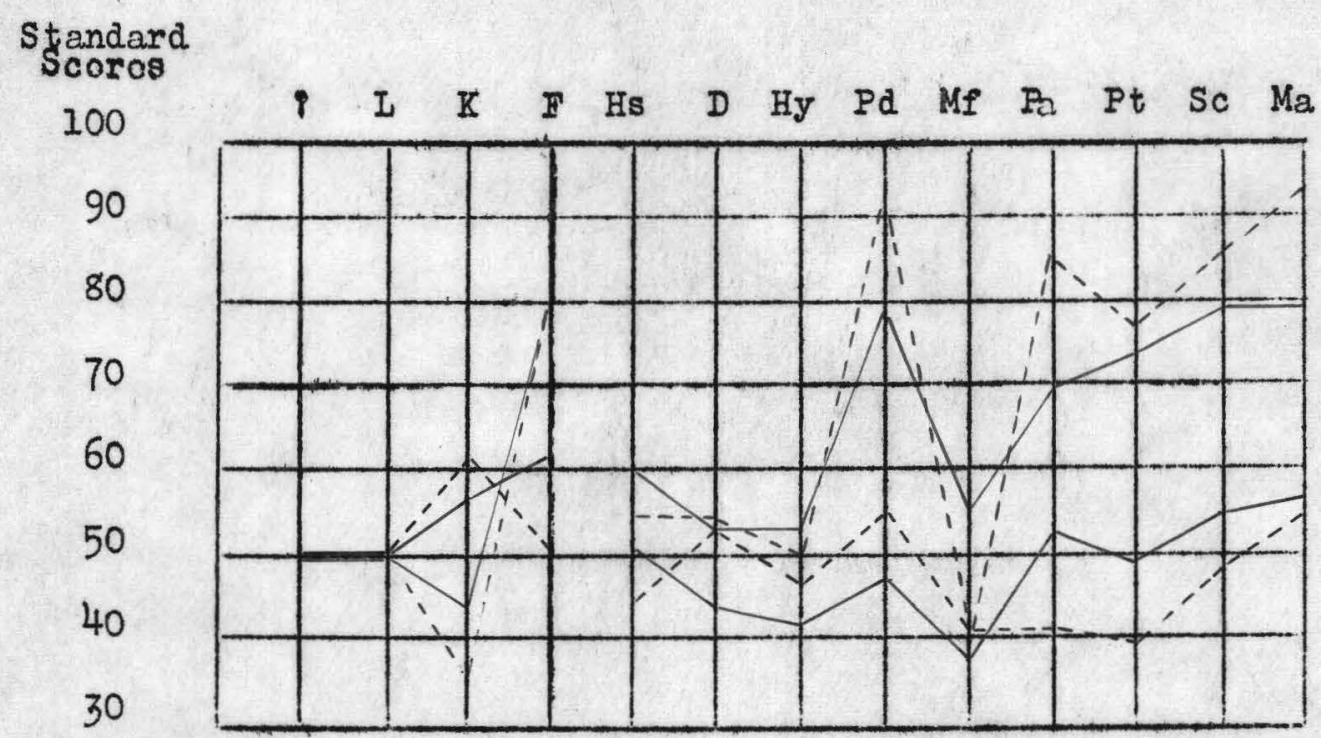

Fig. 27. Pair 9. Pre-test and end-test profiles of the experimental and control subjects. Key: Bxperimental subject pre-test _ , endtest _ _ ; control subject premtest _ , end-test _ _ .

The scores of both the pre-test and end-test are within the normal range, in the case of the experimental subject.

The control subject shows scores indicating abnormality on the Pd and psychotic scales in both tests. The end-test scores denote some decrement on these scales in adjustment, during the time that elapsed while the interviews were in progress.

A nomal profile was scored by the experimental subject on both teats. The control subject presents a profile with some decrement on the end-test Pd and psychotic scores. 


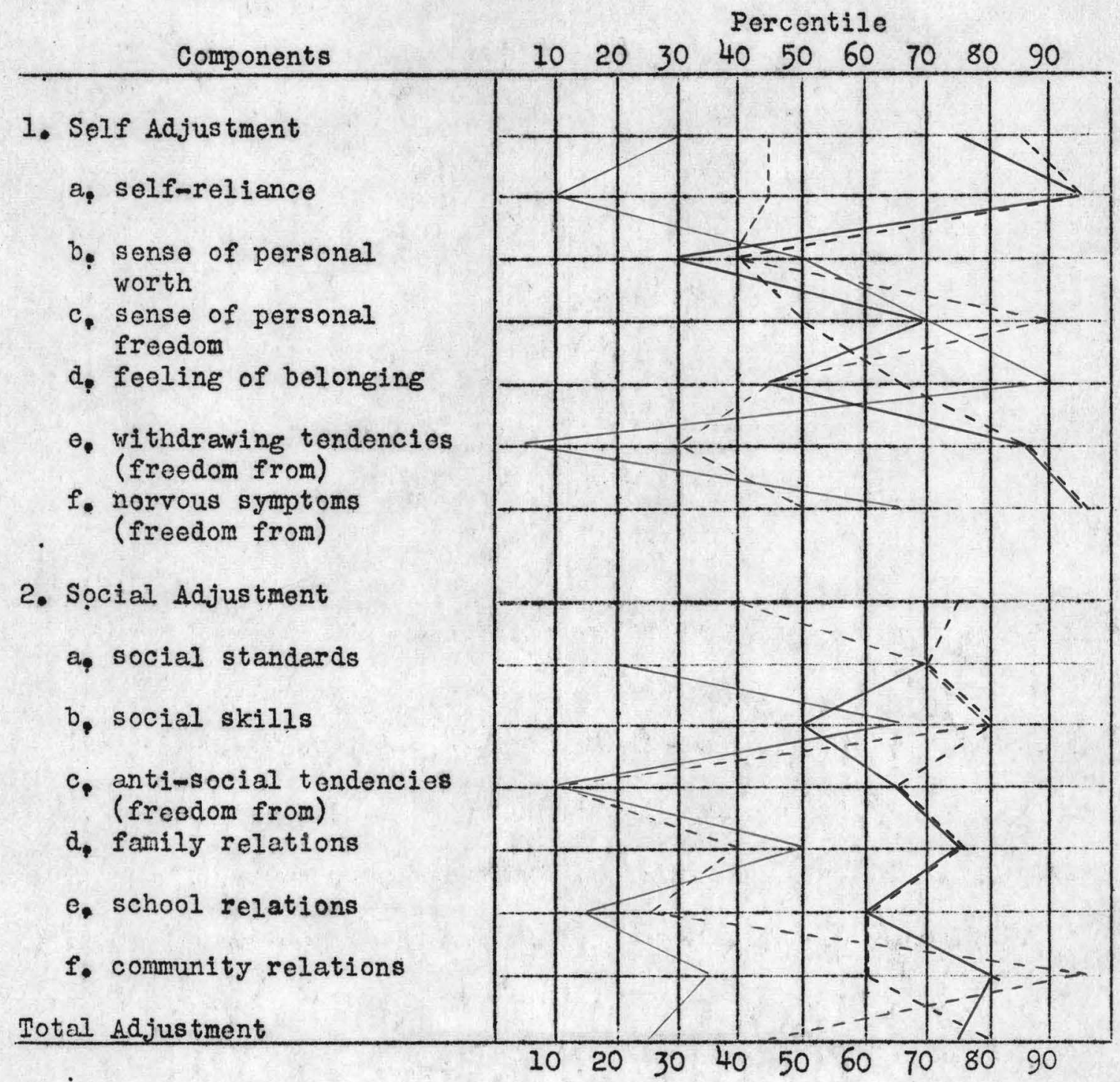

Fig. 28. Pair 9. Premest and end-test profiles of the experimental and control subjects. Key: Experimental subject pre-test -, end-m test. - - ; control subject pre-test __, end-test_- - .

The experimental subject shows an above average adjustment in both the self and social components on each test. There is little difference in the pre-test and end-test scores.

The control subject rated below average in self adjustment and social adjustment on the pre-test. The end-test scores indicate some 
improvement in the two components.

In total adjustment, both subjects are shown by their scores to have made sone improvement. 
RESULTS OF THE H-O-W

Table 18. Pair 9. H-O-W Raw Scores.*

\begin{tabular}{l|c|c|c|c}
\hline \multirow{2}{*}{ Problom } & \multicolumn{2}{c|}{ Experimental Subject } & \multicolumn{2}{|c}{ Control Subject } \\
\cline { 2 - 5 } Behavior & Pre-test & Bnd-test & Pro-test & Ind-test \\
\hline Intolloctual & 15 & 15 & - & - \\
Physical & 13 & 13 & 23 & 23 \\
Social & 26 & 18 & 14 & 14 \\
Trotional & 18 & 14 & 23 & 23 \\
\hline Total & 72 & 60 & 15 & 15 \\
\hline \hline
\end{tabular}

* The higher scores are indicative of maladjustment.

The totil scores indicate that the observer believed the experimental subject made some progress toward better adjustment during the tine of counseling. In the case of the control subject, no improvenent was shown in the end-test rating.

No rating was made for either subject on the bohavior scale.

Sumnary, Pair 2, No statements were made during the interviews thst gave evidence of the attainment of the therspeutic objectives, although the subject expressed himself freely during esch interview. Scores on both the MAPI and the CTP, however, indicated a greater difference of improvement in the experimental subject. Total scores on the HWOMII are in line with the other test findings, All test results give evidence in their total scores of some difference of improved adjustment in the experimental subject. These implications are not consi stent wh th the observed statenents made during the interviews. 
Table 19. Pair 10. Ixperimental Subject. Interview Results.

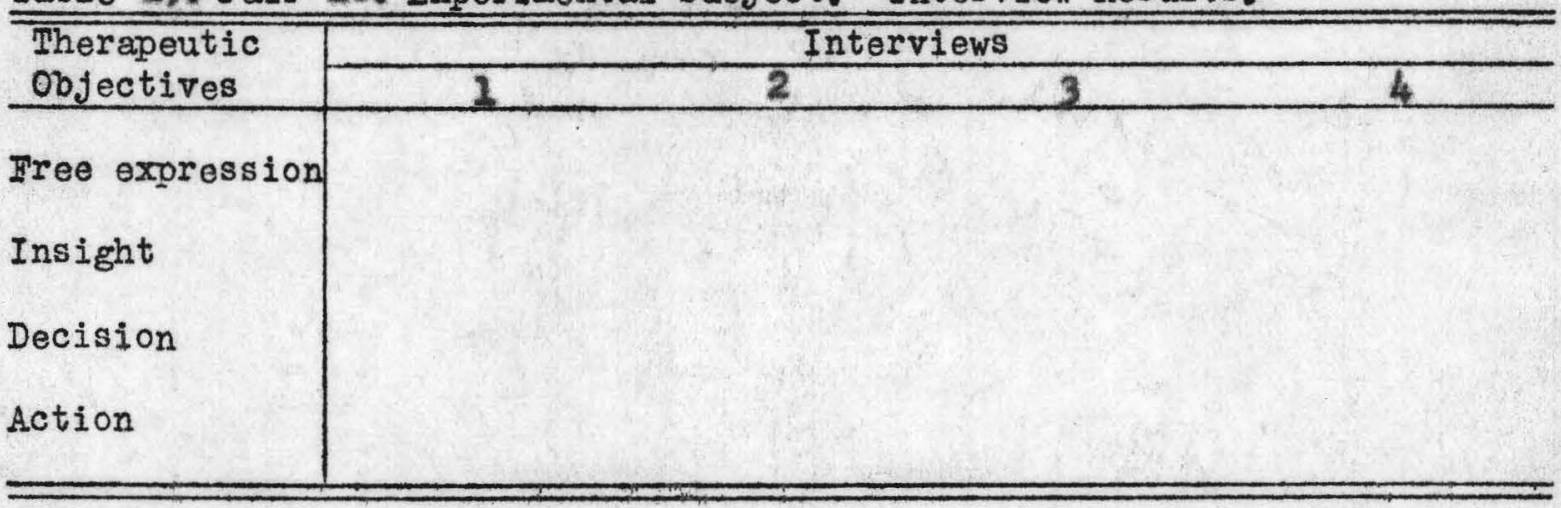

*An $x$ is placed in the square when statements were made indicating the attainment of an objective.

Liepport was never gained wth this subject. His expressions were of a nature that indicated he was suspicious of the counselor's motives. Statenents such as, "we are the gulnea plge and you are the experimentor," will indicate the counselor's fallure in this case to gain the confidence of the subject.

Other statenents sivillar to the above, made during the fourth interview were, in the counselor's opinion, indicative of the futility of continuing the contacts.

At the counselor's suggestion, the interviews were terminated with no objectives having been reached. 


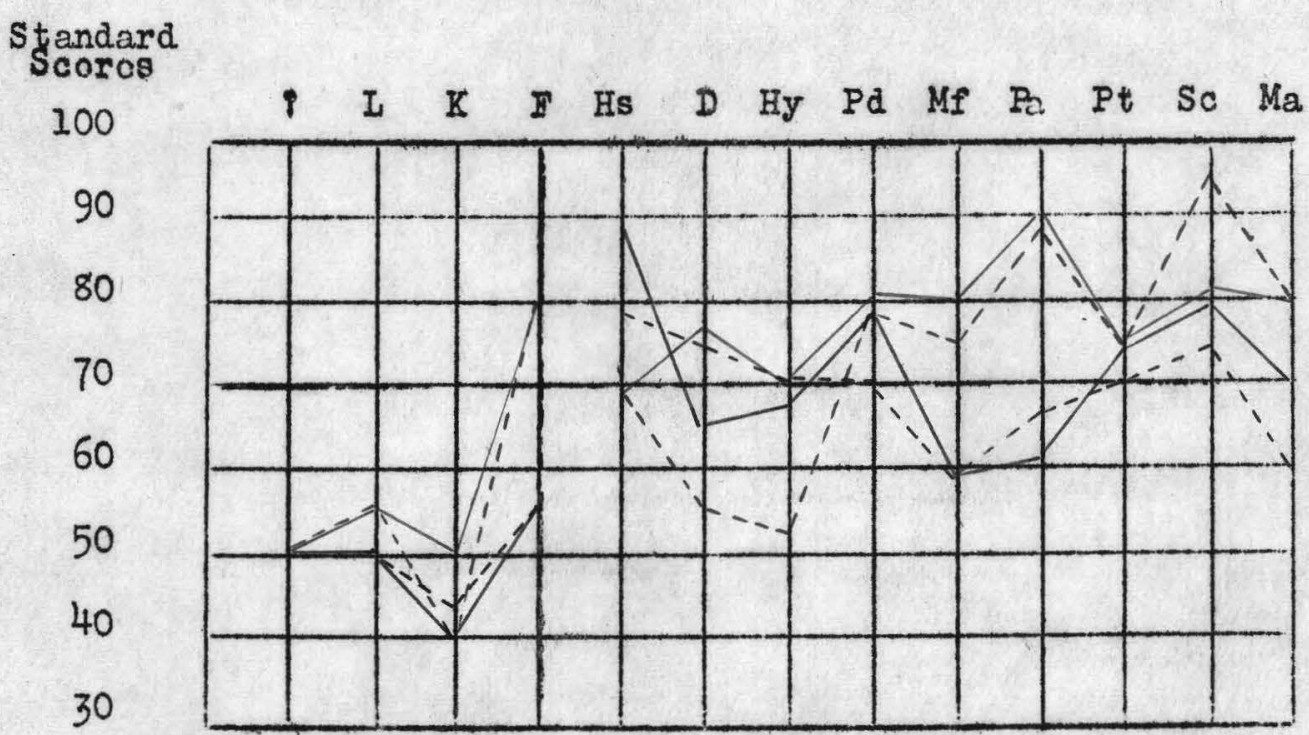

Fig. 29. Pair 10. Premtest and end-test profiles of the experimental and control subjects. Key: Experimental subject pre-test test__ - ; control subject premtest___, end-test_ _ - .

The experimental subject, according to the pre-test scores, has responded quite abnormally on both ends of the profile. The end-test scores show some improvement in responses in every scale where the abnormal responses were most prevalent.

Some improvement is indicated in the control subject's responses on the psychoneurotic end of the scale, while a tendency toward more abnornal responses is shown in the psychoses scales.

It would be difficult to draw a conclusion on the differences of gain or loss with these two subjects, inasmuch as their differences vary widely both in particular seales of improvement and in asount of improvenent or decrement indicated. 


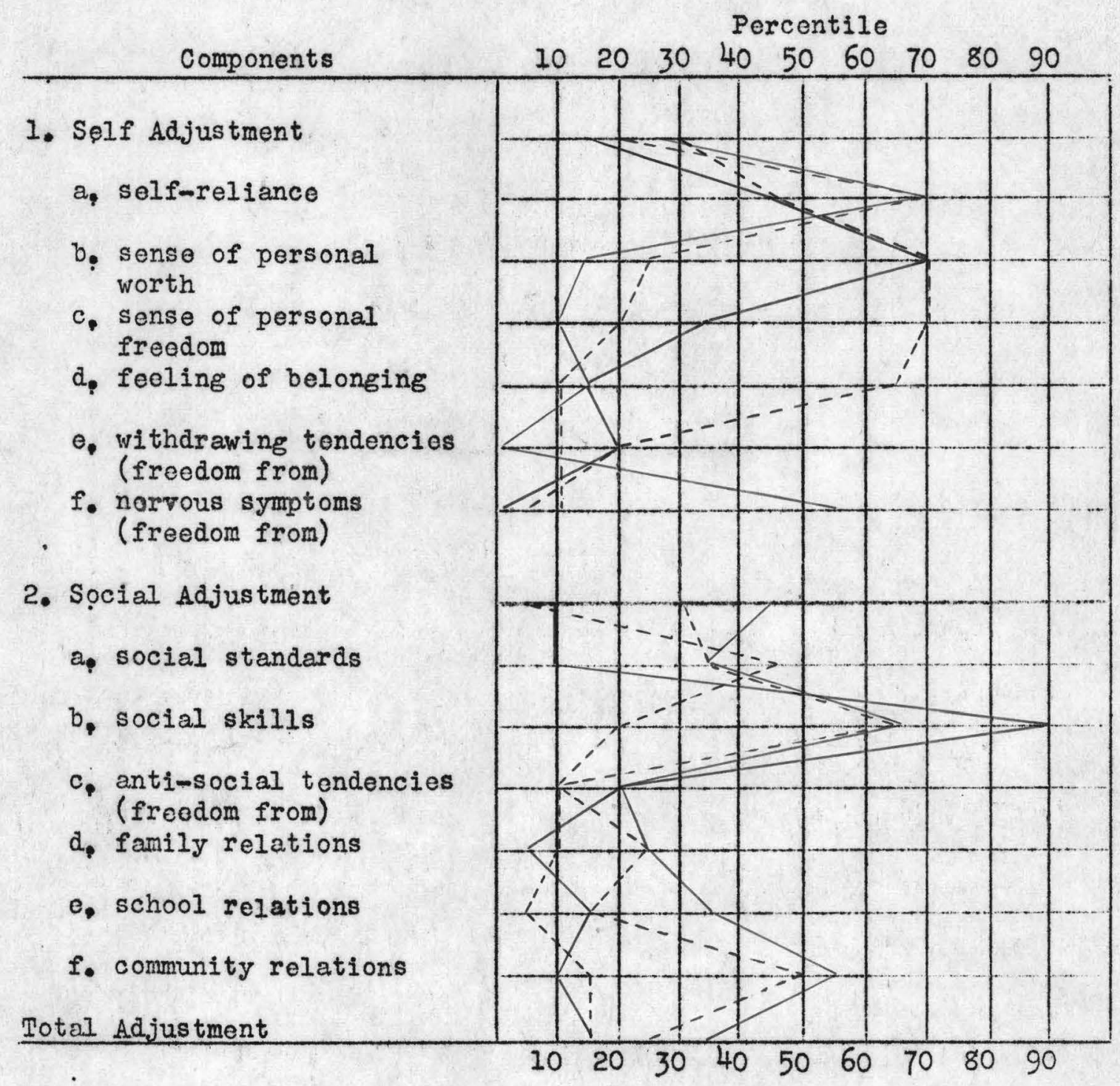

Fig. 20. Pair 20, Pre-test and end-test profiles of the experimental and control subjects. Key: Experimental subject pre-test - endtest__- ; control subject pre-test__, end-test_- - .

The experimental subject, according to the two scores, has made sone improvement in self adjustment during the interviews, but shows some deorement furing the same period in social adjustment.

The test results of the control subject indicate some decrement in both self adjustment and social adjustment. 
The end-score in total adjustment shows no variance with the pretest results, in the case of the experimental subject. The control subject made Lover scores on the end-test, Indicating sone decrement In self, social, and total adjustment. 
RESULTS OF THE H-O-W

Table 20. Pair 20. H-OWW Raw Scores.*

\begin{tabular}{l|c|c|c|c}
\hline \multirow{2}{*}{ Problem } & \multicolumn{2}{c|}{ Experimental Subject } & \multicolumn{2}{c}{ Control Subject } \\
\cline { 2 - 5 } Behavior & Pro-tost & End-test & Pro-test & End-test \\
\hline Intollectual & 15 & 15 & - & - \\
Physical & 11 & 11 & 27 & 27 \\
Social & 24 & 24 & 17 & 17 \\
Brnotional & 17 & 17 & 26 & 17 \\
\hline Total & 67 & 67 & 102 & 86 \\
\hline \hline
\end{tabular}

* The higher scores are indicative of maladjustment.

Total scores Lndicate the experinental subject wss not observed to have evidenced any lmproved adjustuent during the experimental interval. On the other hend, the control subject, by the satre measure, was observed to have Inproved in general adjustment.

No scores were given by the person rating the subjects on the behavior acale.

Sumary, Pair 10. None of the therspeutic objectives were attained during the interviaws. A2l measuring devices were consistent in thair indications, by total pre-test and end-test scores, of no significant differences of improved adjustment in the experimental subject. 


\section{RESULTS OF THE INTERVIBW}

Table 21. Pair 11. Experimental Subject. Interview Results.

\begin{tabular}{|c|c|c|c|c|c|c|}
\hline \multirow{2}{*}{$\begin{array}{l}\text { Therapeutic } \\
\text { Objectives }\end{array}$} & \multicolumn{6}{|c|}{ Interviews } \\
\hline & 1 & 2 & 3 & 4 & 5 & 6 \\
\hline \multicolumn{7}{|c|}{ Free expression } \\
\hline \multicolumn{7}{|l|}{ Insight } \\
\hline \multicolumn{7}{|l|}{ Decision } \\
\hline Action & & & & & & \\
\hline
\end{tabular}

* An $x$ is placed in the square when statements were made indicating the attainment of an objective.

The counselor wondored $2 f$, in this case, the subject had the "will to grow", that Rogers enphastzes as essential to successful non-di rective psychotherapy.

Only ane problem was approached daring the serles and it is questionable if progress tovard lts solution was made.

The Intervicus were terninated at the subject's suggestion that "everything is all right now, and I don't want to couce in any more,"

Interview 5:

Counselor talked with the subject agaln of the purpose of the Interviews, and reviewed a fex of the problems the other girla had been discussing.

C: "Do you have any problens - anything like these - that you think about sometises?"

S: Mo. I don't heve any problems like that," 
Interview 6:

c: "You told tae about one problem you had, of not being sble to get along with the girls,"

S: Wh, yes. But I get along swell with then now."

This statement didn't bear out the obvious facts, and the counselor felt that the interviews were not progressing in way that would justify continuing them. 
RBSULTS OF THE MMPI

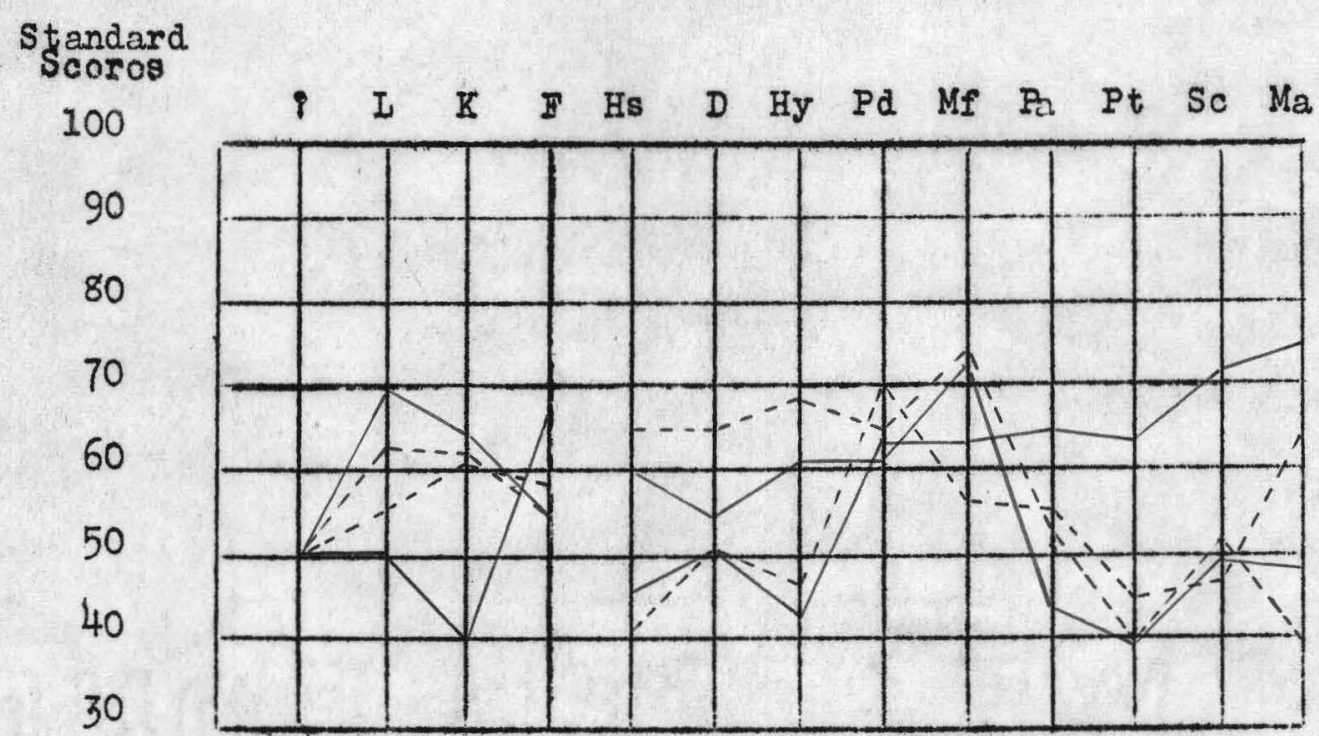

Fig. 21. Pair 11. Pre-test and end-test profiles of the experimental and control subjects. Key: Bxperimental subject premtest test _. -; control subject premtest _ , end-test _- -

The two profiles of the experimental subject, in this caee, show Little consistency. The end-test scores show a tendency toward the abnomal on the Pd saele and an increase in normal responses on the Se and Ma seales. The latter two are the only seores exceeding the nornal range.

The scores of the control subject indi cete a general trend toward beconing more abnomal during the time the experiment was in progress. On the neurotic scales, both subjects wade sn increased number of abnormal responses on the end-test. On the psychotic end of the profile, the experimental, subject gave fewer abnomal responses on the last test. 


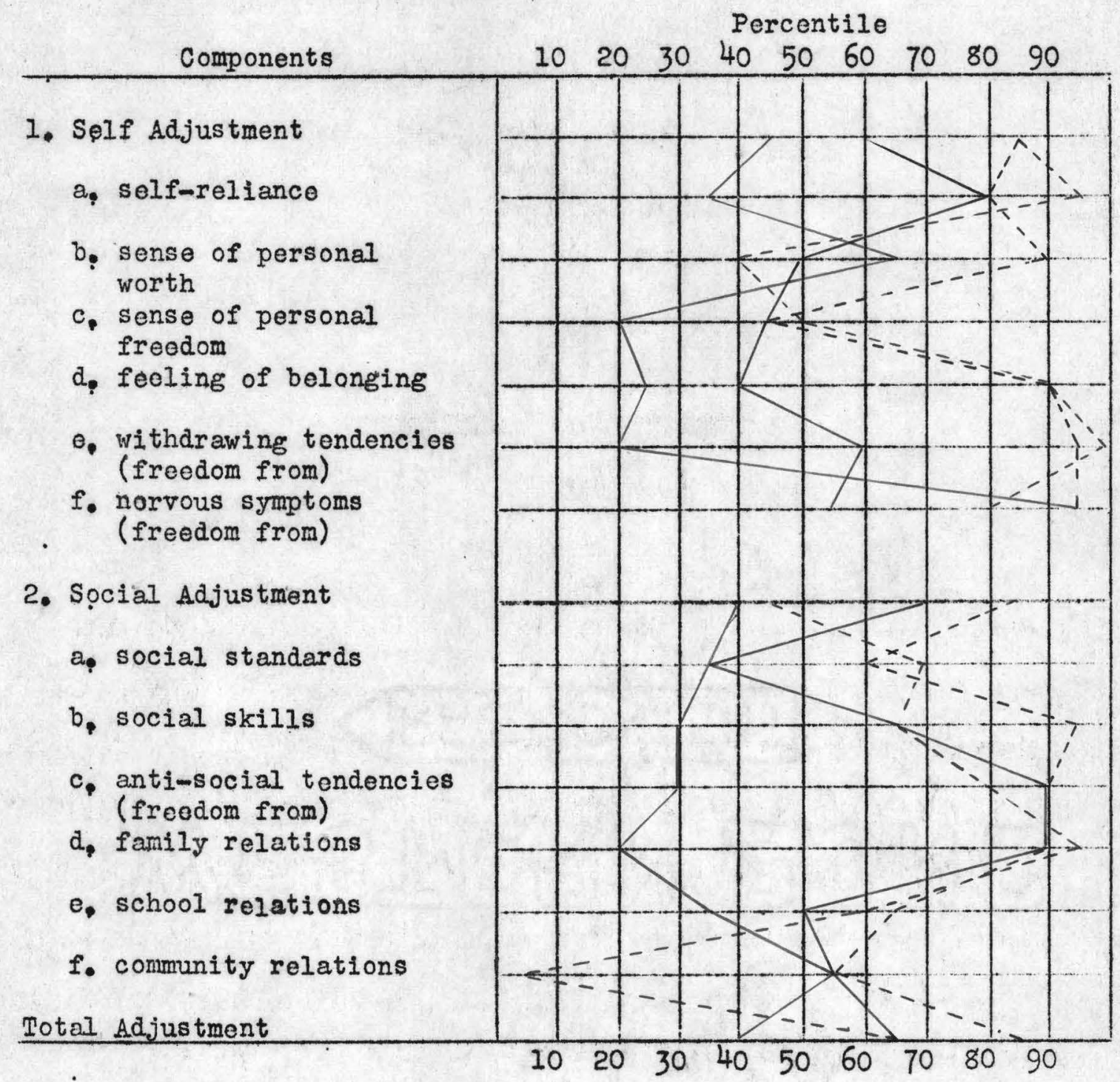

Fig. 22. Pair 11. Pro-test and end-test profiles of the experimental and control subjects. Key: Experimental subject pre-test_, endm test__- ; control subject pre-test__, end-test_-_.

The test results of the experimental subject indicate considersble inprovenent in self adjustment during the interview series. Similar results are found to exist in the component of social adjustment. Scores of the control subject also are representative of lmprovement in self and social edjustment, but in the latter case, to a lesser 


\section{degree.}

The total adjustment end-scores of both subjects are considerably higher than pre-tast scores, indicating some improvement in both cases. 
RRSULTS OF THE H-O-W

Table 22, Pair 21. H-O-W Raw Scores.*

\begin{tabular}{|c|c|c|c|c|}
\hline \multirow[b]{2}{*}{ Problem } & \multicolumn{2}{|c|}{ Experimental Subject } & \multicolumn{2}{|c|}{ Control Subject } \\
\hline & Pre-test & End-test & Pro-test & End-test \\
\hline Behavior & 118 & 74 & 46 & 30 \\
\hline Intollectual & 27 & 22 & 14 & 27 \\
\hline Physical & 19 & 23 & 18 & 25 \\
\hline Social & 40 & 38 & 30 & 23 \\
\hline Enotional & 24 & 35 & 22 & 20 \\
\hline Total & 228 & 197 & 280 & 20.5 \\
\hline
\end{tabular}

* The higher scores are indicativo of maladjus tment.

The scores of the experisental subject, as recorded by the person executing this schedule, indeate considerable taprovenent in behavior problena and at the same tire considerable decroment in emotional problens. A compartson of total scores indicate a greater difference of ingrovenent in the experinental subject, but this difference is not si.guificant.

Sumary. Pair 13. The therspeutic objective, free expression, was attained by the subject during two interviews. No other objectives were reached during the entire aeries of interviews. The counselor felt that non-directive psychotherapy did not succeed with this subject in view of the fact that no therapeutic objectives were reached satiafactorily. Score results of the LUPI, the CYP, and the H-OMII tests, however, all Indicated some Improved adjustment in the subjeet during the experimental period, 
SUWWARX OF TKE RESULTS

Comparative scores and profiles of the experimental and the control subject of each palr have been shown for each of the testing devices, and sumaries of these comparisons have been made. The influence of counseling, as deterwined by the attainment of the therapeutic objectives and scores on the other three measuring instruments, has been presented with each of the eleven pairs.

In addition to this, it was felt that comparisons of premtest and end-test results of the total scores of both groups on each of the testIng instruments would be useful. It is the purpose of this section to present tables and figures showing these results, along with a statist1 asl analysis of the signiflcance of gains that may be found in the scores of either group.

Pollowing are charts presenting the results of the experimental subjects, as a group, and the control subjects, as a group, on the three objective tests; and a table Indicating the success or failure of the exporimental group in attaining the therapeutic objectives. 
SUMAEX OP THE INTERVIBUS

Table 23 presents a sumary view of the success of non-directive psychotherapy with the experimental subjects as deternined by the attairment of the therapeutic objectives.

Table 23. The Intervier Regults with Hleven Exoerimental Subjacts.

\begin{tabular}{|c|c|c|c|c|c|}
\hline \multirow{2}{*}{$\begin{array}{l}\text { Experimental } \\
\text { Subiect }\end{array}$} & & \multicolumn{4}{|c|}{ Therapeutic objectives } \\
\hline & & Eree Expression & Insisht & Decision & Action \\
\hline Peir 1 & : & $x^{*}$ & $x$ & $x$ & $x$ \\
\hline Pair 2 & ? & $x$ & $x$ & $x$ & $x$ \\
\hline Pair 3 & ' & $x$ & $\mathrm{x}$ & $\mathrm{x}$ & $\mathrm{x}$ \\
\hline Pair 4 & ' & $x$ & $x$ & $x$ & $x$ \\
\hline Pale 5 & 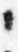 & $\mathbf{x}$ & $x$ & $x$ & $\mathbf{x}$ \\
\hline Pair 6 & : & $\mathbf{x}$ & $\mathbf{x}$ & $\mathrm{x}$ & $\mathrm{x}$ \\
\hline Pair 7 & ! & - & - & - & - \\
\hline Pair 8 & ? & $x$ & - & - & - \\
\hline Pair 9 & 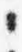 & $x$ & - & - & - \\
\hline Pasr 10 & ! & $x$ & - & - & - \\
\hline Pair 11 & - & - & - & - & - \\
\hline
\end{tabular}

*An $x$ indicates that the therapeutic objective was attained to sone degree with the correaponding subject.

It will be noted in Table 23 that, according to statements made curIng the interviews, six of the eleven subjects attained all the therapeutic objectives. In three cases, one objective was reached and in two cases no objectives were attained by the subjects.

It was not expected that non-directive counseling would be successful with all the subjects, since they did not neet completely Roger's criteria (18, pp. 76-77). In fect, it was one of the purposes of this study, as 
previously stated, to deteraine if the therapeutic objectives, as criterIon of success, could be attained wh delinquent individuels. As a further note of signiflcance, wore extensive psychotherapy might heve been done with some of the six subjects who attained a.l the therapeutic objectives. As soon as the objectives were reached, the interviews were temainated and no further effort was ade to assist the subject to galn deeper insights, which may have been possible if more time had been available.

Since all the objectives were attained by at lesst six of the subjects, some gains on the tests selected to measure laproved personal and social adjustment might, according to the hypothesis, be expected. 
SUMAAFY OF THE LMPI

In figure 23 are presented pre-test and end-test results, and algnificance of these results, for the experimental and control eroups. In addition, statistical comparisons have been computed for the differences in gains shown by the counseled and the non-counseled subjects.

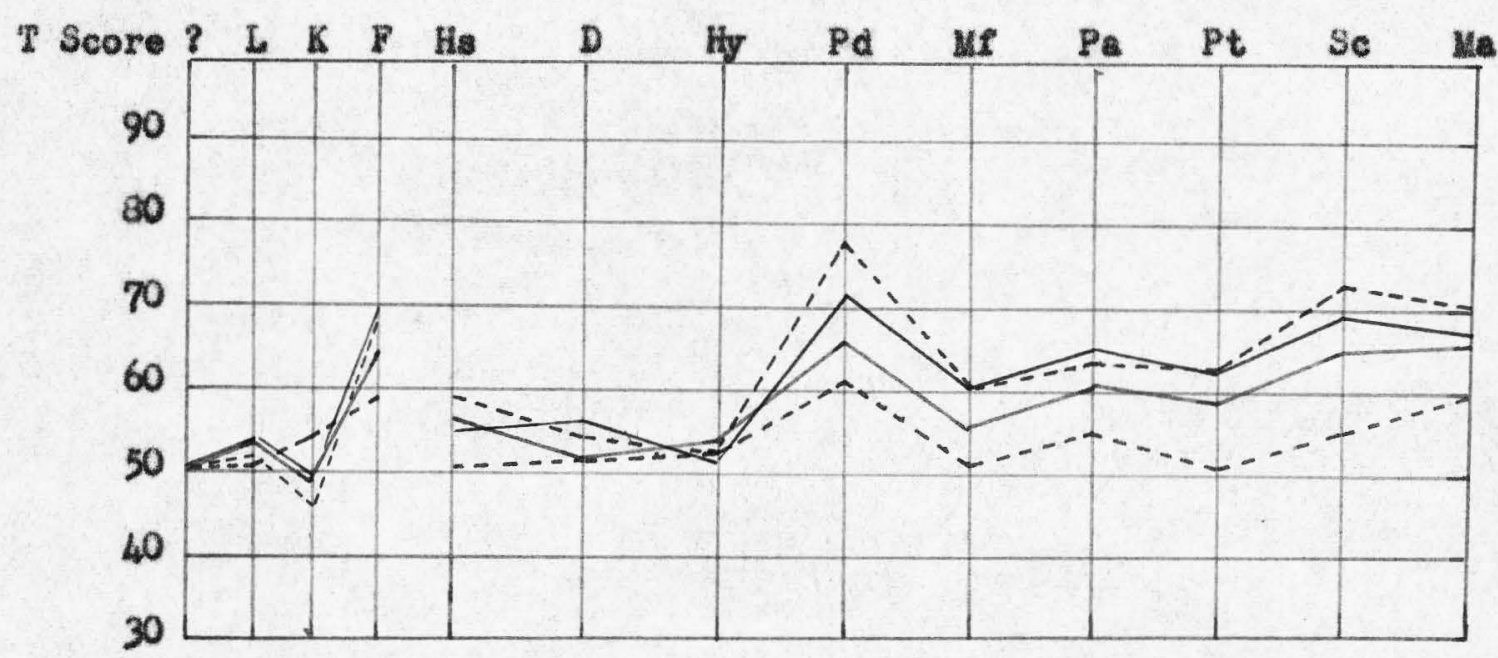

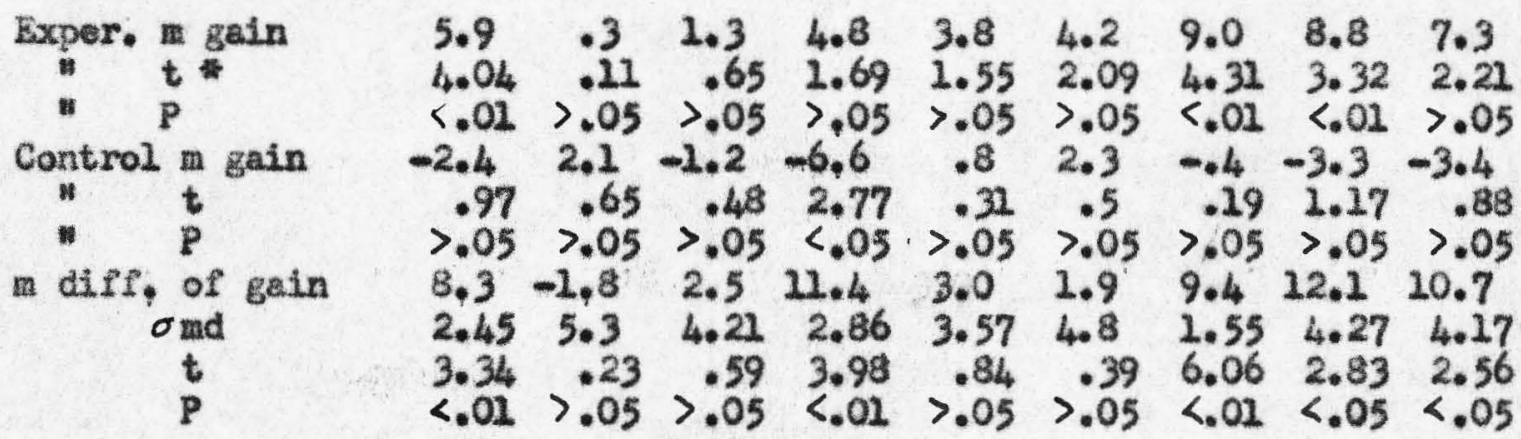

F1g. 23. Comparative mean proflies of the pre-test and end-test scores of ten experimental and ten control subjects on the MaPI. Key: Experimental group pre-test__, end-test...; control group pre-test__, end-test_....

* t scores at 3.25 and 2.26 are 31 gnifleant at the 1 percent and 5 percent levels, respectively.

The four profiles on this ligure represent the mean pre-test and endtest scores of the exparimental and control groups on the various scales of the test. Of the validating seales, $?, L, K$, and $F$, only the responses given 
on the $F$ scale show a tendency to deviate from normal. ks noted prev1ously, Gough's Study (11) Indicates a tendency for the F scale to have a higher score with individuals who respond sbnormally on the psychotic scales. The psychoneurotic tendencies, represented by the $\mathrm{Hs}$, the $\mathrm{D}$, and the Ify scales, are not shown to exist to any great degree in either group. Wore abnormal responsea were wade by all the subjects on the Pd scale than were made on any other scale in the proflie. Deviations from nomal are apparent, but not of an extreme nature, on the Mf, Pa, and Pt scales. Some average tendency towerd a large portion of abnormal responses is evidenced on the Sc and Ma scales. The group of subjects used in the experiment tend to deviate more toward the characteristics of patients diagnosed as psychopathic deviates, schirophrenics, and hyponanics, than of any other type of patient represented on the proflle.

For the experimental subjects, the mean gains from the pre-test to the end-test are presented on the first line below figure 23. On each of the nine scales a gain in the direction of less abnomality is indicated. The statistical signifleance of this gain on each scale is prem sented in the second and third rows of figures under the profile. It is shown to be signifleant af the 1 percent lovel of chance on the Hs, Pt, and Sc scales. Fnd-test gains of the control group are listed in the fourth line, under each of the scales. On six of the nine scales, negative gains are noted. This Indicates a decrement rather than improvement in the personality traits represented by these scales, during the time of the experiment. Wone of the control group gains, however, were statisticaly significant at the 1 percent or at the 5 percent levels, as shown in the fifth and sixth lines, designated as control $t$ and $P$, 
except on the Pd scale, and that in a negative direction.

Beginning at the line disignated as meen difference of gain, the algebrate differences in the gains made by the experimental and control groups are shown. The $t$ ratios for these comparisons indicate that the differences are significant at the 1 percent level on the three scales, $\mathrm{Hs}, \mathrm{Pd}$, and $\mathrm{Pt}$. S1 gnificance at the 5 percent level is shown on the two scales, Sc and Ma. The four scales, D, Ho, Mr, and Pa, show no significant atfferences between the gains made by the two groups.

It is on the seales for measuring hypochondriasis, psychopathic deviation, and psychisthenia that the gains made by the counseled subjects exceed significantly (at the 1 percent level) the negative gains made by the non-counseled subjects. This fact is understandeble in view of the counselor's observations of the subjects during the interviews.

A variety of physical complaints seemed characteristic of a large portion of the subjects. In several cases this observation was confirmed by hospitalization reports and remurks made by the hospital attendant at the institution. It was observed in two cases that hospitaligation rates were reduced considerably during and following the interviews. This observation is somewhat subjective, as no supporting figures were recorded, but it was felt that some symptoms characteristic of the clinically diagnosed hypochondriasis patient were noticeably relieved in sone cases.

We mey also expect, if any change wss recorded, that it would occur on the psychopathic scele. It is found generally that delincquents are described as possessing some of the characteristics comonly ascribed to a psychopathic individual. If a valid assumption has been made in this respect, then the results of the $\mathrm{Pd}$ scale may offer some support to such 
a byothetical statenent.

Sou statenents recorded in the last Intervilew of case 1 offer a ample of many statenents Indicating behavior of a compul sivo nature to be chsracteristic of the experimental subjects. The authors of the test inciudes compulsive bohavior as one characteristic of the psychasthenic patient, in a description of the pt scale. It was not surprising to the investigator to find aigniflcant lmprovement on the Pt scale In viow of the meny soeningly compulsive symptoms demonstrated and expressed by the aubjects during the interviess. 


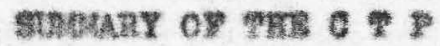

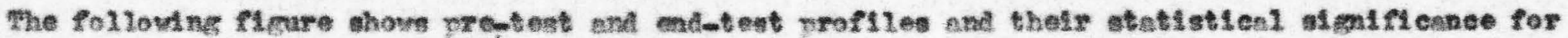
the experimentel and control proups.

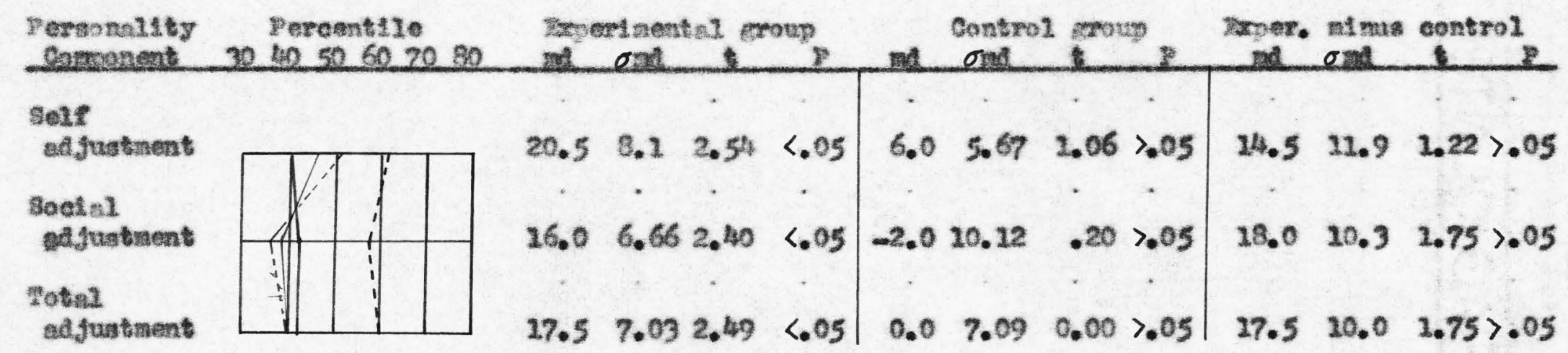

31. 24. Comparative aen profiles of the pre-test and end-tent gocres of ten experimental and ten

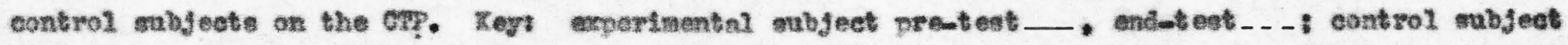
prentent _. end-test_... 
In figure 24, profiles and comparative computations were macle on only the three major personality components, self adjustment, social adjustment, and total adjustment. The four profiles represent pre-test and end-test mean percentile scores of the experimental and control subjects. The mean changes from pre-test to end-test for both groups and the significance of these differences are shown. In addition, the differences between the gains made by experimental and control subjects and the statistical significance of these differences are given. Under the section, experimental group, the mean gains are shown to be 20.5 percentile scores in self adjustment, 26.0 percentile scores in social adjustment, and 17.5 percentile scores in total adjustment. These gains are all significant at the 5 percent level of chance. The mean control gains are shown to be $6,-2$, and 0 for self, social, and totel adjustments. Wone of these gains are significant at the 5 percent level. The experimental group shows a difference in gain over the control group of $14.5,10.3$, and 17.5 percentile scores on the components, self, social, and total adjustments. These differences in gain, however, were not statistically significant at the 5 percent level of chance in any component. 


\section{SUMAAFY OF THE H-O-W}

The following table presents pre-test and end-test toted. scores and changes in score for each subject. In addition, total scores and gains for the experimental and control groups and the significance of these gains are shown. The last column presents the differences in gains made by experimental and control subjects.

Table 24. Comparative Total Raw Scores of kleven Experimental and Geren Control Subiects.

\begin{tabular}{|c|c|c|c|c|c|c|c|}
\hline & Experinent & I Subject & & Conts & 1 subject & & Differ \\
\hline Paix & Pre-test & End-test & Gain & Pre-test & End-test & Gain & Gain \\
\hline 1 & 74 & 62 & 12 & 101 & 101 & 0 & 12 \\
\hline 2 & 214 & 17 & 43 & 180 & 154 & 26 & 17 \\
\hline 3 & 120 & 142 & -22 & 103 & 96 & 7 & -29 \\
\hline 4 & 112 & 129 & -17 & 95 & 109 & -114 & -3 \\
\hline 5 & 58 & 47 & 11 & 109 & 107 & 2 & 9 \\
\hline 6 & 93 & 76 & 17 & 60 & 60 & 0 & 17 \\
\hline 7 & 64 & 68 & -4 & 57 & 58 & -1 & -3 \\
\hline 8 & 109 & 106 & 3 & 83 & 75 & 8 & -5 \\
\hline 9 & 72 & 60 & 12 & 75 & 75 & 0 & 12 \\
\hline 10 & 67 & 67 & 0 & 101 & 86 & 25 & -15 \\
\hline 11 & 218 & 192 & 21 & 130 & 115 & 15 & 6 \\
\hline Total & 2201 & 1125 & 76 & 1094 & 1036 & 58 & 29 \\
\hline Mean & Lfference & & 6.9 & & & 5.3 & 1.7 \\
\hline$\sigma$ md & & & 5.44 & & & 3.45 & 4.33 \\
\hline t & & & 1.27 & & & 1.54 & .44 \\
\hline$P$ & & & $\geq .05$ & & & $\geq .05$ & $5 \quad>.05$ \\
\hline
\end{tabular}


Neither the gains made by the control group or by the experimental group are found to be signifieant, even at the 5 percent level. Nor is the algebraic difference in the gains made by the two groups signifieant. Total rew scores show the experimental aroup to have inproved slightly wore than the control group during the experimental interval. Wide devistions in the scores of some of the experinental subjects reduced the aifnificance of this gain.

As noted previously, the execution of the H-OWl schedules was not accomplished in a manner that conforwed to the author's recorsendations of procedure for using the test. In some cases, the subject was not given a pre-rating until after the interviewing wos in progress. In other cases, the subject was pre-rated and ond-rated several weeks after the interviewing was cospleted. In view of this lack of conforelty to correct procedure by the persons rating the subjects, it is felt that the results as shown here may not be considered to be highly reliable. 
SUMAAK AND CONCLUSTONS

It was the purpose of this study to make application of Carl h. Rogers' non-directive method of psychotherapy in the treatment of juvenile delinquents. The study was set up in an effort to determine the Value of such a treatwert procedure as one method of treeting this type of individuel.

The hypothesis to be teated was that non-directive psychotherapy would Improve the pereonal and social adjustment of institutionalized delinquents. Supporting this general assumption the following three corollaries were assumed: (1) that Improved personal adjustment would be reflected in adjustment inventories, (2) that improved social bohavior would be reflected in social behavior rating scales, and (3) that the therapeutic objectives of non-directive counseling would be attained dur ing the series of interviews with each subject. The general hypothesis is supported to the extent that the results support each of the corollar Les.

In proceding toward an experimental test of the hypotheses, testing devices were selected for the purpose of detecting and measuring improvement that may occur in the individual during the counseling process. The means used and described in the study for this purpose are (1) expressions of the subjects, (2) the Minnesota Multiphasic Personality Inventory, (3) the Callformia Test of Personallty, (4) the Haggerty-01son-Wickman Behavior Rating Schedules. Statenents aade by each subject were presumed to be indicative of better adjustment when they were of such nature as to imply that the therapeutic objectives had been attained. The three other weasuring instruments were administered to the eleven experinental 
subjects before, and after the counseling interviews. A comparison of the pre-test and end-test scores, was presunud to Indicate the lisproved adjustrent of the subject while the interviewing was in progress. ing Amprovenent that might be seasured by this procedure, hovever, wixy be thought of as having occurred, not only from the influence of non-directive counseling, but possibly from other sources.

In order to isolate, as far es posalble, the influence of counseling, a control group was ueed. Twenty two subjects were selected originaliy and equated es nearly as poesible into pairs on the basis of age, intelligence, grade placement and previous records. From each pair, one subject was selected, on the basis of chance, to represent the group to be counseled, while the remalning eleven subjects made up the control group.

Statements made by the subjects curing the interviews were used to determine whether or not the therapeutic objectives were attained with each subject. Some of these statements and a sumpery table of each interview serles were recorded in the stucy. The three objective testing devices were adninistered to the control subject before and after esch series of interviews at the same time they were given to the experimental subject. In addition to observing pre-test to end-test gains made by the subjects who were counseled, cotparisons with the gains made by the subjects who were not counseled were made. The differences of these gains are presuared to be due to counseling.

On the basis of the data cbtained from the interviews and tests, the following conclusions are drawn

(1) Six of the eleven experimental subjects attained all the 
therapeutic objectives of non-directive counselinis, three subjects attained only the first objective, free expression, and the remaining two subjects failed to attain any of the objectives.

(2) The experimental subjects, as a group, made gains on all nine parts of the Minnesota Multiphasic Personality Inventory, but these gains were statistically significant at either the 1 percent or the 5 percent levels only for hypochondriasis, psychasthenia, and schizophrenia.

(3) The control subjects changed their scores from pre-test to endtest on the Minnesota Multiphasic Personality Inventory only slightly. In six instances the changes were negative, on the other three scales they were positive. Only one change, a decrement on the psychopathic ceviate scale, was statisticaly si gnificant, and that only at the 5 percent level of chance.

(4) The algebraic differences in the gains made by the counseled and non-counseled subjects were significantly favorable to the counseled subjects on the scales for measuring iypochondriasis, psychopathle deviate, psychasthenia, schizophrenla, and hypomania. For the first three traits the differences in gain are significant at the 1 percent level and in the last two they are significant at the 5 percent level.

(5) On the Californis Test of Personality, the experimental subjects, as a group, showed significant gains from pre-test to end-test at the 5 percent level in the major personality components, self-adjustment, social adjustment, and total adjustment.

(6) On the Calffornia Test of Personality, the control subjects, as a group, showed gains that were not significant at the 5 percent level In the components of self-adjustment, social adjustrent, and total adjustment. 
(7) The difference in the gains made on the California Test of Personallty by the experimental and control groups were favorable to the experimentsl group, but not to the extent that the gains were significant at the 5 percent level.

(B) Results on the Haggerty-01son-mieknan Behavior Fating Schedules show that neither the gains made by the experimental group nor by the control group are significant at the 5 percent level, although sone gain was made in favor of experimental group. Nor ta the algebraic difference in the gains made by the two groups significant. These results, hovever, may be open to further experimentation due to a lack of conforaity to correct procedure in executing the schedules.

(9) The Minnesota Multiphasic Personality Inventory Indicated inproved general adjustment in the six subjects who attained all the therapeutic objectives.

(10) If the subjects used in this stucy represent typical cases, and if the tests are adequate in measuring changes that occur during non-directive psychotherapy, then the data would tend to support the general hypothesis that non-directive counseling does improve the personal and social adjustment of some delinquents. The three corollaries were supported to the extent that (a) the two adjustment inventories showed differences in pre-test to end-test gains favoring the counseled group, although these differences were less significant on the Californis Test of Personality; and (b) pre-test to end-test gains favored the counseled group on the behavior rating schechles, but the differences of these gains were not significant at the 5 percent level; and (c) six of the eleven subjects that were counseled attained all the the therapeutic objectives of non-directive counseling. 


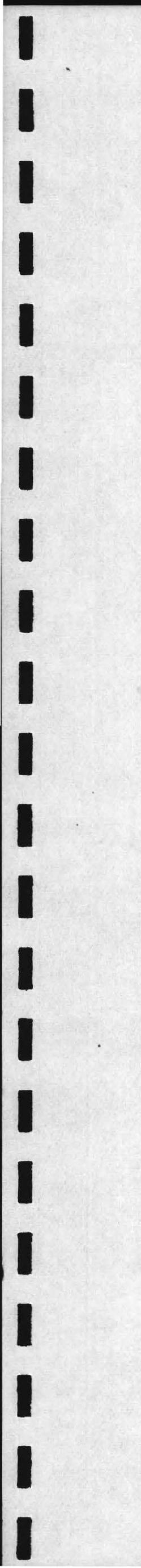




\section{BIBLTOGRAP HII}

(1) Axline, Virginia ll. Morale on the school front. J. educ. res., $1944,37,521-533$.

(2) Baruch, D. W. Incorporation of therapeutic procedures as part of the educstive process. J. consul. psychol., 1940, 4, $165-172$.

(3) Bixier, Ray H. A note on psychotherapy as a function of psychologists. J. consult. psychol., 1945, 9, 238-239.

(4) - Treatment of a reading problen through non-directive play theraps. J. consult. psychol. 1945, 9, 105-118.

(5) - Non-directive play therapy. Unpublished M. A. thesis, Ohio State University, Columbus, Ohio, 1942.

(6) Carrier, B. Psychiatric counseling. J. higher educ., 1941, 12, $201-205$.

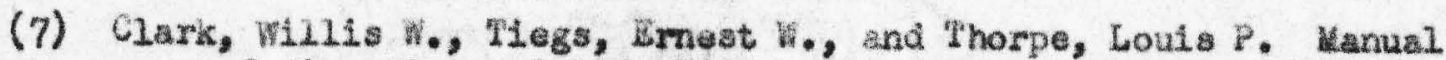
of difections, Calif. Test of Personality. Calif. Test Buresu, Los Angeles. 1942.

(B) Combs, A. W. Follow-up of a case treated by the non-directive method. J. clin. psrchol., 1945, 1, 148-154.

(9) - Some contributions of non-directive methods to coilege counseling. J. consult. peychol. 1945, 9, 218-223.

(10) Covner, B. J. Studies in phonographle recordings of verbal material: I. The use of phonogrsphte recordings in counseling practice and research. J. consult. psychol. $1942,6,105-113$.

(11) Gough, Harrison G. Diagnostic patterns on the Minnesota Multiphasic Personality Inventory. J. clinical psychol., 194,6, $2,23-37$.

(12) Haggerty, $X_{*} \mathbb{E}_{*}$, Olson, W. C., and Wickman, E. K. HaggertyOlson-lilckmen behavior rating schedules, Manual of directions. World Book Co., Yonkers-on-Hudson, N.Y. 1930.

(13) Hathaway, Starke $R_{*}$, and MeKinley, Charnley J. Supplementary manual for the Minuesota Wultiphasic Personality Inventory. Psychol. corp., N. Y. 1946.

(14) The Winesota personslity inventory. The psychological corporation, New York. 1943, rev. ed. 
(15) Keehl, Paul E. Profile analysis of the Linnesota Hultiphasic Personality inventory in differential diagnosis. J. apol. psychol., $1946,30,517-524$.

(16) Muench, George Arthur. An evaluation of non-directive therspy Ph. d. dissertation. The Ohio State Univ. 1945. pp. 278.

(17) Plerson, Geo. A. Rogerst theory of non-directive counseling. Mental health. 1944, 12, 2-5.

(18) Logers, Carl R. Counseling and psychotherapy. Boston, Houghton Mifnin Co. 1942. xiv, $450 \mathrm{pp}$.

(19) The clinical psychologist's approsch to personality problens. Femily, 1937, 18, 233-245.

(20) - Significant aspects of client centered therapy. Aa. psychol. 1946, 1, 425-422.

(21) Counseling. Mev. ed. rev. 1945, 15, 155-163.

(22) - The process of therapy. Jr. cons. psrchol. 1940, 5, 161-164.

(23) The clinieal treatment of the problem child. Houghton Mifrin Co. 1939. Boston, pp. 393.

(24) - The development of insight in a counseling relationship. Jr. consult. psychol. 1944, 8, 331-34l.

(25) - Predicting the outcomes of treatment. Am. Jr. Orthopsychiat. 1941, 11, 210-221.

(26) - Therapy in guldance clinics. J. abn. soc. psychol. $1943,38,284-289$.

(27) - Lectrically recorded interviews in inproving psychotherapeutic technlques. Am. J. Orthopsychlat. 1942, 12, $429-435$.

(28) - - Three surveys of treatment measures used with children. Asi. J. Orthoosvchiat., 1937, 7, 48-57.

(29) - Psychometrie tests and client-centered counseling. Be. psichol. mess. $1946,6,139-144$.

(30) - and Axline, V. H. A teacher therapist deals with a handicapped chilla. J. Bbn. soc. psychol. 1945, 40, 119-143.

(31) -and Wallen. Counseling with returned servicemen. 
(32) Royer, A. E. An analysis of counseling procedures in a nondirective approach. Unpublished H. A. thesis, Ohlo State University, Columbus, Ohio, 1942.

(33) Sargent, Helen. Spontaneous doll play of a nine year old boy. J. consult. psychol. $, 1943,7,216-222$.

(34) - Non-directive counseling applied to a single interview. J. consult. psrchol. 1943, 7, 183-190.

(35) Snyder, W. U. 'Warnth' in non-directive counseling. J. Bbn. \& soc. psichol., 1946, 41, 491-495.

(36) - A short tern non-directive treatment of an adult. J. abn. soc. psychol. 1943, 38, 87-137. (no. 2 suppl.)

(37) - An investigation of the nature of non-directive therepy. J. Sen, psychol. $1945,33,193-223$.

(38) Stogoill, R. M. A test interview for delinquent children. Psvchol. Bull., 2938, 35, 631.

(39) Sullenger, Thomes Earl. Social deterwinants in juvenile delinquency. N. Y., J. Wiley and Sons, ine.; London, Chepman and Hall, Limited, 1936. pp. 412.

(40) Symonds, P. K. Problems falling within the scope of psychiatric counseling. Je appl. pszchol. 1937, 21, 66-74.

(41) Thorne, F. C. A critique of non-directive methods of psychotherapy. J. abr. soc. psychol. $1944,39,459-470$.

(42) Thorpe, Louis P. A psychological view of the causes of criminal behavior. J. clinic. psychopath. 1946, April, 795-302.

(43) Whitaker, C. A. The delinquent's first interview. Probation. $1944,23,15-20$. 